\title{
Can the philicity of radicals be influenced by oriented external electric fields?
}

\author{
Ruben Van Lommel, ${ }^{* a, b}$ Rik H. Verschueren, ${ }^{a}$ Wim M. De Borggraeve, ${ }^{a}$ Freija De \\ Vleeschouwer, ${ }^{b}$ and Thijs Stuyver, $* b, c$
}

a. Molecular Design and Synthesis, Department of Chemistry, KU Leuven, Leuven Chem\&Tech, Celestijnenlaan 200F, 3001 Leuven, Belgium

b. General Chemistry - Eenheid Algemene Chemie (ALGC), Department of Chemistry,

Vrije Universiteit Brussel (VUB), Pleinlaan 2, 1050 Brussels, Belgium

c. Department of Chemical Engineering, Massachusetts Institute of Technology, 77 Massachusetts Avenue, Cambridge, Massachusetts 02139, United States

Correspondence: tstuyver@mit.edu, ruben.vanlommel@kuleuven.be 


\section{Supporting Information \\ - Table of contents -}

1. Theoretical background 3

1.1. Calculating the global electrophilicity index 3

1.2. Relating the global electrophilicity index to the electric field strength 3

2. Summary of computed data 5

2.1. Computational details $\quad 5$

$\begin{array}{lll}\text { 2.2. Electronic properties } & 6\end{array}$

$\begin{array}{ll}\text { 2.3. Structural properties } & 11\end{array}$

2.4. On the gauge dependency in charged systems

2.5. Trends in radical philicity of larger halomethyl radicals 15

3. Spin- and charge delocalization of aryl radical cations in an electric field 18

4. Influence of an OEEF on the regioselectivity of a radical reaction 19

5. Cartesian coordinates $\quad 21$

6. References $\quad 37$ 


\section{Theoretical background}

\subsection{Calculating the global electrophilicity index}

The global electrophilicity index $\omega$ was first defined by Parr et al. within the context of Conceptual Density Functional Theory and extended towards quantifying the philicity of radical species by some of the authors of this work. ${ }^{1-3}$ As denoted in the main text, the global electrophilicity index is defined as in equation 1.

$\omega=\frac{\mu_{C P}^{2}}{2 \eta}$

with $\mu_{\mathrm{CP}}$ the electronic chemical potential and $\eta$ the chemical hardness. For an $N$-electron system, characterized by the external potential $v(\mathbf{r})$ and total energy $E, \mu$ and $\eta$ can be expressed by equations 2 and 3 , respectively. ${ }^{4,5}$

$\mu_{C P}=-\chi=\left(\frac{\partial E}{\partial N}\right)_{\nu(r)} \sim-\frac{(I+A)}{2}$

$\eta=\frac{1}{2}\left(\frac{\partial^{2} E}{\partial N^{2}}\right)_{\nu(r)} \sim \frac{I-A}{2}$

In the above equations, $\chi$ represents the electronegativity as defined by Mulliken, ${ }^{6}$ while $I$ and $A$ represent the vertical ionization energy and electron affinity, respectively. Note that it is common to exclude the factor $1 / 2$ in the expression of equation 3. Also in this work, we computed the chemical hardness as the difference between the vertical ionization energy and the vertical electron affinity. Based on computed electronic energies of a molecular system $\left(E_{N}\right)$ and the electronic energies of the corresponding $N$-1 electron $\left(E_{N-1}\right)$ and $N+1$ electron system $\left(E_{N+1}\right)$, the vertical ionization potential and electron affinity can be easily calculated by equation 4 and 5 , respectively.

$I=E_{N-1}-E_{N}$

$A=E_{N}-E_{N+1}$

Through equations 1 to 5, a direct relationship between the global electrophilicity index and the computable energies $E_{N}, E_{N+1}$ and $E_{N-1}$ can be obtained as provided in equation 6 .

$\omega=\frac{1}{8}\left(\frac{\left(E_{N+1}-E_{N-1}\right)^{2}}{E_{N+1}-2 E_{N}+E_{N-1}}\right)$

\subsection{Relating the global electrophilicity index to the electric field strength}

As described in the main text of this work, the primary mechanism through which electric fields affect the electronic structure of a molecular system, is through an induced dipole moment. If an homogeneous electric field is applied in the z-direction, the energy of a molecule placed in that electric field can be expressed as a Taylor series such as the one provided in equation 7 .

$E^{F}=E^{0}+\mu_{\mathrm{z}}^{0} F+\frac{1}{2 !} \alpha_{\mathrm{zz}} F^{2}+\frac{1}{3 !} \beta_{\mathrm{zzz}} F^{3}+\cdots$ 
Here, $E^{F}$ and $E^{O}$ represent the electronic energy of the system in presence and absence of the electric field, respectively. $F$ denotes the electric field strength, $\mu_{\mathrm{z}}^{0}$ the magnitude of the intrinsic dipole moment, $\alpha_{z z}$ the polarizability and $\beta_{z z z}$ the hyperpolarizability in the z-direction of the system. By combining equations 6 and 7, a direct relationship can be established between the global electrophilicity index $\omega$ and the electric field strength $F$. Only taking into consideration the first three terms of the Taylor expansion, equation 8 is obtained.

$$
\omega=\frac{1}{8}\left(\frac{\left[\left(E_{N+1}^{0}-E_{N-1}^{0}\right)+\left(\mu_{z, N+1}^{0}-\mu_{z, N-1}^{0}\right) F+\frac{1}{2}\left(\alpha_{z z, N+1}-\alpha_{z z, N-1}\right) F^{2}\right]^{2}}{\left(E_{N+1}^{0}-2 E_{N}^{0}+E_{N-1}^{0}\right)+\left(\mu_{z, N+1}^{0}-2 \mu_{z, N}^{0}+\mu_{z, N-1}^{0}\right) F+\frac{1}{2}\left(\alpha_{z z, N+1}-2 \alpha_{z z, N}+\alpha_{z z, N-1}\right) F^{2}}\right)
$$

In case of the monoatomic halogen radicals, equation 8 reduces to the expression given in equation 9, since the dipole moments of the $N, N+1$ and $N-1$ atomic systems in absence of an electric field equal zero.

$$
\omega=\frac{1}{8}\left(\frac{\left(E_{N+1}^{0}-E_{N-1}^{0}\right)^{2}+\left(E_{N+1}^{0}-E_{N-1}^{0}\right)\left(\alpha_{z z, N+1}-\alpha_{z z, N-1}\right) F^{2}+\frac{1}{4}\left(\alpha_{z z, N+1}-\alpha_{z z, N-1}\right)^{2} F^{4}}{\left(E_{N+1}^{0}-2 E_{N}^{0}+E_{N-1}^{0}\right)+\frac{1}{2}\left(\alpha_{z z, N+1}-2 \alpha_{z z, N}+\alpha_{z z, N-1}\right) F^{2}}\right)
$$

For the halogens, we find that $\left(E_{N+1}^{0}-E_{N-1}^{0}\right)^{2} \gg \frac{1}{4}\left(\alpha_{z z, N+1}-\alpha_{z z, N-1}\right)^{2} F^{4}$ at the electric field strengths considered in this work:

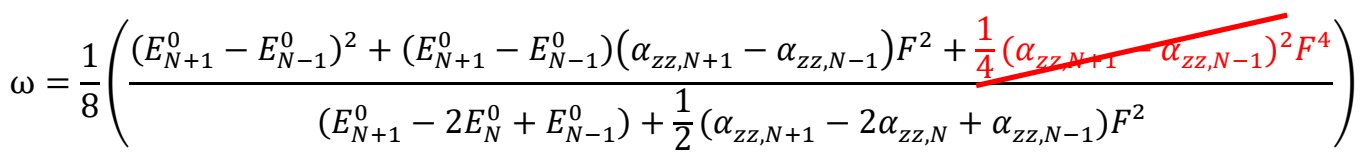

Dividing both the numerator and denominator by $\left(E_{N+1}^{0}-E_{N-1}^{0}\right)^{2}$ results in the following expression:

$$
\omega=\frac{1+\left(\alpha_{z z, N+1}-\alpha_{z z, N-1}\right) F^{2} /\left(E_{N+1}^{0}-E_{N-1}^{0}\right)}{8\left(E_{N+1}^{0}-2 E_{N}^{0}+E_{N-1}^{0}\right) /\left(E_{N+1}^{0}-E_{N-1}^{0}\right)^{2}+4\left(\alpha_{z z, N+1}-2 \alpha_{z z, N}+\alpha_{z z, N-1}\right) F^{2} /\left(E_{N+1}^{0}-E_{N-1}^{0}\right)^{2}}
$$

in which $\omega_{0}$, the electrophilicity index in absence of an OEEF, can be introduced:

$$
\omega=\frac{1+\left(\alpha_{z z, N+1}-\alpha_{z z, N-1}\right) F^{2} /\left(E_{N+1}^{0}-E_{N-1}^{0}\right)}{1 / \omega_{0}+4\left(\alpha_{z z, N+1}-2 \alpha_{z z, N}+\alpha_{z z, N-1}\right) F^{2} /\left(E_{N+1}^{0}-E_{N-1}^{0}\right)^{2}}
$$

Again, dividing both the numerator and denominator by $\omega_{0}$ leads to expression:

$$
\omega=\frac{\omega_{0}+\omega_{0}\left(\alpha_{z z, N+1}-\alpha_{z z, N-1}\right) F^{2} /\left(E_{N+1}^{0}-E_{N-1}^{0}\right)}{1+4 \omega_{0}\left(\alpha_{z z, N+1}-2 \alpha_{z z, N}+\alpha_{z z, N-1}\right) F^{2} /\left(E_{N+1}^{0}-E_{N-1}^{0}\right)^{2}}
$$

First, $b=\frac{4 \omega_{0}\left(\alpha_{Z Z, N+1}-2 \alpha_{Z Z, N}+\alpha_{Z Z, N-1}\right) F^{2}}{\left(E_{N+1}^{0}-E_{N-1}^{0}\right)^{2}}$ is introduced. Next, this expression is split up into two terms:

$$
\omega=\frac{\omega_{0}}{1+b}+\frac{\omega_{0}\left(\alpha_{z z, N+1}-\alpha_{z z, N-1}\right) F^{2} /\left(E_{N+1}^{0}-E_{N-1}^{0}\right)}{1+b}
$$


The first term can be rewritten as:

$\frac{\omega_{0}}{1+b}=\omega_{0}-\frac{\omega_{0} b}{1+b}$

The slightly simplified equation 10 is obtained:

$\omega=\omega_{0}+\frac{\omega_{0}\left(\alpha_{z z, N+1}-\alpha_{z z, N-1}\right) F^{2} /\left(E_{N+1}^{0}-E_{N-1}^{0}\right)}{1+b}-\frac{\omega_{0} b}{1+b}$

As the numerators of terms 2 and 3 as well as parameter $b$ reflect quite small values (in absolute values), the denominators can be approximated by 1 , i.e., $1+b \approx 1$, and equation 10 can be further simplified to $\omega_{0}$ as baseline plus a second order dependency between $\omega$ and $F$ :

$\omega=\omega_{0}+\omega_{0}\left[\frac{\left(E_{N+1}^{0}-E_{N-1}^{0}\right)\left(\alpha_{z z, N+1}-\alpha_{z z, N-1}\right)-4 \omega_{0}\left(\alpha_{z z, N+1}-2 \alpha_{z z, N}+\alpha_{z z, N-1}\right)}{\left(E_{N+1}^{0}-E_{N-1}^{0}\right)^{2}}\right] F^{2}=\omega_{0}+C F^{2}$

The curvature $C$ of the parabolic function, $\omega(F)$, is determined by both the electronic energies and the polarizability $\left(\alpha_{z z}\right)$ values of the $N, N+1$ and $N-1$ electronic systems in absence of an OEEF.

To substantiate the above conditions and derivations, the numerical values for the halogen radicals are provided in the table below.

Table 1: Electronic energies (in eV) and polarizabilities (in a.u.) calculated for the halogen radicals in absence of an OEEF, approximated electrophilicity index (in eV) for a field strength of 0.01 a.u., using Equation (11) upon fulfillment of two conditions (values given in $\mathrm{eV}$ ), and the exact electrophilicity index for $\mathrm{F}=0.01$. All properties were calculated with the (U)B3LYP functional and aug-cc-pVTZ (aug-cc-pVTZ(PP) for iodine) basis set.

\begin{tabular}{|c|c|c|c|c|c|c|c|c|c|c|}
\hline Halogen & $E_{N}^{0}$ & & $E_{N-1}^{0}$ & $E_{N+1}^{0}$ & \multicolumn{2}{|c|}{$\omega_{0}$} & $\alpha_{z z, N}$ & $\alpha_{z z, N-1}$ & \multicolumn{2}{|l|}{$\alpha_{z z, N+1}$} \\
\hline $\mathrm{F}$ & \multicolumn{2}{|l|}{-2714.7764} & -2697.0361 & -2718.3060 & \multicolumn{2}{|c|}{3.979} & 3.567 & 1.829 & \multicolumn{2}{|l|}{8.850} \\
\hline $\mathrm{Cl}$ & \multicolumn{2}{|l|}{-12522.0150} & -12508.9411 & -12525.6936 & \multicolumn{2}{|c|}{3.734} & 14.821 & 8.712 & \multicolumn{2}{|l|}{28.779} \\
\hline $\mathrm{Br}$ & \multicolumn{2}{|l|}{-70047.2591} & -70035.3133 & -70050.8074 & \multicolumn{2}{|c|}{3.574} & 21.437 & 12.675 & \multicolumn{2}{|l|}{41.97} \\
\hline 1 & \multicolumn{2}{|l|}{-8048.6342} & -8038.0091 & -8051.9366 & \multicolumn{2}{|c|}{3.311} & 33.542 & 20.406 & \multicolumn{2}{|l|}{63.759} \\
\hline & \multicolumn{4}{|c|}{ Condition 1} & \multicolumn{3}{|c|}{ Condition 2} & Slope & \multicolumn{2}{|c|}{$F=0.01$ a.u. } \\
\hline & $\left(E_{N+1}^{0}-E_{N-1}^{0}\right)^{2}$ & & $\frac{1}{4}\left(\alpha_{z z, N+1}-\alpha_{z z, N-1}\right)^{2} F^{4}$ & Fulfilled? & $b$ & & Fulfilled? & C & $\omega_{a p p r}$ & $\omega_{\text {exact }}$ \\
\hline $\mathrm{F}$ & 452.4 & $>$ & 0.00009 & $\checkmark$ & -0.00034 & $<<1$ & $\checkmark$ & 49.3 & 3.984 & 3.985 \\
\hline $\mathrm{Cl}$ & 280.6 & $\gg$ & 0.00075 & $\checkmark$ & -0.00114 & $<<1$ & $\checkmark$ & 164.1 & 3.750 & 3.749 \\
\hline $\mathrm{Br}$ & 240.1 & $>>$ & 0.00159 & $\checkmark$ & -0.00191 & $<<1$ & $\checkmark$ & 252.0 & 3.599 & 3.601 \\
\hline 1 & 194.0 & $>>$ & 0.00348 & $\checkmark$ & -0.00317 & $<<1$ & $\checkmark$ & 385.5 & 3.350 & 3.348 \\
\hline
\end{tabular}

\section{Summary of computed data}

\subsection{Computational details}

Throughout this study, the geometry of all radicals were optimized at the DFT-level of theory with the UB3LYP functional and the Dunning's aug-cc-pVDZ basis set. ${ }^{7,} 8$ Previous studies have shown the 
UB3LYP functional to be suitable for the determination of most relevant electrophilicity indices for organic radicals. ${ }^{9,10}$ Frequency analyses were performed to confirm that the resulting geometries correspond to minima on the potential energy surface. Subsequent single point energy calculations were performed with the same functional but the aug-cc-pVTZ basis set (for iodine atoms, an aug-ccpVTZ-PP basis set was used to take relativistic effects in consideration via a pseudopotential). ${ }^{11-13}$ Note that for radicals 1-5 and 9, the corresponding $\mathrm{N}-1$ electron system is characterized by a triplet ground state. All calculations were performed with the Gaussian 16 software (revision A.03). ${ }^{14}$ Below a list of the model radicals that were investigated in this study is provided. Note, that because of the limited structural complexity of the radicals considered in this work, their conformation can be adequately described by their energetically most stable conformation. However, if structural complexity and conformational freedom would increase, it could become more accurate to take into consideration multiple conformations and compute the energetic properties using the Boltzmann distribution of all conformations.

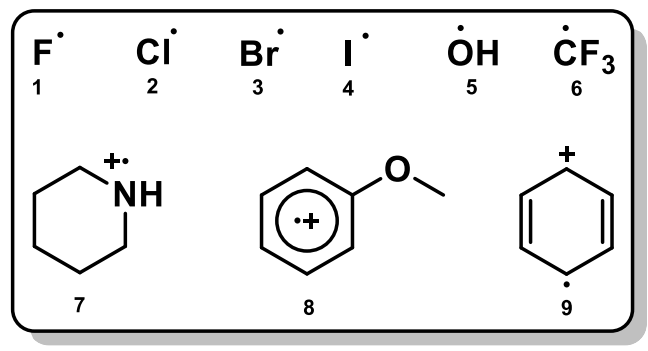

Scheme 1: Model radicals 1-9 investigated in this work.

\subsection{Electronic properties}

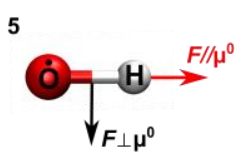

8

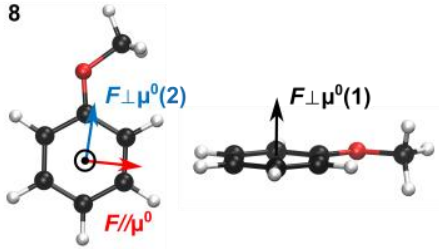

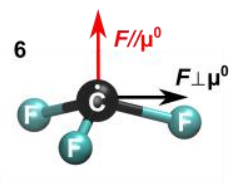

8

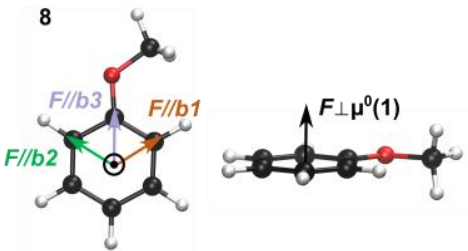

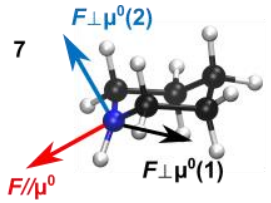

9

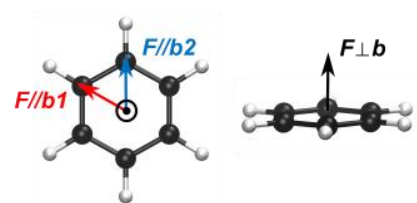

Figure 1: Different directionalities of an OEEF considered for radicals 5-9. The label for each direction corresponds with the one provided in Table 1.

One might wonder, why for the benzene radical cation 9, an OEEF applied in the direction of $F / / b 1$ and $\mathrm{F} / / \mathrm{b} 2$ is expected to provide a different outcome. In this regard, it is important to realize that the symmetry of the benzene radical cation is different from benzene itself. Indeed, the benzene radical cation is known to be a Jahn-Teller active system, in which the degeneracy of the HOMO of benzene is spontaneously distorted. As an effect, the $D_{6 h}$ symmetry is altered to a $D_{2 h}$ symmetry through pairwise 
elongation and contraction of the C-C bonds. ${ }^{15,16}$ Herein, b1 denotes the longer $\mathrm{C}-\mathrm{C}$ bond $(1.433 \AA$ in absence of an OEEF), while b2 denotes the shorter C-C bond (1.374 $\AA$ in absence of an OEEF).

Table 2: Electronic properties calculated for radicals 1-9 in an OEEF with different field strengths $F$ and directionality. All properties were calculated with the (U)B3LYP functional and aug-cc-pVTZ (aug-cc-pVTZ(PP) for iodine) basis set.

\begin{tabular}{|c|c|c|c|c|c|c|}
\hline Entry & $\begin{array}{c}\text { Directionality } \\
\text { OEEF }\end{array}$ & $F$ (a.u.) & $E_{N}(\mathrm{eV})$ & $E_{N-1}(e V)$ & $E_{N+1}(\mathrm{eV})$ & $\omega(\mathrm{eV})$ \\
\hline 1 & N.A. & 0.01 & -2714.7808 & -2697.0386 & -2718.3180 & 3.985 \\
\hline 1 & N.A. & 0.0075 & -2714.7788 & -2697.0375 & -2718.3128 & 3.982 \\
\hline 1 & N.A. & 0.005 & -2714.7775 & -2697.0367 & -2718.3090 & 3.981 \\
\hline 1 & N.A. & 0.0025 & -2714.7766 & -2697.0362 & -2718.3067 & 3.980 \\
\hline 1 & N.A. & 0 & -2714.7764 & -2697.0361 & -2718.3060 & 3.979 \\
\hline 1 & N.A. & -0.0025 & -2714.7766 & -2697.0362 & -2718.3067 & 3.980 \\
\hline 1 & N.A. & -0.005 & -2714.7775 & -2697.0367 & -2718.3090 & 3.981 \\
\hline 1 & N.A. & -0.0075 & -2714.7788 & -2697.0375 & -2718.3128 & 3.982 \\
\hline 1 & N.A. & -0.01 & -2714.7808 & -2697.0386 & -2718.3180 & 3.985 \\
\hline 2 & N.A. & 0.01 & -12522.0361 & -12508.9533 & -12525.7328 & 3.750 \\
\hline 2 & N.A. & 0.0075 & -12522.0268 & -12508.9480 & -12525.7156 & 3.743 \\
\hline 2 & N.A. & 0.005 & -12522.0203 & -12508.9441 & -12525.7034 & 3.738 \\
\hline 2 & N.A. & 0.0025 & -12522.0163 & -12508.9418 & -12525.6960 & 3.735 \\
\hline 2 & N.A. & 0 & -12522.0150 & -12508.9411 & -12525.6936 & 3.734 \\
\hline 2 & N.A. & -0.0025 & -12522.0163 & -12508.9418 & -12525.6960 & 3.735 \\
\hline 2 & N.A. & -0.005 & -12522.0203 & -12508.9441 & -12525.7034 & 3.738 \\
\hline 2 & N.A. & -0.0075 & -12522.0268 & -12508.9480 & -12525.7156 & 3.743 \\
\hline 2 & N.A. & -0.01 & -12522.0361 & -12508.9533 & -12525.7328 & 3.750 \\
\hline 3 & N.A. & 0.01 & -70047.2856 & -70035.3301 & -70050.8647 & 3.601 \\
\hline 3 & N.A. & 0.0075 & -70047.2740 & -70035.3227 & -70050.8396 & 3.589 \\
\hline 3 & N.A. & 0.005 & -70047.2657 & -70035.3175 & -70050.8217 & 3.580 \\
\hline 3 & N.A. & 0.0025 & -70047.2607 & -70035.3143 & -70050.8110 & 3.575 \\
\hline 3 & N.A. & 0 & -70047.2591 & -70035.3133 & -70050.8074 & 3.574 \\
\hline 3 & N.A. & -0.0025 & -70047.2607 & -70035.3143 & -70050.8110 & 3.575 \\
\hline 3 & N.A. & -0.005 & -70047.2657 & -70035.3175 & -70050.8217 & 3.580 \\
\hline 3 & N.A. & -0.0075 & -70047.2740 & -70035.3227 & -70050.8396 & 3.589 \\
\hline 3 & N.A. & -0.01 & -70047.2856 & -70035.3301 & -70050.8647 & 3.601 \\
\hline 4 & N.A. & 0.01 & -8048.6820 & -8038.0384 & -8052.0238 & 3.348 \\
\hline 4 & N.A. & 0.0075 & -8048.6611 & -8038.0256 & -8051.9855 & 3.332 \\
\hline 4 & N.A. & 0.005 & -8048.6462 & -8038.0164 & -8051.9583 & 3.320 \\
\hline 4 & N.A. & 0.0025 & -8048.6372 & -8038.0109 & -8051.9420 & 3.313 \\
\hline 4 & N.A. & 0 & -8048.6342 & -8038.0091 & -8051.9366 & 3.311 \\
\hline 4 & N.A. & -0.0025 & -8048.6372 & -8038.0109 & -8051.9420 & 3.313 \\
\hline 4 & N.A. & -0.005 & -8048.6462 & -8038.0164 & -8051.9583 & 3.320 \\
\hline 4 & N.A. & -0.0075 & -8048.6611 & -8038.0256 & -8051.9855 & 3.332 \\
\hline 4 & N.A. & -0.01 & -8048.6820 & -8038.0384 & -8052.0238 & 3.348 \\
\hline 5 & $F / / \mu^{0}$ & 0.01 & -2061.6048 & -2048.2504 & -2063.4899 & 2.531 \\
\hline 5 & $F / / \mu^{0}$ & 0.0075 & -2061.6436 & -2048.2988 & -2063.5135 & 2.522 \\
\hline 5 & $F / / \mu^{0}$ & 0.005 & -2061.6840 & -2048.3482 & -2063.5408 & 2.513 \\
\hline
\end{tabular}




\begin{tabular}{|c|c|c|c|c|c|c|}
\hline 5 & $F / / \mu^{0}$ & 0.0025 & -2061.7259 & -2048.3985 & -2063.5719 & 2.507 \\
\hline 5 & $F / / \mu^{0}$ & 0 & -2061.7692 & -2048.4501 & -2063.6065 & 2.501 \\
\hline 5 & $F / / \mu^{0}$ & -0.0025 & -2061.8142 & -2048.5015 & -2063.6450 & 2.497 \\
\hline 5 & $F / / \mu^{0}$ & -0.005 & -2061.8606 & -2048.5547 & -2063.6869 & 2.493 \\
\hline 5 & $F / / \mu^{0}$ & -0.0075 & -2061.9085 & -2048.6086 & -2063.7324 & 2.491 \\
\hline 5 & $F / / \mu^{0}$ & -0.01 & -2061.9579 & -2048.6634 & -2063.7814 & 2.491 \\
\hline 5 & $F \perp \mu^{0}$ & 0.01 & -2061.7775 & -2048.4548 & -2063.6465 & 2.519 \\
\hline 5 & $F \perp \mu^{0}$ & 0.0075 & -2061.7739 & -2048.4527 & -2063.6290 & 2.511 \\
\hline 5 & $F \perp \mu^{0}$ & 0.005 & -2061.7713 & -2048.4513 & -2063.6165 & 2.505 \\
\hline 5 & $F \perp \mu^{0}$ & 0.0025 & -2061.7698 & -2048.4504 & -2063.6090 & 2.502 \\
\hline 5 & $F \perp \mu^{0}$ & 0 & -2061.7692 & -2048.4501 & -2063.6065 & 2.501 \\
\hline 5 & $F \perp \mu^{0}$ & -0.0025 & -2061.7698 & -2048.4504 & -2063.6090 & 2.502 \\
\hline 5 & $F \perp \mu^{0}$ & -0.005 & -2061.7713 & -2048.4513 & -2063.6165 & 2.505 \\
\hline 5 & $F \perp \mu^{0}$ & -0.0075 & -2061.7739 & -2048.4527 & -2063.6290 & 2.511 \\
\hline 5 & $F \perp \mu^{0}$ & -0.01 & -2061.7775 & -2048.4548 & -2063.6465 & 2.519 \\
\hline 6 & $F / / \mu^{0}$ & 0.01 & -9189.3730 & -9178.0270 & -9190.3260 & 1.819 \\
\hline 6 & $\mathrm{~F} / / \mathrm{\mu}^{0}$ & 0.0075 & -9189.3705 & -9178.0311 & -9190.2204 & 1.771 \\
\hline 6 & $F / / \mu^{0}$ & 0.005 & -9189.3711 & -9178.0373 & -9190.1330 & 1.730 \\
\hline 6 & $F / / \mu^{0}$ & 0.0025 & -9189.3746 & -9178.0460 & -9190.0637 & 1.697 \\
\hline 6 & $F / / \mu^{0}$ & 0 & -9189.3805 & -9178.0444 & -9190.0225 & 1.677 \\
\hline 6 & $F / / \mu^{0}$ & -0.0025 & -9189.3904 & -9178.0688 & -9189.9823 & 1.653 \\
\hline 6 & $F / / \mu^{0}$ & -0.005 & -9189.4027 & -9178.0838 & -9189.9700 & 1.643 \\
\hline 6 & $F / / \mu^{0}$ & -0.0075 & -9189.4179 & -9178.1008 & -9189.9766 & 1.639 \\
\hline 6 & $F / / \mu^{0}$ & -0.01 & -9189.4361 & -9178.1200 & -9190.0015 & 1.641 \\
\hline 6 & $F \perp \mu^{0}$ & 0.01 & -9189.4165 & -9178.0824 & -9190.1457 & 1.715 \\
\hline 6 & $F \perp \mu^{0}$ & 0.0075 & -9189.4009 & -9178.0711 & -9190.0868 & 1.696 \\
\hline 6 & $F \perp \mu^{0}$ & 0.005 & -9189.3899 & -9178.0630 & -9190.0457 & 1.682 \\
\hline 6 & $F \perp \mu^{0}$ & 0.0025 & -9189.3833 & -9178.0616 & -9190.0184 & 1.672 \\
\hline 6 & $F \perp \mu^{0}$ & 0 & -9189.3805 & -9178.0444 & -9190.0225 & 1.677 \\
\hline 6 & $F \perp \mu^{0}$ & -0.0025 & -9189.3832 & -9178.0625 & -9190.0176 & 1.672 \\
\hline 6 & $F \perp \mu^{0}$ & -0.005 & -9189.3898 & -9178.0631 & -9190.0453 & 1.682 \\
\hline 6 & $F \perp \mu^{0}$ & -0.0075 & -9189.4007 & -9178.0713 & -9190.0853 & 1.695 \\
\hline 6 & $F \perp \mu^{0}$ & -0.01 & -9189.4161 & -9178.0827 & -9190.1419 & 1.714 \\
\hline 7 & $F / / \mu^{0}$ & 0.01 & -6849.3575 & -6834.4129 & -6857.0317 & 8.796 \\
\hline 7 & $F / / \mu^{0}$ & 0.0075 & -6849.3676 & -6834.3934 & -6856.9903 & 8.682 \\
\hline 7 & $F / / \mu^{0}$ & 0.005 & -6849.3922 & -6834.3894 & -6856.9637 & 8.572 \\
\hline 7 & $F / / \mu^{0}$ & 0.0025 & -6849.4309 & -6834.3917 & -6856.9558 & 8.469 \\
\hline 7 & $F / / \mu^{0}$ & 0 & -6849.4837 & -6834.4007 & -6856.9652 & 8.373 \\
\hline 7 & $F / / \mu^{0}$ & -0.0025 & -6849.5512 & -6834.4226 & -6856.9911 & 8.280 \\
\hline 7 & $F / / \mu^{0}$ & -0.005 & -6849.6334 & -6834.4474 & -6857.0354 & 8.193 \\
\hline 7 & $F / / \mu^{0}$ & -0.0075 & -6849.7310 & -6834.4652 & -6857.0982 & 8.107 \\
\hline 7 & $F / / \mu^{0}$ & -0.01 & -6849.8471 & -6834.3592 & -6857.1072 & 7.862 \\
\hline 7 & $F \perp \mu^{0}(1)$ & 0.01 & -6849.5878 & -6834.5018 & -6857.0592 & 8.353 \\
\hline 7 & $F \perp \mu^{0}(1)$ & 0.0075 & -6849.5431 & -6834.4522 & -6857.0185 & 8.359 \\
\hline 7 & $F \perp \mu^{0}(1)$ & 0.005 & -6849.5109 & -6834.4192 & -6856.9894 & 8.364 \\
\hline 7 & $F \perp \mu^{0}(1)$ & 0.0025 & -6849.4911 & -6834.4031 & -6856.9713 & 8.368 \\
\hline 7 & $F \perp \mu^{0}(1)$ & 0 & -6849.4837 & -6834.4007 & -6856.9652 & 8.373 \\
\hline 7 & $F \perp \mu^{0}(1)$ & -0.0025 & -6849.4891 & -6834.4185 & -6856.9698 & 8.376 \\
\hline
\end{tabular}




\begin{tabular}{|c|c|c|c|c|c|c|}
\hline 7 & $F \perp \mu^{0}(1)$ & -0.005 & -6849.5070 & -6834.4549 & -6856.9839 & 8.375 \\
\hline 7 & $F \perp \mu^{0}(1)$ & -0.0075 & -6849.5376 & -6834.5086 & -6857.0088 & 8.373 \\
\hline 7 & $F \perp \mu^{0}(1)$ & -0.01 & -6849.5809 & -6834.5785 & -6857.0450 & 8.370 \\
\hline 7 & $F \perp \mu^{0}(2)$ & 0.01 & -6849.6512 & -6834.6742 & -6857.0925 & 8.337 \\
\hline 7 & $F \perp \mu^{0}(2)$ & 0.0075 & -6849.5949 & -6834.5952 & -6857.0425 & 8.340 \\
\hline 7 & $F \perp \mu^{0}(2)$ & 0.005 & -6849.5482 & -6834.5240 & -6857.0044 & 8.347 \\
\hline 7 & $F \perp \mu^{0}(2)$ & 0.0025 & -6849.5112 & -6834.4603 & -6856.9784 & 8.358 \\
\hline 7 & $F \perp \mu^{0}(2)$ & 0 & -6849.4837 & -6834.4007 & -6856.9652 & 8.373 \\
\hline 7 & $F \perp \mu^{0}(2)$ & -0.0025 & -6849.4663 & -6834.3521 & -6856.9640 & 8.391 \\
\hline 7 & $F \perp \mu^{0}(2)$ & -0.005 & -6849.4588 & -6834.3042 & -6856.9773 & 8.415 \\
\hline 7 & $F \perp \mu^{0}(2)$ & -0.0075 & -6849.4617 & -6834.2542 & -6857.0074 & 8.446 \\
\hline 7 & $F \perp \mu^{0}(2)$ & -0.01 & -6849.4940 & -6833.9475 & -6856.9535 & 8.181 \\
\hline 8 & $\mathrm{~F} / / \mathrm{\mu}^{0}$ & 0.01 & -9431.6745 & -9417.4691 & -9439.5288 & 9.578 \\
\hline 8 & $F / / \mu^{0}$ & 0.0075 & -9431.6555 & -9417.4563 & -9439.4981 & 9.554 \\
\hline 8 & $F / / \mu^{0}$ & 0.005 & -9431.6507 & -9417.4573 & -9439.4832 & 9.533 \\
\hline 8 & $F / / \mu^{0}$ & 0.0025 & -9431.6603 & -9417.4713 & -9439.4848 & 9.518 \\
\hline 8 & $F / / \mu^{0}$ & 0 & -9431.6840 & -9417.4989 & -9439.5024 & 9.506 \\
\hline 8 & $F / / \mu^{0}$ & -0.0025 & -9431.7218 & -9417.5396 & -9439.5360 & 9.497 \\
\hline 8 & $F / / \mu^{0}$ & -0.005 & -9431.7737 & -9417.5939 & -9439.5855 & 9.493 \\
\hline 8 & $F / / \mu^{0}$ & -0.0075 & -9431.8398 & -9417.6621 & -9439.6507 & 9.492 \\
\hline 8 & $F / / \mu^{0}$ & -0.01 & -9431.9200 & -9417.7434 & -9439.7322 & 9.496 \\
\hline 8 & $F \perp \mu^{0}(1)$ & 0.01 & -9431.7536 & -9417.5543 & -9439.5931 & 9.546 \\
\hline 8 & $F \perp \mu^{0}(1)$ & 0.0075 & -9431.7232 & -9417.5301 & -9439.5534 & 9.528 \\
\hline 8 & $F \perp \mu^{0}(1)$ & 0.005 & -9431.7014 & -9417.5127 & -9439.5251 & 9.516 \\
\hline 8 & $F \perp \mu^{0}(1)$ & 0.0025 & -9431.6883 & -9417.5023 & -9439.5080 & 9.508 \\
\hline 8 & $F \perp \mu^{0}(1)$ & 0 & -9431.6840 & -9417.4989 & -9439.5024 & 9.506 \\
\hline 8 & $F \perp \mu^{0}(1)$ & -0.0025 & -9431.6881 & -9417.5019 & -9439.5080 & 9.508 \\
\hline 8 & $F \perp \mu^{0}(1)$ & -0.005 & -9431.7010 & -9417.5120 & -9439.5249 & 9.516 \\
\hline 8 & $F \perp \mu^{0}(1)$ & -0.0075 & -9431.7225 & -9417.5289 & -9439.5532 & 9.529 \\
\hline 8 & $F \perp \mu^{0}(1)$ & -0.01 & -9431.7527 & -9417.5527 & -9439.5929 & 9.548 \\
\hline 8 & $F \perp \mu^{0}(2)$ & 0.01 & -9431.8577 & -9417.7614 & -9439.5496 & 9.266 \\
\hline 8 & $F \perp \mu^{0}(2)$ & 0.0075 & -9431.7807 & -9417.6624 & -9439.5048 & 9.327 \\
\hline 8 & $F \perp \mu^{0}(2)$ & 0.005 & -9431.7260 & -9417.5854 & -9439.4818 & 9.387 \\
\hline 8 & $F \perp \mu^{0}(2)$ & 0.0025 & -9431.6937 & -9417.5316 & -9439.4802 & 9.445 \\
\hline 8 & $F \perp \mu^{0}(2)$ & 0 & -9431.6840 & -9417.4989 & -9439.5024 & 9.506 \\
\hline 8 & $F \perp \mu^{0}(2)$ & -0.0025 & -9431.6968 & -9417.4883 & -9439.5471 & 9.566 \\
\hline 8 & $F \perp \mu^{0}(2)$ & -0.005 & -9431.7320 & -9417.5024 & -9439.6121 & 9.624 \\
\hline 8 & $F \perp \mu^{0}(2)$ & -0.0075 & -9431.7901 & -9417.5388 & -9439.7009 & 9.683 \\
\hline 8 & $F \perp \mu^{0}(2)$ & -0.01 & -9431.8711 & -9417.5986 & -9439.8118 & 9.741 \\
\hline 8 & $F / / b 1$ & 0.01 & -9429.9162 & -9413.9612 & -9439.4930 & 12.775 \\
\hline 8 & $\mathrm{~F} / / \mathrm{b} 1$ & 0.0075 & -9430.3312 & -9414.8194 & -9439.4663 & 11.908 \\
\hline 8 & $\mathrm{~F} / / \mathrm{b} 1$ & 0.005 & -9430.7642 & -9415.6950 & -9439.4590 & 11.074 \\
\hline 8 & $\mathrm{~F} / / \mathrm{b} 1$ & 0.0025 & -9431.2151 & -9416.5881 & -9439.4710 & 10.274 \\
\hline 8 & $\mathrm{~F} / / \mathrm{b} 1$ & 0 & -9431.6840 & -9417.4989 & -9439.5024 & 9.506 \\
\hline 8 & $\mathrm{~F} / / \mathrm{b} 1$ & -0.0025 & -9432.1709 & -9418.4278 & -9439.5527 & 8.769 \\
\hline 8 & $\mathrm{~F} / / \mathrm{b} 1$ & -0.005 & -9432.6760 & -9419.3748 & -9439.6224 & 8.064 \\
\hline 8 & $\mathrm{~F} / / \mathrm{b} 1$ & -0.0075 & -9433.1994 & -9420.3403 & -9439.7115 & 7.390 \\
\hline 8 & $\mathrm{~F} / / \mathrm{b} 1$ & -0.01 & -9433.7412 & -9421.3245 & -9439.8200 & 6.747 \\
\hline
\end{tabular}




\begin{tabular}{|c|c|c|c|c|c|c|}
\hline 8 & $\mathrm{~F} / / \mathrm{b} 2$ & 0.01 & -9432.6732 & -9419.2664 & -9439.7068 & 8.195 \\
\hline 8 & $\mathrm{~F} / / \mathrm{b} 2$ & 0.0075 & -9432.4041 & -9418.8040 & -9439.6313 & 8.508 \\
\hline 8 & $\mathrm{~F} / / \mathrm{b} 2$ & 0.005 & -9432.1495 & -9418.3553 & -9439.5722 & 8.831 \\
\hline 8 & $\mathrm{~F} / / \mathrm{b} 2$ & 0.0025 & -9431.9095 & -9417.9203 & -9439.5291 & 9.163 \\
\hline 8 & $\mathrm{~F} / / \mathrm{b} 2$ & 0 & -9431.6840 & -9417.4989 & -9439.5024 & 9.506 \\
\hline 8 & $\mathrm{~F} / / \mathrm{b} 2$ & -0.0025 & -9431.4730 & -9417.0915 & -9439.4916 & 9.857 \\
\hline 8 & $\mathrm{~F} / / \mathrm{b} 2$ & -0.005 & -9431.2765 & -9416.6978 & -9439.4971 & 10.219 \\
\hline 8 & $\mathrm{~F} / / \mathrm{b} 2$ & -0.0075 & -9431.0947 & -9416.3179 & -9439.5187 & 10.591 \\
\hline 8 & $\mathrm{~F} / / \mathrm{b} 2$ & -0.01 & -9430.9276 & -9415.9518 & -9439.5568 & 10.974 \\
\hline 8 & $\mathrm{~F} / / \mathrm{b} 3$ & 0.01 & -9431.9367 & -9417.8888 & -9439.5784 & 9.179 \\
\hline 8 & $\mathrm{~F} / / \mathrm{b} 3$ & 0.0075 & -9431.8405 & -9417.7584 & -9439.5271 & 9.262 \\
\hline 8 & $\mathrm{~F} / / \mathrm{b} 3$ & 0.005 & -9431.7663 & -9417.6501 & -9439.4973 & 9.344 \\
\hline 8 & $\mathrm{~F} / / \mathrm{b} 3$ & 0.0025 & -9431.7141 & -9417.5636 & -9439.4890 & 9.425 \\
\hline 8 & $\mathrm{~F} / / \mathrm{b} 3$ & 0 & -9431.6840 & -9417.4989 & -9439.5024 & 9.506 \\
\hline 8 & $\mathrm{~F} / / \mathrm{b} 3$ & -0.0025 & -9431.6757 & -9417.4561 & -9439.5372 & 9.586 \\
\hline 8 & $\mathrm{~F} / / \mathrm{b} 3$ & -0.005 & -9431.6895 & -9417.4354 & -9439.5940 & 9.666 \\
\hline 8 & $\mathrm{~F} / / \mathrm{b} 3$ & -0.0075 & -9431.7255 & -9417.4369 & -9439.6728 & 9.746 \\
\hline 8 & $\mathrm{~F} / / \mathrm{b} 3$ & -0.01 & -9431.7838 & -9417.4610 & -9439.7740 & 9.828 \\
\hline 9 & $\mathrm{~F} / / \mathrm{b} 1$ & 0.01 & -6312.0646 & -6295.5921 & -6322.0979 & 13.638 \\
\hline 9 & $\mathrm{~F} / / \mathrm{b} 1$ & 0.0075 & -6312.2876 & -6296.0840 & -6322.0507 & 13.087 \\
\hline 9 & $\mathrm{~F} / / \mathrm{b} 1$ & 0.005 & -6312.5239 & -6296.5872 & -6322.0163 & 12.543 \\
\hline 9 & $\mathrm{~F} / / \mathrm{b} 1$ & 0.0025 & -6312.7727 & -6297.1030 & -6321.9957 & 12.015 \\
\hline 9 & $\mathrm{~F} / / \mathrm{b} 1$ & 0 & -6313.0341 & -6297.6308 & -6321.9891 & 11.502 \\
\hline 9 & $\mathrm{~F} / / \mathrm{b} 1$ & -0.0025 & -6313.3073 & -6298.1723 & -6321.9957 & 11.005 \\
\hline 9 & $\mathrm{~F} / / \mathrm{b} 1$ & -0.005 & -6313.5932 & -6298.7258 & -6322.0163 & 10.522 \\
\hline 9 & $\mathrm{~F} / / \mathrm{b} 1$ & -0.0075 & -6313.8916 & -6299.2919 & -6322.0507 & 10.053 \\
\hline 9 & $\mathrm{~F} / / \mathrm{b} 1$ & -0.01 & -6314.2032 & -6299.8693 & -6322.0979 & 9.592 \\
\hline 9 & $\mathrm{~F} / / \mathrm{b} 2$ & 0.01 & -6313.1410 & -6297.7340 & -6322.0991 & 11.507 \\
\hline 9 & $\mathrm{~F} / / \mathrm{b} 2$ & 0.0075 & -6313.0941 & -6297.6891 & -6322.0508 & 11.505 \\
\hline 9 & $\mathrm{~F} / / \mathrm{b} 2$ & 0.005 & -6313.0606 & -6297.6570 & -6322.0165 & 11.504 \\
\hline 9 & $\mathrm{~F} / / \mathrm{b} 2$ & 0.0025 & -6313.0405 & -6297.6378 & -6321.9957 & 11.503 \\
\hline 9 & $\mathrm{~F} / / \mathrm{b} 2$ & 0 & -6313.0341 & -6297.6308 & -6321.9891 & 11.502 \\
\hline 9 & $\mathrm{~F} / / \mathrm{b} 2$ & -0.0025 & -6313.0405 & -6297.6378 & -6321.9957 & 11.503 \\
\hline 9 & $\mathrm{~F} / / \mathrm{b} 2$ & -0.005 & -6313.0606 & -6297.6570 & -6322.0165 & 11.504 \\
\hline 9 & $\mathrm{~F} / / \mathrm{b} 2$ & -0.0075 & -6313.0941 & -6297.6891 & -6322.0508 & 11.505 \\
\hline 9 & $\mathrm{~F} / / \mathrm{b} 2$ & -0.01 & -6313.1410 & -6297.7340 & -6322.0991 & 11.507 \\
\hline 9 & $F \perp b$ & 0.01 & -6313.0837 & -6297.6693 & -6322.0553 & 11.538 \\
\hline 9 & $F \perp b$ & 0.0075 & -6313.0619 & -6297.6527 & -6322.0262 & 11.522 \\
\hline 9 & $F \perp b$ & 0.005 & -6313.0463 & -6297.6408 & -6322.0054 & 11.511 \\
\hline 9 & $F \perp b$ & 0.0025 & -6313.0369 & -6297.6337 & -6321.9930 & 11.504 \\
\hline 9 & $F \perp b$ & 0 & -6313.0341 & -6297.6308 & -6321.9891 & 11.502 \\
\hline 9 & $F \perp b$ & -0.0025 & -6313.0369 & -6297.6337 & -6321.9930 & 11.504 \\
\hline 9 & $F \perp b$ & -0.005 & -6313.0463 & -6297.6408 & -6322.0054 & 11.511 \\
\hline 9 & $F \perp b$ & -0.0075 & -6313.0619 & -6297.6527 & -6322.0262 & 11.522 \\
\hline 9 & $F \perp b$ & -0.01 & -6313.0837 & -6297.6693 & -6322.0553 & 11.538 \\
\hline
\end{tabular}

For the monoatomic halogen radicals 1-4, a perfect quadratic relationship between the field strength $F$ and the global electrophilicity $\omega$ is obtained through the computed datapoints available in Table 1. 
Below, the quadratic fits are provided, including the $\mathrm{R}^{2}$-values and equations, which are obtained through a least-squared $2^{\text {nd }}$ order polynomial fitting procedure executed in Microsoft Excel.

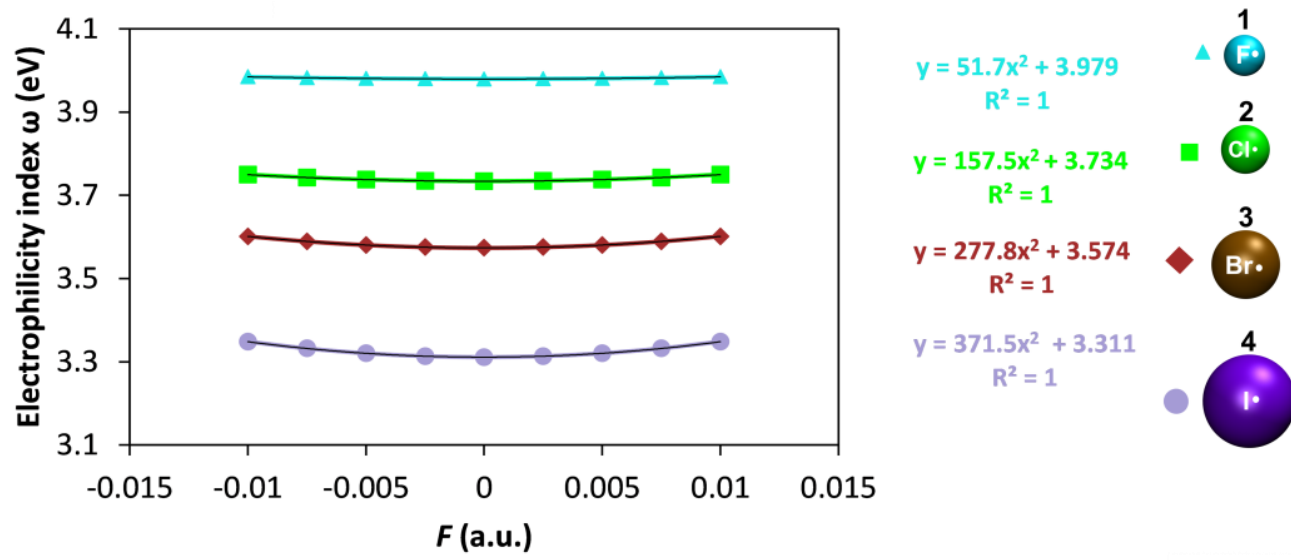

Figure 2: Quadratic fitting between the global electrophilicity index $\omega$ and electric field strength $F$ for radicals 1-4. Equations and $\mathrm{R}^{2}$-values of the quadratic fits are provided alongside the plot.

Table 3: Polarizability values (in a.u.) for the $N$-electron, $N-1$ electron and $N+1$ electron system of radicals 1-4 computed at the the (U)B3LYP functional and aug-cc-pVTZ (aug-cc-pVTZ(PP) for iodine) basis set. The curvature values $C$ are computed based on equation 11 in subsection 1.2, the curvature values a, result from the quadratic fit presented in Figure 2 above.

\begin{tabular}{cccccc}
\hline Radical & $\boldsymbol{\alpha}_{z, N}$ (a.u.) & $\boldsymbol{\alpha}_{z z, N-1}$ (a.u.) & $\boldsymbol{\alpha}_{z,, N+1}$ (a.u.) & $C$ (a.u.) & a \\
\hline $\mathbf{1}$ & 3.567 & 1.829 & 8.850 & 49.3 & 51.7 \\
$\mathbf{2}$ & 14.821 & 8.712 & 28.779 & 164.1 & 157.5 \\
$\mathbf{3}$ & 21.437 & 12.675 & 41.970 & 252.0 & 277.8 \\
$\mathbf{4}$ & 33.542 & 20.406 & 63.759 & 385.5 & 371.5 \\
\hline
\end{tabular}

The curvature values, $C$, based on equation 11 in subsection 1.2 as derived from the Taylor expression to second order, result in an almost perfect fitting of $\omega(F)$ compared to the computed values with a maximum deviation of $0.002 \mathrm{eV}$ for the strongest $\operatorname{OEEF}(F=0.01)$.

\subsection{Structural properties}

An electric field can also induce structural alterations in a molecular system. Below, the geometric parameters that are used to highlight these OEEF induced structural alterations for radicals 5-7 are summarized.

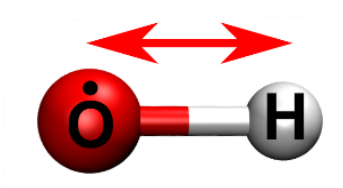

Figure 3: For radical 5, the main geometric parameter to describe the electric field induced structural alterations is the $\mathrm{O}-\mathrm{H}$ bond length. 
Table 4: Change in bond length of radical 5 , induced by an OEEF.

\begin{tabular}{cccc}
\hline Entry & $\begin{array}{c}\text { Directionality } \\
\text { OEEF }\end{array}$ & $\boldsymbol{F}$ (a.u.) & $\begin{array}{c}\text { Bond length } \\
(\AA)\end{array}$ \\
\hline 5 & $F / / \mu^{0}$ & 0.01 & 0.97852 \\
5 & $F / / \mu^{0}$ & 0.0075 & 0.97864 \\
5 & $F / / \mu^{0}$ & 0.005 & 0.97881 \\
5 & $F / / \mu^{0}$ & 0.0025 & 0.97902 \\
5 & $F / / \mu^{0}$ & 0 & 0.97948 \\
5 & $F / / \mu^{0}$ & -0.0025 & 0.97948 \\
5 & $F / / \mu^{0}$ & -0.005 & 0.97995 \\
5 & $F / / \mu^{0}$ & -0.0075 & 0.98036 \\
5 & $F / / \mu^{0}$ & -0.01 & 0.98081 \\
\hline
\end{tabular}

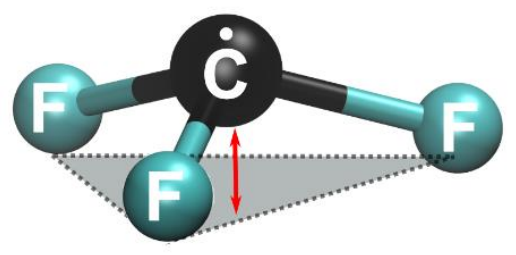

Figure 4: For radical 6, the main geometric parameter to describe the electric field induced structural alterations is the distance between the $\mathrm{C}$ atom and the plane defined by the three $\mathrm{F}$ atoms.

Table 5: Change in bond length of radical 6, induced by an OEEF.

\begin{tabular}{cccc}
\hline Entry & $\begin{array}{c}\text { Directionality } \\
\text { OEEF }\end{array}$ & $\boldsymbol{F}$ (a.u.) & $\begin{array}{c}\text { Distance to } \\
\text { plane (Å) }\end{array}$ \\
\hline 6 & $F / / \mu^{0}$ & 0.01 & 0.390 \\
6 & $F / / \mu^{0}$ & 0.0075 & 0.393 \\
6 & $F / / \mu^{0}$ & 0.005 & 0.396 \\
6 & $F / / \mu^{0}$ & 0.0025 & 0.399 \\
6 & $F / / \mu^{0}$ & 0 & 0.403 \\
6 & $F / / \mu^{0}$ & -0.0025 & 0.405 \\
6 & $F / / \mu^{0}$ & -0.005 & 0.408 \\
6 & $F / / \mu^{0}$ & -0.0075 & 0.411 \\
6 & $F / / \mu^{0}$ & -0.01 & 0.414 \\
\hline
\end{tabular}




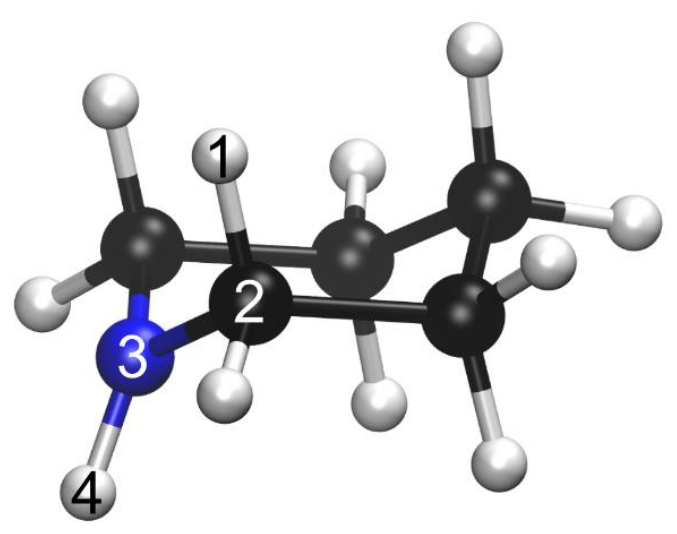

Figure 5: For radical 7, the main geometric parameter to describe the electric field induced structural alterations is the dihedral angle over H1-C2-N3-H4.

Table 6: Change in dihedral angle of radical 7, induced by an OEEF.

\begin{tabular}{|c|c|c|c|}
\hline Entry & $\begin{array}{c}\text { Directionality } \\
\text { OEEF }\end{array}$ & $F$ (a.u.) & $\begin{array}{l}\text { Dihedral } \\
\text { angle }\left(^{\circ}\right)\end{array}$ \\
\hline 7 & $F / / \mu^{0}$ & 0.01 & -91.625 \\
\hline 7 & $F / / \mu^{0}$ & 0.0075 & -125.065 \\
\hline 7 & $F / / \mu^{0}$ & 0.005 & -132.926 \\
\hline 7 & $F / / \mu^{0}$ & 0.0025 & -138.424 \\
\hline 7 & $F / / \mu^{0}$ & 0 & -142.877 \\
\hline 7 & $F / / \mu^{0}$ & -0.0025 & -146.3 \\
\hline 7 & $F / / \mu^{0}$ & -0.005 & -149.393 \\
\hline 7 & $F / / \mu^{0}$ & -0.0075 & -152.215 \\
\hline 7 & $F / / \mu^{0}$ & -0.01 & -154.672 \\
\hline 7 & $F \perp \mu^{0}(1)$ & 0.01 & -140.590 \\
\hline 7 & $F \perp \mu^{0}(1)$ & 0.0075 & -141.037 \\
\hline 7 & $F \perp \mu^{0}(1)$ & 0.005 & -141.542 \\
\hline 7 & $F \perp \mu^{0}(1)$ & 0.0025 & -142.184 \\
\hline 7 & $F \perp \mu^{0}(1)$ & 0 & -142.877 \\
\hline 7 & $F \perp \mu^{0}(1)$ & -0.0025 & -143.289 \\
\hline 7 & $F \perp \mu^{0}(1)$ & -0.005 & -144.220 \\
\hline 7 & $F \perp \mu^{0}(1)$ & -0.0075 & -145.325 \\
\hline 7 & $F \perp \mu^{0}(1)$ & -0.01 & -146.341 \\
\hline 7 & $F \perp \mu^{0}(2)$ & 0.01 & -148.668 \\
\hline 7 & $F \perp \mu^{0}(2)$ & 0.0075 & -147.469 \\
\hline 7 & $F \perp \mu^{0}(2)$ & 0.005 & -146.118 \\
\hline 7 & $F \perp \mu^{0}(2)$ & 0.0025 & -144.563 \\
\hline 7 & $F \perp \mu^{0}(2)$ & 0 & -142.877 \\
\hline 7 & $F \perp \mu^{0}(2)$ & -0.0025 & -140.436 \\
\hline 7 & $F \perp \mu^{0}(2)$ & -0.005 & -137.463 \\
\hline 7 & $F \perp \mu^{0}(2)$ & -0.0075 & -133.134 \\
\hline 7 & $F \perp \mu^{0}(2)$ & -0.01 & -71.203 \\
\hline
\end{tabular}

As mentioned in the main text, the structural changes of radical $\mathbf{7}$ induced by an OEEF are relatively small until a field strength $F<-0.075$ a.u. is applied in the $F / / \mu^{0}$ or $F \perp \mu^{0}(2)$ direction (Figure $2 b$ in main 
text). These structural changes are significant to the extent that they have a direct impact on the philicity of $\mathbf{7}$ in an electric field. Indeed, when investigating the change in $\omega$ upon imposing an OEEF on 7, a sudden shift is observed when $F<-0.0075$ a.u. and in the direction $F / / \mu^{0}$ or $F \perp \mu^{0}(2)$ (Figure 6a). However, when the geometry is fixed, i.e. $\omega$ is computed at the equilibrium geometry of $\mathbf{7}$ in absence of an electric field, these shifts are non-existent (Figure 6b). This confirms that the structural changes of a radical, induced by an electric field, can influence the philicity and other electronic properties of that radical.

A Optimized geometry

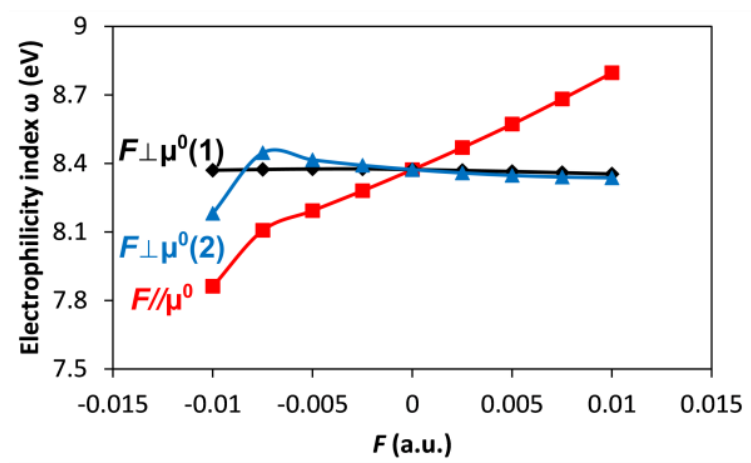

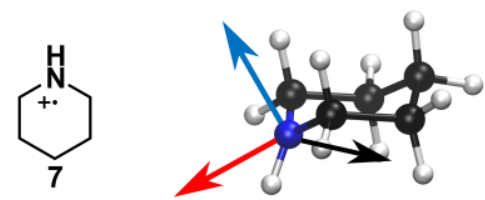

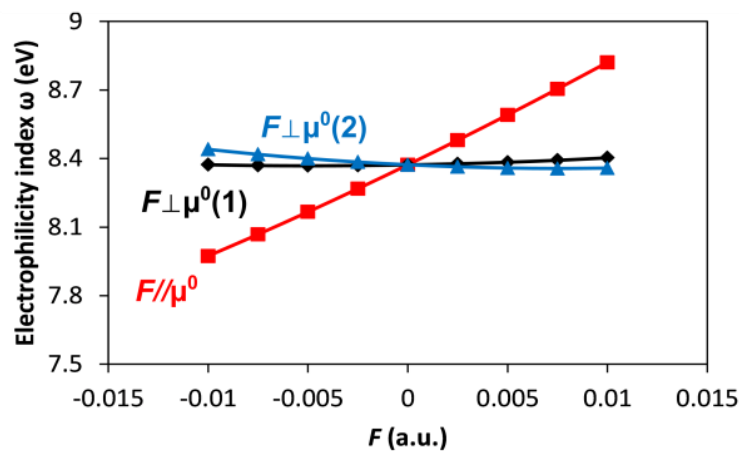

Figure 6: a) The global electrophilicity index $\omega$ of $\mathbf{7}$ computed with different OEEFs, allowing the geometry to relax for each change in electric field properties. b) The global electrophilicity index $\omega$ of $\mathbf{7}$ computed with different OEEFs, fixating the geometry of $\mathbf{7}$ at the equilibrium geometry in absence of an OEEF.

Table 7: Electronic properties calculated for radical $\mathbf{7}$ in an OEEF with different field strengths $F$ and directionality and having a fixed geometry based on the equilibrium geometry of the radical in absence of an OEEF. All properties are calculated with the (U)B3LYP functional and aug-cc-pVTZ basis set.

\begin{tabular}{ccccccc}
\hline Entry & $\begin{array}{c}\text { Directionality } \\
\text { OEEF }\end{array}$ & $\boldsymbol{F}(\mathbf{a . u})$. & $\mathbf{E}_{\mathrm{N}}(\mathbf{e V})$ & $\mathbf{E}_{\mathrm{N}-1}(\mathbf{e V})$ & $\mathbf{E}_{\mathrm{N}+1}(\mathbf{e V})$ & $\boldsymbol{\omega}(\mathbf{e V})$ \\
\hline 7 & $F / / \mu^{0}$ & 0.01 & -6849.3400 & -6834.2743 & -6857.0528 & 8.821 \\
7 & $F / / \mu^{0}$ & 0.0075 & -6849.3575 & -6834.2867 & -6857.0120 & 8.704 \\
7 & $F / / \mu^{0}$ & 0.005 & -6849.3874 & -6834.3120 & -6856.9838 & 8.591 \\
7 & $F / / \mu^{0}$ & 0.0025 & -6849.4295 & -6834.3500 & -6856.9682 & 8.480 \\
7 & $F / / \mu^{0}$ & 0 & -6849.4837 & -6834.4007 & -6856.9652 & 8.373 \\
7 & $F / / \mu^{0}$ & -0.0025 & -6849.5498 & -6834.4640 & -6856.9746 & 8.268 \\
7 & $F / / \mu^{0}$ & -0.005 & -6849.6278 & -6834.5398 & -6856.9966 & 8.166 \\
7 & $F / / \mu^{0}$ & -0.0075 & -6849.7177 & -6834.6280 & -6857.0312 & 8.068 \\
7 & $F / / \mu^{0}$ & -0.01 & -6849.8192 & -6834.7287 & -6857.0787 & 7.973 \\
7 & $F \perp \mu^{0}(1)$ & 0.01 & -6849.5766 & -6834.5242 & -6857.0689 & 8.404 \\
7 & $F \perp \mu^{0}(1)$ & 0.0075 & -6849.5352 & -6834.4738 & -6857.0234 & 8.393 \\
7 & $F \perp \mu^{0}(1)$ & 0.005 & -6849.5059 & -6834.4364 & -6856.9910 & 8.384 \\
7 & $F \perp \mu^{0}(1)$ & 0.0025 & -6849.4887 & -6834.4121 & -6856.9716 & 8.377 \\
7 & $F \perp \mu^{0}(1)$ & 0 & -6849.4837 & -6834.4007 & -6856.9652 & 8.373 \\
7 & $F \perp \mu^{0}(1)$ & -0.0025 & -6849.4907 & -6834.4023 & -6856.9716 & 8.370 \\
7 & $F \perp \mu^{0}(1)$ & -0.005 & -6849.5098 & -6834.4169 & -6856.9910 & 8.368 \\
7 & $F \perp \mu^{0}(1)$ & -0.0075 & -6849.5410 & -6834.4444 & -6857.0234 & 8.370
\end{tabular}




\begin{tabular}{lcccccc}
7 & $F \perp \mu^{0}(1)$ & -0.01 & -6849.5842 & -6834.4850 & -6857.0691 & 8.373 \\
7 & $F \perp \mu^{0}(2)$ & 0.01 & -6849.6483 & -6834.6244 & -6857.1103 & 8.358 \\
7 & $F \perp \mu^{0}(2)$ & 0.0075 & -6849.5933 & -6834.5560 & -6857.0570 & 8.356 \\
7 & $F \perp \mu^{0}(2)$ & 0.005 & -6849.5475 & -6834.4960 & -6857.0151 & 8.358 \\
7 & $F \perp \mu^{0}(2)$ & 0.0025 & -6849.5110 & -6834.4442 & -6856.9845 & 8.364 \\
7 & $F \perp \mu^{0}(2)$ & 0 & -6849.4837 & -6834.4007 & -6856.9652 & 8.373 \\
7 & $F \perp \mu^{0}(2)$ & -0.0025 & -6849.4656 & -6834.3655 & -6856.9569 & 8.385 \\
7 & $F \perp \mu^{0}(2)$ & -0.005 & -6849.4567 & -6834.3386 & -6856.9599 & 8.400 \\
7 & $F \perp \mu^{0}(2)$ & -0.0075 & -6849.4571 & -6834.3200 & -6856.9740 & 8.419 \\
7 & $F \perp \mu^{0}(2)$ & -0.01 & -6849.4667 & -6834.3097 & -6856.9995 & 8.441 \\
\hline
\end{tabular}

\subsection{On the gauge dependency in charged systems}

Radicals 7, 8 and $\mathbf{9}$ are all positively charged species. Importantly, having a charge in a molecular system, brings along the gauge dependency of the dipole moment, meaning the dipole moment (and in presence of an OEEF also the electronic energy) will be different when changing the gauge origin. ${ }^{17}$ For this reason it is important to take special note on the relative position of all atoms in the molecular system to the origin (see cartesian coordinates in section 4).

In this study, potential effects induced by the gauge dependency was minimized by keeping the origin fixed within a certain radical and starting the geometry optimization from the exact same structure. As such the gauge dependency does not affect the general trends in $\omega$ observed in this study. Figure 6 above strengthens this statement, as the increasing or decreasing trends obtained from performing calculations at a fixed geometry (and also fixed gauge origin) are similar to when the geometries are optimized for each value in $F$.

\subsection{Trends in radical philicity of larger halomethyl radicals}

Following the trends observed for the monoatomic halogens, it would be interesting to see how changing the type of halogen would affect the change in electrophilicity index for different halomethyl radicals such as 6 . For this reason the global electrophilicity index $\omega$ is also computed for $\mathrm{CCl}_{3}{ }^{\bullet}(\mathbf{6 b})$, $\mathrm{CBr}_{3}{ }^{\circ}(6 \mathrm{c})$ and $\mathrm{Cl}_{3}{ }^{\circ}(\mathbf{6 d})$ at the same level of theory as described in the computational details section. The results of these computations are summarized in Figure 7.

From these results a number of differences can be deduced between the trifluoromethyl radical (6) and the other halomethylradicals. First, $\omega$ increases when an electric field is applied alongside the intrinsic dipole moment of $\mathbf{6}$ in the positive direction. On the other hand for $\mathbf{6 b}, \mathbf{6 c}$ and $\mathbf{6 d}, \boldsymbol{\omega}$ decreases when an electric field is applied alongside the intrinsic dipole in the positive direction. This suggests, that similar to the aryl radical cations, it is not the intrinsic dipole moment, but the larger polarizability that plays a crucial role on how the philicty is altered by an electric field. Second, our results indicate that $\omega$, and the corresponding tendency of the radicals to behave as an electrophile, increases in the order of $\mathrm{Cl}_{3}{ }^{\circ}<\mathrm{CBr}_{3}{ }^{\circ}<\mathrm{CCl}_{3}{ }^{\circ}$ similar to the monoatomic halogens. However, $\mathrm{CF}_{3}{ }^{\circ}$ surprisingly does not follow this expected trend and can have its philicity altered to a greater extent compared to the other trihalomethyl radicals. Currently, we are unsure how to explain these results. 

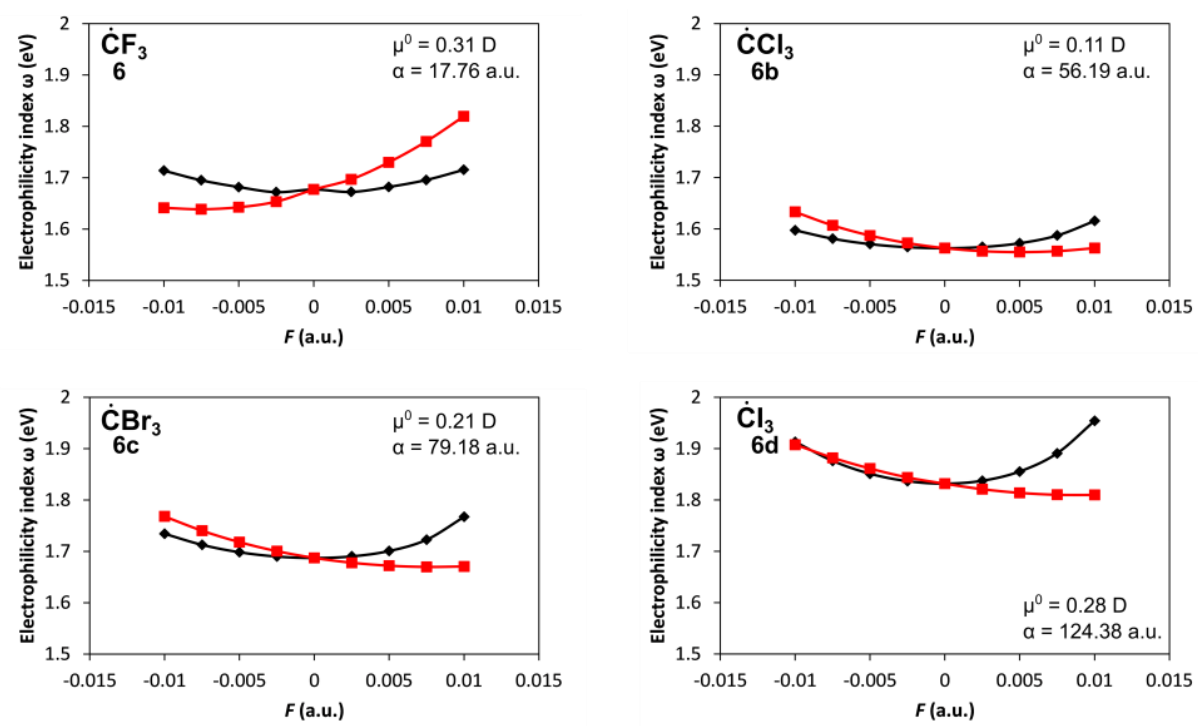

Figure 7. The electrophilicity index $\omega$ of the trihalomethyl radicals $6, \mathbf{6 b}, \mathbf{6 c}$ and $\mathbf{6 d}$ in an OEEF with $\mathrm{F}$ ranging from 0.01 to 0.01 a.u. alongside $\left(F / / \mu^{0}\right)$ (red curves) or perpendicular $\left(F \perp \mu^{0}\right)$ to the intrinsic dipole of the radical (black curve), computed at the (U)B3LYP/aug-cc-pVTZ(-PP)//(U)B3LYP/aug-cc-pVDZ(-PP) density functional level of theory. The magnitude of $\mu^{0}$ and $\alpha$ is computed at the UB3LYP/aug-cc-pVDZ(-PP) level of theory and is provided in the graphs.

Table 8: Electronic properties calculated for radicals $\mathbf{6 b}, \mathbf{6 c}$ and $\mathbf{6 d}$ in an OEEF with different field strengths $F$ and directionality. All properties were calculated with the (U)B3LYP functional and aug-cc-pVTZ (aug-cc-pVTZ(PP) for iodine) basis set.

\begin{tabular}{|c|c|c|c|c|c|c|}
\hline Entry & $\begin{array}{c}\text { Directionality } \\
\text { OEEF }\end{array}$ & $F$ (a.u.) & $E_{N}(e V)$ & $\mathrm{E}_{\mathrm{N}-1}(\mathrm{eV})$ & $\mathrm{E}_{\mathrm{N}+1}(\mathrm{eV})$ & $\omega(\mathrm{eV})$ \\
\hline $6 b$ & $F / / \mu^{0}$ & 0.01 & -38606.4216 & -38597.5656 & -38607.4549 & 1.563 \\
\hline $6 b$ & $F / / \mu^{0}$ & 0.0075 & -38606.3942 & -38597.5367 & -38607.4157 & 1.557 \\
\hline $6 b$ & $F / / \mu^{0}$ & 0.005 & -38606.3739 & -38597.5130 & -38607.3910 & 1.555 \\
\hline $6 b$ & $F / / \mu^{0}$ & 0.0025 & -38606.3607 & -38597.4947 & -38607.3804 & 1.557 \\
\hline $6 b$ & $F / / \mu^{0}$ & 0 & -38606.3545 & -38597.4817 & -38607.3839 & 1.563 \\
\hline $6 b$ & $F / / \mu^{0}$ & -0.0025 & -38606.3555 & -38597.4741 & -38607.4022 & 1.573 \\
\hline $6 b$ & $F / / \mu^{0}$ & -0.005 & -38606.3635 & -38597.4718 & -38607.4361 & 1.587 \\
\hline $6 b$ & $F / / \mu^{0}$ & -0.0075 & -38606.3787 & -38597.4749 & -38607.4865 & 1.607 \\
\hline $6 b$ & $F / / \mu^{0}$ & -0.01 & -38606.4010 & -38597.4833 & -38607.5550 & 1.633 \\
\hline $6 b$ & $F \perp \mu^{0}$ & 0.01 & -38606.45386 & -38597.55938 & -38607.5796 & 1.616 \\
\hline $6 b$ & $F \perp \mu^{0}$ & 0.0075 & -38606.41019 & -38597.52518 & -38607.48439 & 1.587 \\
\hline $6 b$ & $F \perp \mu^{0}$ & 0.005 & -38606.3792 & -38597.50091 & -38607.42613 & 1.572 \\
\hline $6 b$ & $F \perp \mu^{0}$ & 0.0025 & -38606.36069 & -38597.48643 & -38607.39421 & 1.565 \\
\hline $6 b$ & $F \perp \mu^{0}$ & 0 & -38606.35454 & -38597.48172 & -38607.38395 & 1.563 \\
\hline $6 b$ & $F \perp \mu^{0}$ & -0.0025 & -38606.36072 & -38597.48684 & -38607.39364 & 1.565 \\
\hline $6 b$ & $F \perp \mu^{0}$ & -0.005 & -38606.37917 & -38597.50186 & -38607.42297 & 1.571 \\
\hline $6 b$ & $F \perp \mu^{0}$ & -0.0075 & -38606.40994 & -38597.52687 & -38607.47282 & 1.581 \\
\hline $6 b$ & $F \perp \mu^{0}$ & -0.01 & -38606.45313 & -38597.56199 & -38607.54537 & 1.597 \\
\hline $6 c$ & $F / / \mu^{0}$ & 0.01 & -211180.6912 & -211172.2752 & -211182.0122 & 1.670 \\
\hline $6 c$ & $F / / \mu^{0}$ & 0.0075 & -211180.6518 & -211172.2323 & -211181.9707 & 1.669 \\
\hline $6 c$ & $F / / \mu^{0}$ & 0.005 & -211180.6223 & -211172.1973 & -211181.9443 & 1.672 \\
\hline $6 c$ & $F / / \mu^{0}$ & 0.0025 & -211180.6027 & -211172.1702 & -211181.9333 & 1.678 \\
\hline $6 c$ & $F / / \mu^{0}$ & 0 & -211180.5929 & -211172.1512 & -211181.9379 & 1.687 \\
\hline $6 c$ & $F / / \mu^{0}$ & -0.0025 & -211180.5930 & -211172.1400 & -211181.9586 & 1.700 \\
\hline
\end{tabular}




\begin{tabular}{|c|c|c|c|c|c|c|}
\hline $6 c$ & $F / / \mu^{0}$ & -0.005 & -211180.6029 & -211172.1369 & -211181.9960 & 1.718 \\
\hline $6 c$ & $F / / \mu^{0}$ & -0.0075 & -211180.6228 & -211172.1417 & -211182.0507 & 1.740 \\
\hline $6 c$ & $F / / \mu^{0}$ & -0.01 & -211180.6526 & -211172.1545 & -211182.1236 & 1.768 \\
\hline $6 c$ & $F \perp \mu^{0}$ & 0.01 & -211180.7312 & -211172.2583 & -211182.2053 & 1.767 \\
\hline $6 c$ & $F \perp \mu^{0}$ & 0.0075 & -211180.6703 & -211172.2118 & -211182.0729 & 1.723 \\
\hline $6 c$ & $F \perp \mu^{0}$ & 0.005 & -211180.6272 & -211172.1782 & -211181.9942 & 1.701 \\
\hline $6 c$ & $F \perp \mu^{0}$ & 0.0025 & -211180.6015 & -211172.1579 & -211181.9515 & 1.690 \\
\hline $6 c$ & $F \perp \mu^{0}$ & 0 & -211180.5929 & -211172.1512 & -211181.9379 & 1.687 \\
\hline $6 c$ & $F \perp \mu^{0}$ & -0.0025 & -211180.6015 & -211172.1581 & -211181.951 & 1.690 \\
\hline $6 c$ & $F \perp \mu^{0}$ & -0.005 & -211180.6271 & -211172.1791 & -211181.9902 & 1.698 \\
\hline $6 c$ & $F \perp \mu^{0}$ & -0.0075 & -211180.67 & -211172.214 & -211182.0561 & 1.713 \\
\hline $6 c$ & $F \perp \mu^{0}$ & -0.01 & -211180.7302 & -211172.2633 & -211182.1506 & 1.734 \\
\hline $6 d$ & $F / / \mu^{0}$ & 0.01 & -25183.3629 & -25175.5562 & -25185.0043 & 1.810 \\
\hline $6 d$ & $F / / \mu^{0}$ & 0.0075 & -25183.3039 & -25175.4910 & -25184.9451 & 1.810 \\
\hline $6 d$ & $F / / \mu^{0}$ & 0.005 & -25183.2599 & -25175.4389 & -25184.9055 & 1.814 \\
\hline $6 d$ & $F / / \mu^{0}$ & 0.0025 & -25183.2310 & -25175.3997 & -25184.8857 & 1.821 \\
\hline $6 d$ & $F / / \mu^{0}$ & 0 & -25183.2171 & -25175.3736 & -25184.8859 & 1.832 \\
\hline $6 d$ & $F / / \mu^{0}$ & -0.0025 & -25183.2183 & -25175.3627 & -25184.9035 & 1.844 \\
\hline $6 d$ & $F / / \mu^{0}$ & -0.005 & -25183.2345 & -25175.3640 & -25184.9429 & 1.861 \\
\hline $6 d$ & $F / / \mu^{0}$ & -0.0075 & -25183.2660 & -25175.3790 & -25185.0026 & 1.882 \\
\hline $6 d$ & $F / / \mu^{0}$ & -0.01 & -25183.3128 & -25175.4077 & -25185.0835 & 1.908 \\
\hline $6 d$ & $F \perp \mu^{0}$ & 0.01 & -25183.42445 & -25175.53631 & -25185.26188 & 1.954 \\
\hline $6 d$ & $F \perp \mu^{0}$ & 0.0075 & -25183.33294 & -25175.46561 & -25185.0843 & 1.891 \\
\hline $6 d$ & $F \perp \mu^{0}$ & 0.005 & -25183.26834 & -25175.41466 & -25184.97042 & 1.855 \\
\hline $6 d$ & $F \perp \mu^{0}$ & 0.0025 & -25183.22984 & -25175.38384 & -25184.90652 & 1.837 \\
\hline $6 d$ & $F \perp \mu^{0}$ & 0 & -25183.21708 & -25175.37361 & -25184.88587 & 1.832 \\
\hline $6 d$ & $F \perp \mu^{0}$ & -0.0025 & -25183.22987 & -25175.38436 & -25184.90549 & 1.837 \\
\hline $6 d$ & $F \perp \mu^{0}$ & -0.005 & -25183.26834 & -25175.41671 & -25184.96421 & 1.851 \\
\hline $6 d$ & $F \perp \mu^{0}$ & -0.0075 & -25183.33262 & -25175.47029 & -25185.06342 & 1.876 \\
\hline $6 d$ & $F \perp \mu^{0}$ & -0.01 & -25183.42318 & -25175.54567 & -25185.20462 & 1.913 \\
\hline
\end{tabular}




\section{Spin- and charge delocalization of aryl radical cations in an electric field}

A

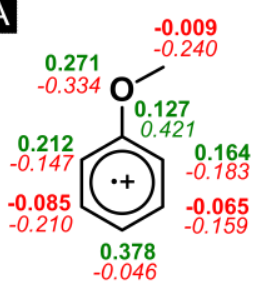

\section{-0.01 a.u}

B

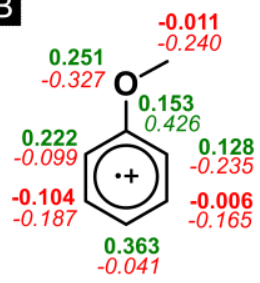

\section{-0.01 a.u}

C

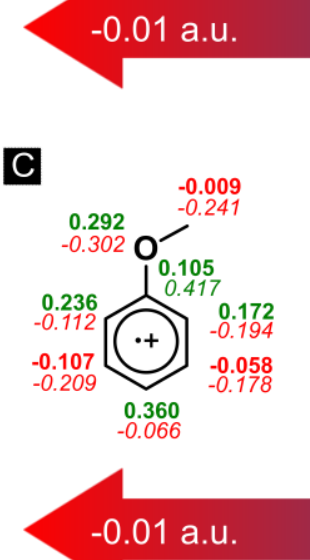

\section{-0.01 a.u.}
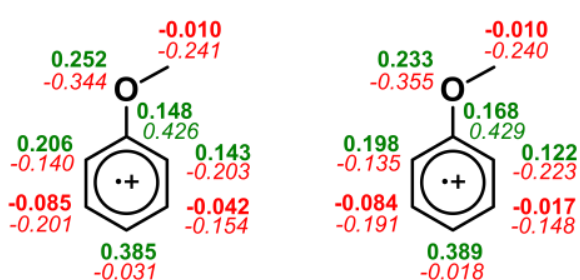

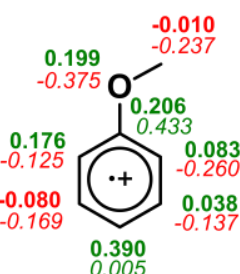

0.01 a.u.

\subsection{5 a.u.}

\section{Field strength}
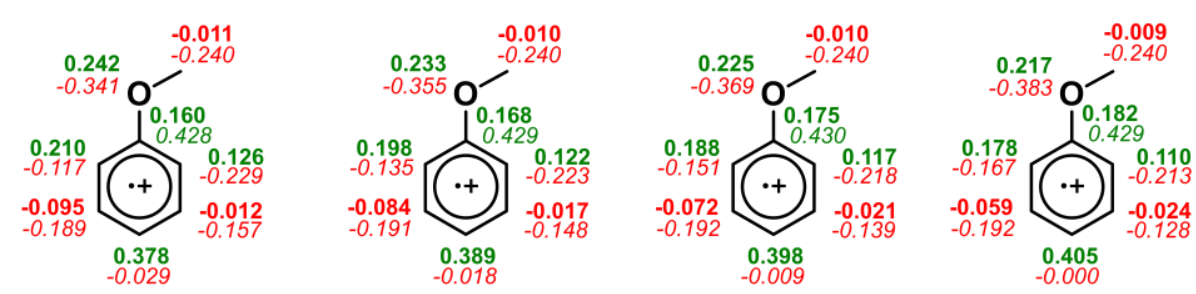

-0.005 a.u.

0.00 a.u.

0.005 a.u.

0.01 a.u.

bold = NBO spin

italic $=$ NBO charge

Field strength $\bigcirc$
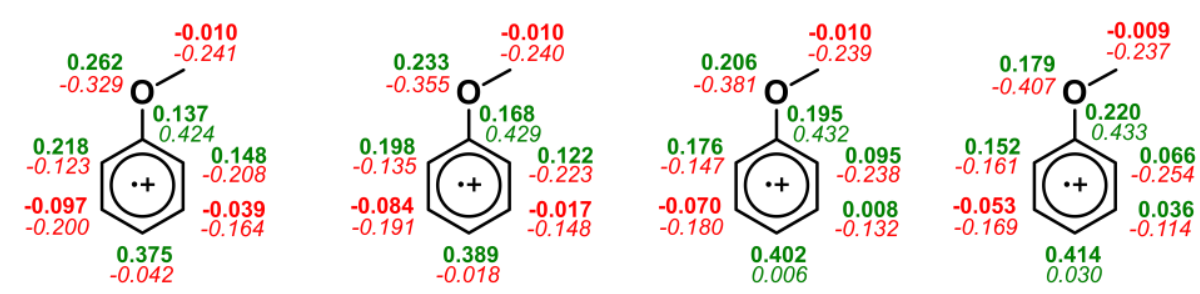

\section{-0.005 a.u.}

0.00 a.u.

0.005 a.u.

0.01 a.u.

Figure 8: NBO spin densities (bold) and NBO atomic charges (italic) are provided for all heavy atoms of radical 8, both in absence of an OEEF and in presence of an OEEF with a field strength of -0.01 a.u. , -0.005 a.u., 0.005 a.u. or 0.01 a.u. in the direction illustrated by the red arrow: a) F//b1, b) F//b2 and c) F//b3. Computations were performed at the DFTlevel of theory with the UB3LYP functional and aug-cc-pVTZ basis set. 
A
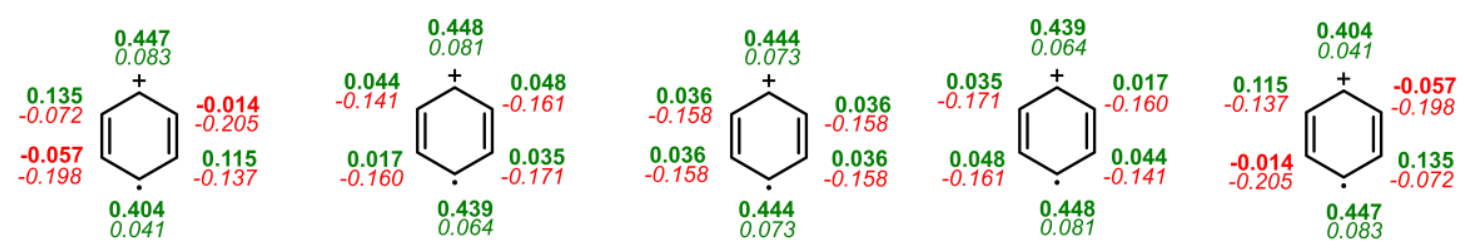

\section{-0.01 a.u}

-0.005 a.u.

0.00 a.u.

0.005 a.u.

0.01 a.u.

bold = NBO spin

italic $=N B O$ charge

Field strength

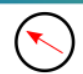

B
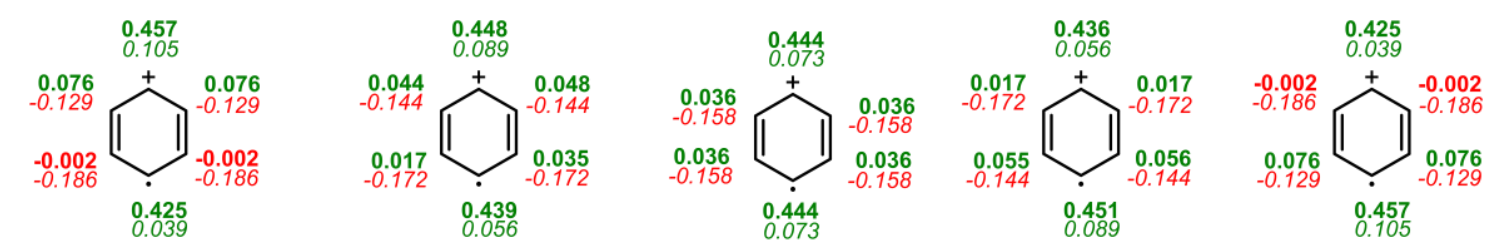

\section{-0.01 a.u.}

\section{-0.005 a.u.}

0.00 a.u.

0.005 a.u.

0.01 a.u.

bold $=$ NBO spin

italic $=$ NBO charge

Field strength

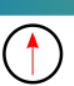

Figure 9: NBO spin densities (bold) and NBO atomic charges (italic) are provided for all heavy atoms of radical 9, both in absence of an OEEF and in presence of an OEEF with a field strength of -0.01 a.u. , -0.005 a.u., 0.005 a.u. or 0.01 a.u. in the direction illustrated by the red arrow: a) F//b1 and b) F//b2. Computations were performed at the DFT-level of theory with the UB3LYP functional and aug-cc-pVTZ basis set.

\section{Influence of an OEEF on the regioselectivity of a radical reaction}

As mentioned in the main manuscript, the reactivity of radical cationic species has previously been linked to its local spin density. To further investigate the potency of an OEEF to alter the regioselective outcome of a reaction involving radicals, the nucleophilic addition of $\mathrm{NH}_{3}$ to radical cation 8 is investigated (Scheme 2). This reaction can result in 4 different regioisomers as $\mathrm{NH}_{3}$ can be added ipso, ortho, meta or para with respect to the methoxy-substituent. Herein, the transition states of the addition reaction giving rise to the different products is located at the UB3LYP/aug-cc-PVDZ level of theory with an OEEF applied in the $F / / \mathrm{b} 3$ direction and a field strength ranging from -0.01 a.u. to 0.01 a.u.. The choice of the field direction is based on the fact that an electric field applied in this direction gives rise to the largest change in local spin density on the carbon atoms of the arene ring (Figure 8). Note, that to yield the ortho or meta product, two transition states were found depending on the position of the methoxy substituent. These transition states are classified ortho- 1 and ortho- 2 and meta-1 and meta-2. Furthermore, frequency calculations were performed to check whether the located structures were characterized by a single imaginary frequency that corresponds to the addition and thus confirms the nature of the stationary point as a transition state. The cartesian coordinates, energetic levels and number of imaginary frequencies can be found in section 5 . 


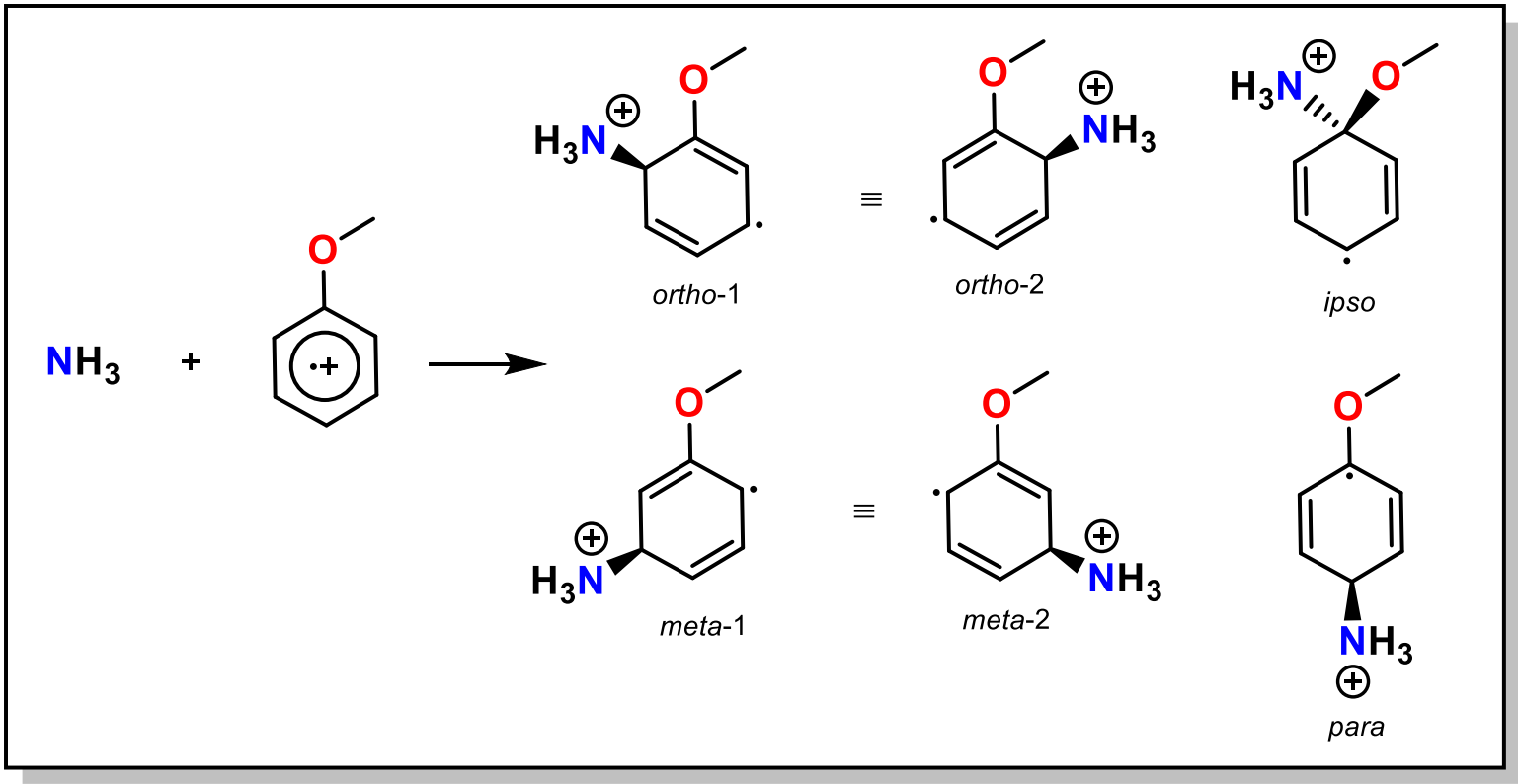

Scheme 2. The nucleophilic addition of $\mathrm{NH}_{3}$ to radical 8 has 4 regioselective outcomes (ortho, meta, para and ipso). At the transition state level a differentiation between ortho- 1 and ortho- 2 and meta-1 and meta- 2 is made based on the relative orientation of the methoxy-substituent.

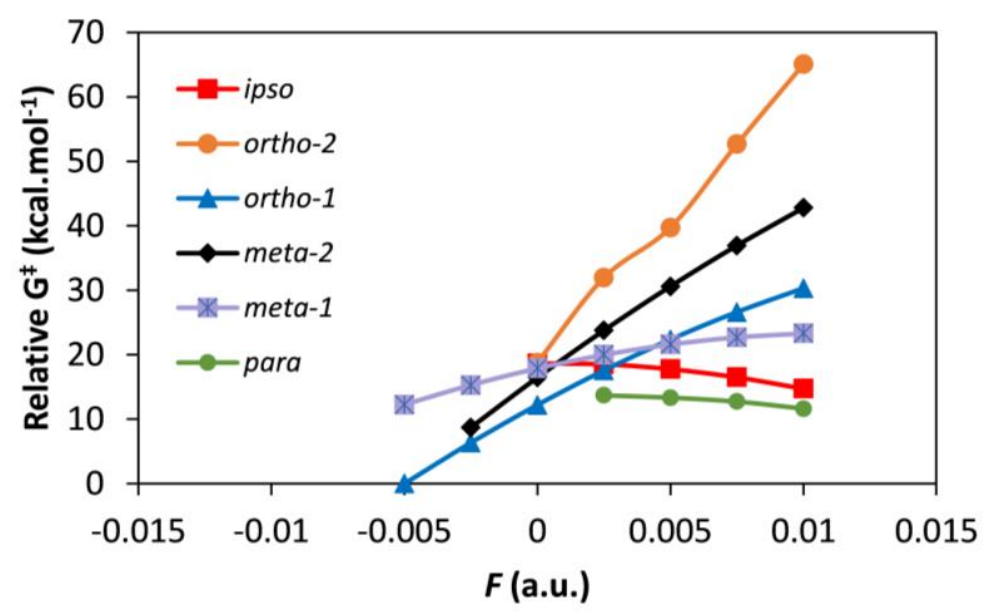

Figure 10. Relative Gibbs free energies $\left(G^{\ddagger}\right)$ of the transition states corresponding with the nucleophilic addition of $\mathrm{NH}_{3}$ to radical cation 8. Values are computed at the UB3LYP/aug-Cc-PVDZ level of theory, all structures were characterized by a single imaginary frequency. An OEEF is applied in the $F / / \mathrm{b} 3$ direction and transition states were searched with a field strength ranging from -0.01 a.u. to 0.1 a.u.

From Figure 10, different transition states have their relative Gibbs free energy crossover. For example at $F=0$ a.u., the transition state ortho- 1 is more stable compared to the transition states meta- 1 and ipso. In contrast, at $F=0.01$ a.u. both transition states meta- 1 and ipso are more stable compared to transtion state ortho-1. Other crossovers can be observed as well and suggest an OEEF to be able to alter the regioselective outcome of the reaction, as the activation barrier associated with the formation of a specific regioisomer is affected in different ways. Notably, at some fields, no transition state was found. We hypothesize this can be explained by the effective flattening of the potential energy surface. 


\section{Cartesian coordinates}

Below, the coordinates of the equilibrium structures are provided for radicals 5-8 in the presence of different electric fields oriented parallel to the intrinsic dipole moment $\mu^{0}$ of the radical $\left(F / / \mu^{0}\right)$. For $\mathbf{9}$, coordinates are provided of the equilibrium structure in the presence of an electric field oriented parallel to the shorter $\mathrm{C}-\mathrm{C}$ bond (b1).

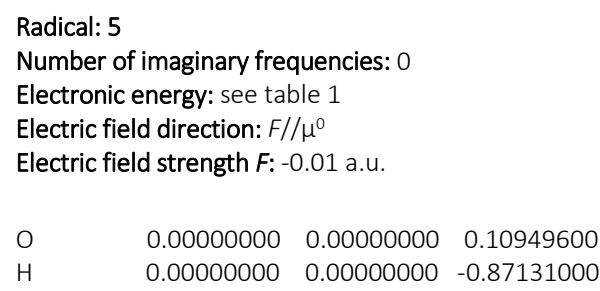

Radical: 6

Number of imaginary frequencies: 0

Electronic energy: see table 1

Electric field direction: $F / / \mu^{0}$

Electric field strength $F$ : -0.01 a.u.

$\begin{array}{lrrr}C & 0.00006700 & -0.00003900 & 0.33810500 \\ F & -0.00014800 & 1.26617300 & -0.07609400 \\ F & -1.09661500 & -0.63295800 & -0.07609400 \\ F & 1.09669600 & -0.63317600 & -0.07606300\end{array}$

Radical: 6

Number of imaginary frequencies: 0

Electronic energy: see table 1

Electric field direction: $F / / \mu^{0}$

Electric field strength $F$ : -0.005 a.u.
Radical: 5

Number of imaginary frequencies: 0

Electronic energy: see table 1

Electric field direction: $F / / \mu^{0}$

Electric field strength $F$ : -0.0075 a.u

$\begin{array}{lllll}\text { o } & 0.00000000 & 0.00000000 & 0.10927100\end{array}$

H $\quad 0.00000000 \quad 0.00000000 \quad-0.87108500$

Radical: 5

Number of imaginary frequencies: 0

Electronic energy: see table 1

Electric field direction: $F / / \mu^{0}$

Electric field strength $F$ : -0.0025 a.u

$\begin{array}{lllll}0 & 0.00000000 & 0.00000000 & 0.10883100\end{array}$

$\begin{array}{llll}H & 0.00000000 & 0.00000000 & -0.87064500\end{array}$

Radical: 5

Number of imaginary frequencies: 0

Electronic energy: see table 1

Electric field direction: $F / / \mu^{0}$

Electric field strength F: 0.0025 a.u.

$\begin{array}{llll}\mathrm{O} & 0.00000000 & 0.00000000 & 0.10860500 \\ \mathrm{H} & 0.00000000 & 0.00000000 & -0.87041900\end{array}$

Radical: 5

Number of imaginary frequencies: 0

Electronic energy: see table 1

Electric field direction: $F / / \mu^{0}$

Electric field strength F: 0.0075 a.u.

$\begin{array}{llll}0 & 0.00000000 & 0.00000000 & 0.10841300\end{array}$

$\begin{array}{lllll}H & 0.00000000 & 0.00000000 & -0.87022700\end{array}$
Radical: 6

Number of imaginary frequencies: 0

Electronic energy: see table 1

Electric field direction: $F / / \mu^{0}$

Electric field strength $F$ : -0.0075 a.u

$\begin{array}{lrrr}C & 0.00003600 & -0.00002100 & 0.33574900 \\ F & -0.00008600 & 1.26668100 & -0.07530400 \\ F & -1.09702400 & -0.63326500 & -0.07530400 \\ F & 1.09707400 & -0.63339400 & -0.07528700\end{array}$

Radical: 6

Number of imaginary frequencies: 0

Electronic energy: see table 1

Electric field direction: $F / / \mu^{0}$

Electric field strength $F$ : -0.0025 a.u 


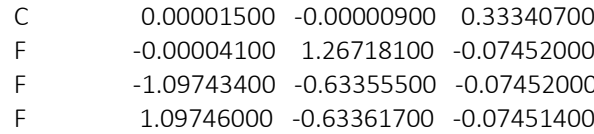

Radical: 6

Number of imaginary frequencies: 0

Electronic energy: see table 1

Electric field direction: $F / / \mu^{0}$

Electric field strength $F: 0$ a.u.

$\begin{array}{llll}\text { C } & 0.00000000 & 0.00000000 & 0.32956100\end{array}$

F $\quad 0.00000000 \quad 1.26824700 \quad-0.07323600$

F $\quad-1.09833400-0.63412300-0.07323600$

F $\quad 1.09833400-0.63412300 \quad-0.07323600$

Radical: 6

Number of imaginary frequencies: 0

Electronic energy: see table 1

Electric field direction: $F / / \mu^{0}$

Electric field strength $F$ : 0.0050 a.u.

$\begin{array}{llll}\text { C } & 0.00001800 & -0.00001000 & 0.32417100\end{array}$

F $\quad-0.00001000 \quad 1.26907100 \quad-0.07144200$

F $\quad-1.09905700-0.63452600 \quad-0.07144200$

F $\quad \begin{array}{llll}1.09904900 & -0.63453400 & -0.07143400\end{array}$

Radical: 6

Number of imaginary frequencies: 0

Electronic energy: see table 1

Electric field direction: $F / / \mu^{0}$

Electric field strength $F$ : 0.01 a.u.

$\begin{array}{lrrr}C & 0.00006900 & -0.00004000 & 0.31962800 \\ F & -0.00008100 & 1.26996500 & -0.06993500 \\ F & -1.09986600 & -0.63491100 & -0.06993500 \\ F & 1.09987800 & -0.63501200 & -0.06990600\end{array}$

Radical: 7

Number of imaginary frequencies: 0

Electronic energy: see table 1

Electric field direction: $F / / \mu^{0}$

Electric field strength $F$ : -0.01 a.u.

$\begin{array}{llll}\text { C } & -1.27464100 & -0.60635900 & 0.22547700\end{array}$

$\begin{array}{lllll}\text { C } & -1.13283900 & 0.79022400 & -0.53323800\end{array}$

$\begin{array}{lllll}\text { C } & 0.20233400 & 1.42539000 & -0.16925000\end{array}$

$\begin{array}{lllll}\text { C } & 1.38472300 & 0.51071100 & -0.46293500\end{array}$

$\begin{array}{llll}\text { C } & 1.17525400 & -0.87638200 & 0.28874500\end{array}$

$\begin{array}{lllll}\mathrm{H} & 0.31999100 & 2.34612100 & -0.76775500\end{array}$

$\begin{array}{lllll}H & -1.22232000 & 0.60587000 & -1.61244800\end{array}$

$\begin{array}{llll}H & -1.99568600 & 1.38893600 & -0.21324400\end{array}$

$\begin{array}{llll}H & -1.29745000 & -0.41203000 & 1.30496200\end{array}$

H $\quad-2.17883300-1.13054700 \quad-0.10140400$

$\begin{array}{lllll}H & 1.49141900 & 0.30837000 & -1.53752100\end{array}$

H $\quad 2.33755400 \quad 0.91127600 \quad-0.09277400$

H $\quad 1.95647300 \quad-1.59044700 \quad 0.00638400$

H $\quad \begin{array}{llll}1.18401200 & -0.69119100 & 1.37011800\end{array}$

H $\quad-0.15278800-1.94050400-0.94137700$

$\begin{array}{llll}\mathrm{H} & 0.20752700 & 1.73688200 & 0.88462500\end{array}$

$\begin{array}{lllll}\mathrm{N} & -0.11093000 & -1.36974600 & -0.09810300\end{array}$

Radical: 7

Number of imaginary frequencies: 0

Electronic energy: see table 1

Electric field direction: $F / / \mu^{0}$

Electric field strength $F$ : -0.005 a.u.

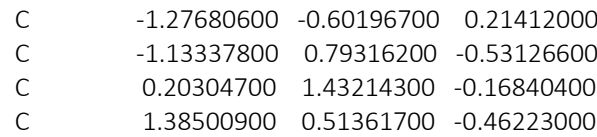

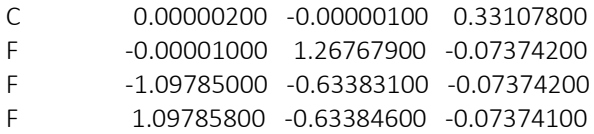

Radical: 6

Number of imaginary frequencies: 0

Electronic energy: see table 1

Electric field direction: $F / / \mu^{0}$

Electric field strength $F: 0.0025$ a.u.

$\begin{array}{llll}\text { C } & 0.00000100 & -0.00000100 & 0.32644200\end{array}$

F $\quad \begin{array}{llll}\text { C } & 0.00001000 & 1.26861200 & -0.07219700\end{array}$

F $\quad-1.09864900 \quad-0.63431400-0.07219600$

F $\quad 1.09863800-0.63429600 \quad-0.07219600$

Radical: 6

Number of imaginary frequencies: 0

Electronic energy: see table 1

Electric field direction: $F / / \mu^{0}$

Electric field strength $F$ : 0.0075 a.u.

$\begin{array}{llll}\text { C } & 0.00004000 & -0.00002300 & 0.32189500\end{array}$

F $\quad-0.00003900 \quad 1.26952400-0.07068600$

F $\quad-1.09946300 \quad-0.63472700 \quad-0.07068600$

F $\quad \begin{array}{llll}1.09946300 & -0.63477200 & -0.07066900\end{array}$

Radical: 7

Number of imaginary frequencies: 0

Electronic energy: see table 1

Electric field direction: $F / / \mu^{0}$

Electric field strength $F$ : -0.0075 a.u.

C $\quad-1.27573800 \quad-0.60407000 \quad 0.22018200$

C $\quad-1.13323100 \quad 0.79133000 \quad-0.53212400$

C $\quad 0.20268400 \quad 1.42868600-0.16906300$

$\begin{array}{lllll}\text { C } & 1.38488900 & 0.51184300 & -0.46249400\end{array}$

$\begin{array}{lllll}\text { C } & 1.17694900 & -0.87487400 & 0.28436700\end{array}$

$\begin{array}{llll}\mathrm{H} & 0.32053900 & 2.34964400 & -0.76506200\end{array}$

H $\quad-1.22292000 \quad 0.61255800 \quad-1.61218100$

H $\quad-1.99450800 \quad 1.39158700 \quad-0.21129700$

H $\quad-1.29916600-0.41284800 \quad 1.30063600$

H $\quad-2.17829300-1.13094400-0.10597200$

H $\quad 1.49239200 \quad 0.31389800 \quad-1.53769800$

H $\quad 2.33706400 \quad 0.91317900 \quad-0.09180300$

H $\quad 1.95661100-1.59037700 \quad 0.00285500$

H $\quad \begin{array}{llll}H & 1.18516100 & -0.69125200 & 1.36640200\end{array}$

H $\quad-0.15596500-1.97028700-0.92180300$

$\begin{array}{llll}\mathrm{H} & 0.20769900 & 1.73625300 & 0.88613800\end{array}$

N $\quad-0.11036700 \quad-1.36775300 \quad-0.10082200$

Radical: 7

Number of imaginary frequencies: 0

Electronic energy: see table 1

Electric field direction: $F / / \mu^{0}$

Electric field strength $F$ : -0.0025 a.u.

$\begin{array}{llll}\text { C } & -1.27802400 & -0.59952500 & 0.20722300 \\ \text { C } & -1.13353200 & 0.79510300 & -0.53031200 \\ \text { C } & 0.20343700 & 1.43581600 & -0.16739900 \\ \text { C } & 1.38515000 & 0.51544500 & -0.46191800\end{array}$




$\begin{array}{lrrr}\mathrm{C} & 1.17867600 & -0.87344500 & 0.27914000 \\ \mathrm{H} & 0.32111300 & 2.35397200 & -0.76144600 \\ \mathrm{H} & -1.22299900 & 0.61997500 & -1.61216800 \\ \mathrm{H} & -1.99322800 & 1.39465300 & -0.20939900 \\ \mathrm{H} & -1.30191000 & -0.41376200 & 1.29558300 \\ \mathrm{H} & -2.17761300 & -1.13117500 & -0.11206300 \\ \mathrm{H} & 1.49307600 & 0.32025400 & -1.53809400 \\ \mathrm{H} & 2.33650500 & 0.91560600 & -0.09087900 \\ \mathrm{H} & 1.95671000 & -1.59018700 & -0.00220600 \\ \mathrm{H} & 1.18738900 & -0.69174800 & 1.36199200 \\ \mathrm{H} & -0.15975500 & -2.00395000 & -0.89742000 \\ \mathrm{H} & 0.20785500 & 1.73583200 & 0.88815800 \\ \mathrm{~N} & -0.10988900 & -1.36640500 & -0.10315700\end{array}$

Radical: 7

Number of imaginary frequencies: 0

Electronic energy: see table 1

Electric field direction: $F / / \mu^{0}$

Electric field strength $F$ : 0 a.u.

$\begin{array}{lrrr}\mathrm{C} & -1.23934400 & -0.78453800 & 0.23688400 \\ \mathrm{C} & -1.26760900 & 0.72202700 & -0.23748000 \\ \mathrm{C} & 0.00004100 & 1.43906200 & 0.22363100 \\ \mathrm{C} & 1.26765100 & 0.72193800 & -0.23747200 \\ \mathrm{C} & 1.23930800 & -0.78458600 & 0.23687700 \\ \mathrm{H} & 0.00007600 & 2.45845800 & -0.19301400 \\ \mathrm{H} & -1.36663800 & 0.74305500 & -1.33109800 \\ \mathrm{H} & -2.17707800 & 1.16050700 & 0.19293700 \\ \mathrm{H} & -1.25982200 & -0.80072300 & 1.33588500 \\ \mathrm{H} & -2.08073200 & -1.35174200 & -0.17228600 \\ \mathrm{H} & 1.36667900 & 0.74298400 & -1.33109200 \\ \mathrm{H} & 2.17713600 & 1.16040100 & 0.19293100 \\ \mathrm{H} & 2.08064400 & -1.35186400 & -0.17230300 \\ \mathrm{H} & 1.25979500 & -0.80083200 & 1.33587700 \\ \mathrm{H} & -0.00006200 & -1.92804100 & -1.05073700 \\ \mathrm{H} & 0.00003900 & 1.54432500 & 1.31839900 \\ \mathrm{~N} & -0.00004600 & -1.35142200 & -0.20859100\end{array}$

Radical: 7

Number of imaginary frequencies: 0

Electronic energy: see table 1

Electric field direction: $F / / \mu^{0}$

Electric field strength F: 0.0050 a.u.

C $\quad-1.28303000 \quad-0.59088300 \quad 0.17669200$

C $\quad-1.13247900 \quad 0.80504700 \quad-0.52868900$

$\begin{array}{lllll}\text { C } & 0.20483300 & 1.44956200 & -0.16029000\end{array}$

C $\quad \begin{array}{llll}1.38528000 & 0.52507700 & -0.46190900\end{array}$

$\begin{array}{lllll}\text { C } & 1.18918000 & -0.86524300 & 0.24482900\end{array}$

$\begin{array}{lllll}\mathrm{H} & 0.32370200 & 2.37919700 & -0.73758600\end{array}$

H $\quad-1.21800200 \quad 0.66110200 \quad-1.61414500$

H $\quad-1.98697300 \quad 1.41195600 \quad-0.20298900$

H $\quad-1.32793100 \quad-0.42440700 \quad 1.26457600$

H $\quad-2.17486300-1.12824700 \quad-0.15788500$

$\begin{array}{llll}H & 1.49318700 & 0.35770600 & -1.54193200\end{array}$

H $\quad 2.33425200 \quad 0.93109400 \quad-0.08927700$

H $\quad 1.95904700-1.58667800-0.04290100$

H $\quad \begin{array}{llll}1.20986200 & -0.70333200 & 1.33417900\end{array}$

$\begin{array}{lllll}H & -0.18143800 & -2.17923100 & -0.72719800\end{array}$

$\begin{array}{llll}\mathrm{H} & 0.20809700 & 1.73300100 & 0.90301400\end{array}$

$\begin{array}{lllll}\mathrm{N} & -0.10892300 & -1.36914700 & -0.10822800\end{array}$

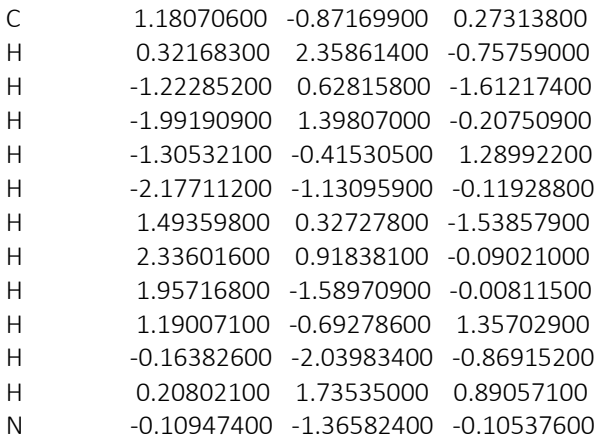

Radical: 7

Number of imaginary frequencies: 0

Electronic energy: see table 1

Electric field direction: $F / / \mu^{0}$

Electric field strength $F$ : 0.0025 a.u.

$\begin{array}{llll}\text { C } & -1.28096500 & -0.59408300 & 0.18931800\end{array}$

$\begin{array}{lllll}\text { C } & -1.13325700 & 0.80071700 & -0.52883500\end{array}$

C $\quad 0.20433500 \quad 1.44432600-0.16366100$

$\begin{array}{lllll}\text { C } & 1.38534200 & 0.52078800 & -0.46166200\end{array}$

C $\quad 1.18570900-0.86766000 \quad 0.25691400$

$\begin{array}{llll}\mathrm{H} & 0.32294800 & 2.37062900 & -0.74665100\end{array}$

H $\quad-1.22085200 \quad 0.64816300 \quad-1.61292700$

$\mathrm{H} \quad-1.98886500 \quad 1.40646600 \quad-0.20398100$

H $\quad-1.31675300-0.42039600 \quad 1.27516100$

$\begin{array}{llll}H & -2.17598300 & -1.12947000 & -0.14050600\end{array}$

H $\quad \begin{array}{llll}1.49384100 & 0.34518500 & -1.54032900\end{array}$

$\begin{array}{lllll}H & 2.33495000 & 0.92575900 & -0.08931500\end{array}$

H $\quad 1.95853600 \quad-1.58795000 \quad-0.02650400$

H $\quad \begin{array}{llll}H & 1.19966400 & -0.69773500 & 1.34385000\end{array}$

H $\quad-0.17419400-2.12542700 \quad-0.78947600$

$\begin{array}{llll}H & 0.20826500 & 1.73428900 & 0.89752400\end{array}$

N $\quad-0.10892000-1.36702800-0.10865900$

Radical: 7

Number of imaginary frequencies: 0

Electronic energy: see table 1

Electric field direction: $F / / \mu^{0}$

Electric field strength $F: 0.0075$ a.u.

$\begin{array}{lrrr}\mathrm{C} & -1.28617500 & -0.58660600 & 0.15820600 \\ \mathrm{C} & -1.13107100 & 0.81110000 & -0.52924600 \\ \mathrm{C} & 0.20538000 & 1.45612700 & -0.15474000 \\ \mathrm{C} & 1.38507600 & 0.53121100 & -0.46265900 \\ \mathrm{C} & 1.19434400 & -0.86199900 & 0.22666700 \\ \mathrm{H} & 0.32465200 & 2.39103300 & -0.72323300 \\ \mathrm{H} & -1.21284800 & 0.67862100 & -1.61653400 \\ \mathrm{H} & -1.98461900 & 1.41911800 & -0.20298300 \\ \mathrm{H} & -1.34780400 & -0.43104600 & 1.24877600 \\ \mathrm{H} & -2.17287800 & -1.12636200 & -0.18579100 \\ \mathrm{H} & 1.49162100 & 0.37544400 & -1.54461500 \\ \mathrm{H} & 2.33339800 & 0.93846000 & -0.08994100 \\ \mathrm{H} & 1.95932800 & -1.58479600 & -0.07023500 \\ \mathrm{H} & 1.22848900 & -0.71395100 & 1.31964000 \\ \mathrm{H} & -0.19131200 & -2.24681800 & -0.63009600 \\ \mathrm{H} & 0.20746600 & 1.72989400 & 0.91151800 \\ \mathrm{~N} & -0.10924500 & -1.37285600 & -0.10447200\end{array}$

Radical: 7

Number of imaginary frequencies: 0

Electronic energy: see table 1

Electric field direction: $F / / \mu^{0}$

Electric field strength $F$ : 0.01 a.u.

$\begin{array}{lrrr}C & -1.30418100 & -0.56881900 & 0.07886000 \\ C & -1.12266000 & 0.83157900 & -0.53992400 \\ C & 0.20565700 & 1.47183000 & -0.12243000 \\ C & 1.38211300 & 0.55387200 & -0.47150300\end{array}$




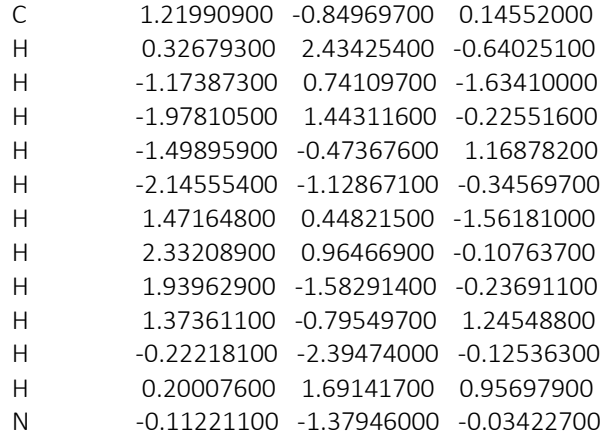

Radical: 8

Number of imaginary frequencies: 0

Electronic energy: see table 1

Electric field direction: $F / / \mu^{0}$

Electric field strength $F$ : -0.01 a.u.

$\begin{array}{lrrr}\text { C } & -0.51523300 & -1.32838700 & -0.00000500 \\ \mathrm{C} & -1.85388200 & -1.02741300 & -0.00000700 \\ \mathrm{C} & -2.26967400 & 0.33095600 & 0.00000400 \\ \mathrm{C} & -1.31704400 & 1.38789100 & 0.00001300 \\ \mathrm{C} & 0.03301200 & 1.11161600 & 0.00001600 \\ \mathrm{C} & 0.45188900 & -0.25763600 & 0.00001500 \\ \mathrm{H} & -0.14201100 & -2.35199600 & -0.00001400 \\ \mathrm{H} & -2.59968200 & -1.82187400 & -0.00001700 \\ \mathrm{H} & -3.33313500 & 0.57246300 & -0.00000200 \\ \mathrm{H} & -1.66330700 & 2.42157500 & 0.00002000 \\ \mathrm{H} & 0.76126400 & 1.91987800 & 0.00002200 \\ \mathrm{O} & 1.70037600 & -0.65730500 & 0.00000200 \\ \mathrm{C} & 2.81996500 & 0.28848000 & -0.00002300 \\ \mathrm{H} & 2.77743300 & 0.90197900 & 0.90661300 \\ \mathrm{H} & 3.70826000 & -0.34525300 & -0.00007600 \\ \mathrm{H} & 2.77736000 & 0.90203100 & -0.90661900\end{array}$

Radical: 8

Number of imaginary frequencies: 0

Electronic energy: see table 1

Electric field direction: $F / / \mu^{0}$

Electric field strength $F$ : -0.005 a.u.

\begin{tabular}{|c|c|c|c|}
\hline C & -0.51485000 & -1.32810800 & -0.00000800 \\
\hline C & -1.85485800 & -1.02636600 & -0.00000200 \\
\hline C & -2.26858300 & 0.32984900 & 0.00000100 \\
\hline C & -1.31468300 & 1.38697300 & 0.00000800 \\
\hline C & 0.03409500 & 1.11196500 & -0.00000200 \\
\hline C & 0.45235300 & -0.25822000 & -0.00003000 \\
\hline $\mathrm{H}$ & -0.14313100 & -2.35203000 & -0.00000900 \\
\hline $\mathrm{H}$ & -2.59981100 & -1.82115400 & 0.00000000 \\
\hline $\mathrm{H}$ & -3.33181900 & 0.57193800 & 0.00001100 \\
\hline $\mathrm{H}$ & -1.66152100 & 2.41999100 & 0.00002600 \\
\hline $\mathrm{H}$ & 0.76407600 & 1.91814600 & 0.00001500 \\
\hline $\mathrm{O}$ & 1.70042300 & -0.65517100 & -0.00000900 \\
\hline C & 2.81746200 & 0.28845900 & -0.00001500 \\
\hline $\mathrm{H}$ & 2.77473500 & 0.90202100 & 0.90683500 \\
\hline $\mathrm{H}$ & 3.70703100 & -0.34338000 & -0.00007000 \\
\hline $\mathrm{H}$ & 2.77467200 & 0.90209500 & -0.90681100 \\
\hline
\end{tabular}

Radical: 8

Number of imaginary frequencies: 0

Electronic energy: see table 1

Electric field direction: $F / / \mu^{0}$

Electric field strength $F: 0$ a.u.

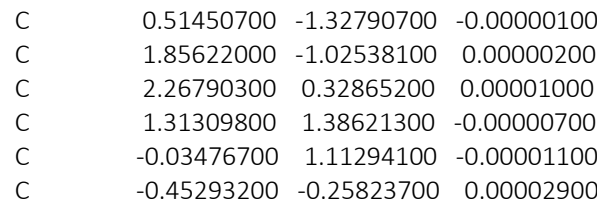

Radical: 8

Number of imaginary frequencies: 0

Electronic energy: see table 1

Electric field direction: $F / / \mu^{0}$

Electric field strength $F$ : -0.0075 a.u

C $\quad-0.51503600-1.32811900-0.00000500$

C $\quad-1.85435300-1.02688200-0.00000700$

$\begin{array}{llll}\text { C } & -2.26918500 & 0.33038100 & 0.00000400\end{array}$

$\begin{array}{llll}\text { C } & -1.31600500 & 1.38738900 & 0.00001300\end{array}$

C $\quad 0.03342500 \quad 1.11189700 \quad 0.00001600$

$\begin{array}{llll}\text { C } & 0.45209600 & -0.25776600 & 0.00001500\end{array}$

H $\quad-0.14245000-2.35181100-0.00001400$

H $\quad-2.59980300-1.82138700 \quad-0.00001700$

H $\quad-3.33257400 \quad 0.57195100 \quad-0.00000200$

$\begin{array}{llll}H & -1.66254200 & 2.42069100 & 0.00002000\end{array}$

$\begin{array}{llll}\mathrm{H} & 0.76237300 & 1.91919500 & 0.00002200\end{array}$

$\begin{array}{lllll}0 & 1.70036500 & -0.65611500 & 0.00000200\end{array}$

$\begin{array}{lllll}\text { C } & 2.81893700 & 0.28841700 & -0.00002300\end{array}$

$\begin{array}{llll}\mathrm{H} & 2.77636500 & 0.90184100 & 0.90677000\end{array}$

H $\quad 3.70769000 \quad-0.34457000 \quad-0.00007700$

H $\quad 2.77629000 \quad 0.90189400 \quad-0.90677500$

Radical: 8

Number of imaginary frequencies: 0

Electronic energy: see table 1

Electric field direction: $F / / \mu^{0}$

Electric field strength $F$ : -0.0025 a.u.

C $\quad-0.51463600-1.32790000-0.00000700$

C $\quad-1.85548600-1.02588000-0.00000200$

$\begin{array}{lllll}\text { C } & -2.26825800 & 0.32923700 & 0.00000100\end{array}$

$\begin{array}{lllll}\text { C } & -1.31393200 & 1.38655700 & 0.00000800\end{array}$

C $\quad 0.03438800 \quad 1.11247400 \quad-0.00000200$

C $\quad 0.45255700 \quad-0.25815400-0.00002900$

H $\quad-0.14346000-2.35205800-0.00000900$

$\begin{array}{llll}H & -2.60013400 & -1.82081000 & 0.00000000\end{array}$

H $\quad-3.33149100 \quad 0.57120600 \quad 0.00001100$

$\begin{array}{llll}H & -1.66104200 & 2.41936000 & 0.00002600\end{array}$

H $\quad 0.76483300 \quad 1.91798300 \quad 0.00001500$

$\begin{array}{lllll}\text { O } & 1.70044300 & -0.65388000 & -0.00000900\end{array}$

C $\quad 2.81686000 \quad 0.28833100 \quad-0.00001500$

$\mathrm{H} \quad 2.77419400 \quad 0.90182000 \quad 0.90705300$

H $\quad 3.70662500 \quad-0.34317600 \quad-0.00007100$

$\begin{array}{lllll}H & 2.77413000 & 0.90189500 & -0.90702900\end{array}$

Radical: 8

Number of imaginary frequencies: 0

Electronic energy: see table 1

Electric field direction: $F / / \mu^{0}$

Electric field strength $F: 0.0025$ a.u.

C $\quad-0.51418600-1.32774900-0.00000800$

C $\quad-1.85696600 \quad-1.02497400 \quad-0.00000100$

$\begin{array}{llll}\text { C } & -2.26773800 & 0.32799600 & 0.00000100\end{array}$

C $\quad-1.31260800 \quad 1.38588800 \quad 0.00000800$

C $\quad 0.03499500 \quad 1.11365500-0.00000300$

C $\quad 0.45302000-0.25798000 \quad-0.00003400$ 


$\begin{array}{llll}H & 0.14374800 & -2.35237700 & -0.00000900 \\ H & 2.60061200 & -1.82049900 & 0.00001600 \\ H & 3.33111900 & 0.57065800 & 0.00001200 \\ H & 1.66055000 & 2.41887000 & -0.00001100 \\ H & -0.76583600 & 1.91773600 & -0.00005500 \\ \mathrm{O} & -1.70059400 & -0.65270800 & -0.00004300 \\ \mathrm{C} & -2.81607800 & 0.28810900 & 0.00002600 \\ \mathrm{H} & -2.77346900 & 0.90175500 & -0.90714000 \\ \mathrm{H} & -3.70632800 & -0.34266300 & 0.00011800 \\ \mathrm{H} & -2.77334500 & 0.90184400 & 0.90712300\end{array}$

Radical: 8

Number of imaginary frequencies: 0

Electronic energy: see table 1

Electric field direction: $F / / \mu^{0}$

Electric field strength F: 0.0050 a.u.

$\begin{array}{lll}-2.26755200 & 0.32736500 & 0.00000100\end{array}$

$\begin{array}{llll}-1.31205000 & 1.38562600 & 0.00000800\end{array}$

$0.03530200 \quad 1.11433500-0.00000300$

$0.45327400-0.25785000-0.00003300$

$-0.14444200-2.35326300-0.00000900$

$\begin{array}{llll}-2.60151100 & -1.82044400 & 0.00000100\end{array}$

$\begin{array}{lll}-3.33083700 & 0.56912300 & 0.00001200\end{array}$

$\begin{array}{lll}-1.66006100 & 2.41835900 & 0.00002600\end{array}$

$\begin{array}{lll}0.76700200 & 1.91837800 & 0.00001600\end{array}$

$1.70069700-0.65005500-0.00000900$

$2.81551200 \quad 0.28787100 \quad-0.00001500$

$\begin{array}{llll}2.77317900 & 0.90147600 & 0.90770700\end{array}$

$3.70572200-0.34311800-0.00006900$

$\begin{array}{llll}2.77311900 & 0.90155000 & -0.90768400\end{array}$

Radical: 8

Number of imaginary frequencies: 0

Electronic energy: see table 1

Electric field direction: $F / / \mu^{0}$

Electric field strength $F$ : 0.01 a.u.

C $\quad-0.51349000-1.32844300-0.00000400$

C $\quad-1.85975900-1.02369000 \quad-0.00000800$

$\begin{array}{lllll}\text { C } & -2.26700100 & 0.32618600 & 0.00000300\end{array}$

$\begin{array}{lllll}\text { C } & -1.31033800 & 1.38516400 & 0.00001200\end{array}$

$\begin{array}{llll}\text { C } & 0.03651800 & 1.11524300 & 0.00001500\end{array}$

C $\quad 0.45397300 \quad-0.25819900 \quad 0.00001700$

$\begin{array}{lllll}\mathrm{H} & -0.14562900 & -2.35533100 & -0.00001100\end{array}$

H $\quad-2.60246000 \quad-1.82092400-0.00001800$

$\begin{array}{lllll}H & -3.33017100 & 0.56880000 & -0.00000400\end{array}$

$\begin{array}{llll}H & -1.65894500 & 2.41829000 & 0.00001900\end{array}$

$\begin{array}{llll}H & 0.76956600 & 1.91827300 & 0.00002200\end{array}$

$\begin{array}{lllll}\text { O } & 1.70116100 & -0.64802800 & 0.00000500\end{array}$

$\begin{array}{lllll}\text { C } & 2.81400400 & 0.28780400 & -0.00002300\end{array}$

$\begin{array}{llll}\mathrm{H} & 2.77154000 & 0.90198200 & 0.90796300\end{array}$

H $\quad 3.70516600-0.34216600-0.00008400$

H $\quad 2.77145400 \quad 0.90204400 \quad-0.90796200$

Radical: 9

Number of imaginary frequencies: 0

Electronic energy: see table 1

Electric field direction: $F / / b 1$

Electric field strength F: -0.01 a.u.

$\begin{array}{lrrr}C & 1.23629300 & 0.66208300 & 0.00009100 \\ C & -0.00626800 & 1.39896400 & 0.00000800 \\ C & -0.03205400 & 2.81192800 & -0.00004900 \\ C & 1.16555000 & 3.49939300 & -0.00002400 \\ C & 2.41078400 & 2.76474500 & 0.00005900 \\ C & 2.43017800 & 1.33821400 & 0.00011600 \\ H & 1.20447500 & -0.42806900 & 0.00013400 \\ H & -0.94614100 & 0.84313000 & -0.00001000 \\ H & -0.98414600 & 3.34170600 & -0.00011100\end{array}$

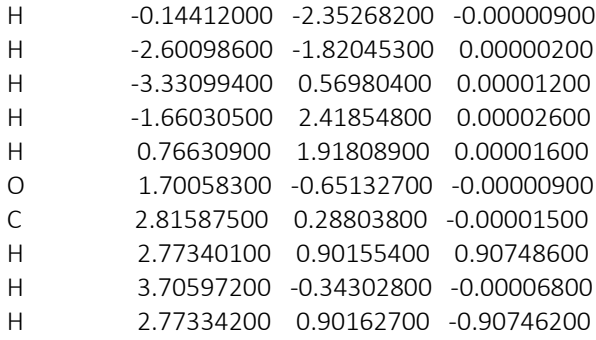

Radical: 8

Number of imaginary frequencies: 0

Electronic energy: see table 1

Electric field direction: $F / / \mu^{0}$

Electric field strength $F$ : 0.0075 a.u.

C $\quad-0.51373500-1.32815400 \quad-0.00000400$

C $\quad-1.85874500-1.02409500-0.00000800$

$\begin{array}{llll}\text { C } & -2.26717000 & 0.32679600 & 0.00000300\end{array}$

C $\quad-1.31097700 \quad 1.38537500 \quad 0.00001200$

$\begin{array}{llll}\text { C } & 0.03603600 & 1.11462700 & 0.00001500\end{array}$

C $\quad 0.45364200-0.25820800 \quad 0.00001700$

H $\quad-0.14517400-2.35430600 \quad-0.00001200$

H $\quad-2.60187200-1.82068000-0.00001800$

$\mathrm{H} \quad-3.33034700 \quad 0.56918100 \quad-0.00000400$

$\begin{array}{llll}H & -1.65928200 & 2.41824700 & 0.00001900\end{array}$

$\begin{array}{llll}H & 0.76859800 & 1.91798700 & 0.00002200\end{array}$

$\begin{array}{lllll}\text { O } & 1.70094500 & -0.64915500 & 0.00000400\end{array}$

$\begin{array}{lllll}\text { C } & 2.81447100 & 0.28791300 & -0.00002300\end{array}$

$\begin{array}{lllll}\mathrm{H} & 2.77196300 & 0.90184400 & 0.90778300\end{array}$

H $\quad 3.70536000-0.34226900-0.00008300$

$\begin{array}{llll}H & 2.77187900 & 0.90190400 & -0.90778300\end{array}$
Radical: 9

Number of imaginary frequencies: 0

Electronic energy: see table 1

Electric field direction: $F / / b 1$

Electric field strength F: -0.0075 a.u.

$\begin{array}{llll}\text { C } & 1.23198100 & 0.65317100 & 0.00009100\end{array}$

$\begin{array}{llll}\text { C } & 0.00076000 & 1.38894700 & 0.00000900\end{array}$

C $\quad-0.02146000 \quad 2.81658600-0.00004900$

C $\quad 1.16970800 \quad 3.50681300-0.00002400$

$\begin{array}{llll}\text { C } & 2.40268700 & 2.77381300 & 0.00005900\end{array}$

$\begin{array}{llll}\text { C } & 2.42096700 & 1.33646700 & 0.00011600\end{array}$

H $\quad 1.20488800 \quad-0.43642000 \quad 0.00013400$

H $\quad-0.94488000 \quad 0.84288700 \quad-0.00001000$

H $\quad-0.97765200 \quad 3.33939100-0.00011100$ 
$\begin{array}{llll}H & 1.19426500 & 4.59012200 & -0.00006600\end{array}$

$\begin{array}{llll}H & 3.35125300 & 3.32018100 & 0.00007900\end{array}$

$\begin{array}{lllll}H & 3.38362900 & 0.81118500 & 0.00017900\end{array}$

Radical: 9

Number of imaginary frequencies: 0

Electronic energy: see table 1

Electric field direction: $F / / b 1$

Electric field strength F: -0.005 a.u.

$\begin{array}{lrrr}\text { C } & 1.23169200 & 0.65290700 & 0.00009100 \\ \mathrm{C} & 0.00071900 & 1.38795500 & 0.00000900 \\ \mathrm{C} & -0.02068700 & 2.81762400 & -0.00004900 \\ \mathrm{C} & 1.16986800 & 3.50668500 & -0.00002400 \\ \mathrm{C} & 2.40197800 & 2.77349000 & 0.00005900 \\ \mathrm{C} & 2.42081700 & 1.33746100 & 0.00011600 \\ \mathrm{H} & 1.20495700 & -0.43648500 & 0.00013400 \\ \mathrm{H} & -0.94494900 & 0.84204000 & -0.00001000 \\ \mathrm{H} & -0.97698500 & 3.34008000 & -0.00011100 \\ \mathrm{H} & 1.19558600 & 4.59633600 & -0.00006600 \\ \mathrm{H} & 3.34749300 & 3.31994900 & 0.00007900 \\ \mathrm{H} & 3.37732800 & 0.81554200 & 0.00017900\end{array}$

Radical: 9

Number of imaginary frequencies: 0

Electronic energy: see table 1

Electric field direction: $F / / b 1$

Electric field strength $F: 0$ a.u.

$\begin{array}{lrrr}\text { C } & -1.25090600 & 0.68680300 & 0.00002200 \\ \mathrm{C} & 0.00006500 & 1.38631400 & 0.00000900 \\ \mathrm{C} & 1.25096900 & 0.68669600 & -0.00001300 \\ \mathrm{C} & 1.25090500 & -0.68680300 & -0.00002200 \\ \mathrm{C} & -0.00006500 & -1.38631400 & -0.00000900 \\ \mathrm{C} & -1.25096900 & -0.68669600 & 0.00001300 \\ \mathrm{H} & -2.18135200 & 1.25388800 & 0.00003800 \\ \mathrm{H} & 0.00011100 & 2.47820100 & 0.00001600 \\ \mathrm{H} & 2.18146700 & 1.25369400 & -0.00002200 \\ \mathrm{H} & 2.18135200 & -1.25388700 & -0.00003800 \\ \mathrm{H} & -0.00011200 & -2.47820100 & -0.00001600 \\ \mathrm{H} & -2.18146700 & -1.25369400 & 0.00002200\end{array}$

Radical: 9

Number of imaginary frequencies: 0

Electronic energy: see table 1

Electric field direction: $F / / b 1$

Electric field strength $F$ : 0.0050 a.u.

$\begin{array}{llll}\text { C } & 1.23143500 & 0.65224600 & 0.00009200\end{array}$

$\begin{array}{lllll}\text { C } & -0.00067500 & 1.38544000 & 0.00000900\end{array}$

$\begin{array}{lllll}\text { C } & -0.01951400 & 2.82147000 & -0.00004900\end{array}$

C $\quad 1.16961000 \quad 3.50602400 \quad-0.00002400$

$\begin{array}{llll}\text { C } & 2.40058400 & 2.77097500 & 0.00005900\end{array}$

$\begin{array}{llll}\text { C } & 2.42199000 & 1.34130600 & 0.00011700\end{array}$

$\begin{array}{llll}\mathrm{H} & 1.20571700 & -0.43740600 & 0.00013400\end{array}$

H $\quad-0.94619100 \quad 0.83898200 \quad-0.00001100$

$\begin{array}{llll}H & -0.97602500 & 3.34338800 & -0.00011100\end{array}$

$\begin{array}{llll}H & 1.19634600 & 4.59541600 & -0.00006600\end{array}$

$\begin{array}{llll}H & 3.34625200 & 3.31689100 & 0.00007800\end{array}$

$\begin{array}{llll}H & 3.37828700 & 0.81885000 & 0.00017900\end{array}$

Radical: 9

Number of imaginary frequencies: 0

Electronic energy: see table 1

Electric field direction: $F / / b 1$

Electric field strength $F$ : 0.01 a.u.

$\begin{array}{lllll}\text { C } & 1.23575300 & 0.65953700 & 0.00009200\end{array}$

$\begin{array}{lllll}\text { C } & -0.00948100 & 1.39418600 & 0.00000800\end{array}$

$\begin{array}{lllll}\text { C } & -0.02887500 & 2.82071600 & -0.00004900\end{array}$

C $\quad 1.16501000 \quad 3.49684800 \quad-0.00002300$

$\begin{array}{llll}\text { C } & 2.40757100 & 2.75996600 & 0.00006000\end{array}$

$\begin{array}{llll}H & 1.19525100 & 4.59679900 & -0.00006600\end{array}$

$\begin{array}{lllll}H & 3.34810500 & 3.32068600 & 0.00007900\end{array}$

$\begin{array}{lllll}H & 3.37746500 & 0.81444300 & 0.00017900\end{array}$

Radical: 9

Number of imaginary frequencies: 0

Electronic energy: see table 1

Electric field direction: $F / / b 1$

Electric field strength $F$ : -0.0025 a.u

$\begin{array}{llll}\text { C } & 1.23144200 & 0.65270800 & 0.00009200\end{array}$

$\begin{array}{lllll}\text { C } & 0.00049200 & 1.38688700 & 0.00000900\end{array}$

$\begin{array}{lllll}\text { C } & -0.01997300 & 2.81885600 & -0.00004900\end{array}$

C $\quad \begin{array}{lllll}\text { C } & 1.16996200 & 3.50657500 & -0.00002400\end{array}$

$\begin{array}{llll}\text { C } & 2.40147400 & 2.77301300 & 0.00005900\end{array}$

$\begin{array}{llll}\text { C } & 2.42086100 & 1.33870100 & 0.00011600\end{array}$

H $\quad 1.20523200 \quad-0.43660500 \quad 0.00013400$

H $\quad-0.94520100 \quad 0.84110900 \quad-0.00001100$

H $\quad-0.97652200 \quad 3.34076100-0.00011100$

H $\quad \begin{array}{llll}H & 1.19586900 & 4.59601300 & -0.00006600\end{array}$

$\begin{array}{llll}\mathrm{H} & 3.34705200 & 3.31921500 & 0.00007800\end{array}$

$\begin{array}{lllll}H & 3.37713100 & 0.81635100 & 0.00017900\end{array}$

Radical: 9

Number of imaginary frequencies: 0

Electronic energy: see table 1

Electric field direction: $F / / b 1$

Electric field strength $F$ : 0.0025 a.u.

$\begin{array}{lrrr}\text { C } & 1.23134100 & 0.65235500 & 0.00009200 \\ \text { C } & -0.00017100 & 1.38591800 & 0.00000900 \\ \text { C } & -0.01955800 & 2.82023000 & -0.00004900 \\ \text { C } & 1.16986100 & 3.50622200 & -0.00002400 \\ \text { C } & 2.40081100 & 2.77204400 & 0.00005900 \\ \text { C } & 2.42127500 & 1.34007400 & 0.00011600 \\ \text { H } & 1.20543400 & -0.43708300 & 0.00013400 \\ \text { H } & -0.94574900 & 0.83971600 & -0.00001100 \\ \text { H } & -0.97582800 & 3.34258000 & -0.00011100 \\ H & 1.19607100 & 4.59553500 & -0.00006600 \\ H & 3.34650400 & 3.31782100 & 0.00007800 \\ H & 3.37782500 & 0.81817000 & 0.00017900\end{array}$

Radical: 9

Number of imaginary frequencies: 0

Electronic energy: see table 1

Electric field direction: $F / / b 1$

Electric field strength $F$ : 0.0075 a.u.

$\begin{array}{lrrr}\text { C } & 1.23159500 & 0.65211700 & 0.00009200 \\ \text { C } & -0.00138400 & 1.38511700 & 0.00000900 \\ \text { C } & -0.01966400 & 2.82246400 & -0.00004800 \\ \text { C } & 1.16932200 & 3.50576000 & -0.00002400 \\ \text { C } & 2.40054300 & 2.76998400 & 0.00005900 \\ \text { C } & 2.42276300 & 1.34234400 & 0.00011700 \\ \text { H } & 1.20605200 & -0.43786800 & 0.00013400 \\ \text { H } & -0.94680200 & 0.83824400 & -0.00001100 \\ \text { H } & -0.97616200 & 3.34448800 & -0.00011100 \\ \text { H } & 1.19641500 & 4.59535000 & -0.00006600 \\ \text { H } & 3.34618300 & 3.31604400 & 0.00007800 \\ \text { H } & 3.37895500 & 0.81953900 & 0.00017900\end{array}$




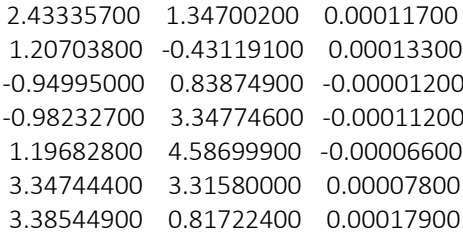

Below, the coordinates of the equilibrium structures are provided for radicals $\mathbf{6 b}, \mathbf{6 c}$ and $\mathbf{6} \mathbf{d}$ in the presence of different electric fields oriented parallel to the intrinsic dipole moment $\mu^{0}$ of the radical $\left(F / / \mu^{0}\right)$.

Radical: $6 \mathrm{~b}$

Number of imaginary frequencies: 0

Electronic energy: see table 8

Electric field direction: $F / / \mu^{0}$

Electric field strength $F$ : -0.01 a.u.

$\begin{array}{lrrr}\text { C } & 0.00001500 & -0.00001400 & 0.18131200 \\ \text { Cl } & -1.47502000 & -0.85172500 & -0.15413000 \\ \text { Cl } & 0.00010800 & 1.70326800 & -0.15413100 \\ \text { Cl } & 1.47489600 & -0.85152800 & -0.15307000\end{array}$

Radical: $6 \mathrm{~b}$

Number of imaginary frequencies: 0

Electronic energy: see table 8

Electric field direction: $F / / \mu^{0}$

Electric field strength $F$ : -0.005 a.u

C $\quad 0.00002000 \quad-0.00001700 \quad 0.18282100$

$\mathrm{Cl} \quad-1.47481600-0.85159500-0.15463000$

Cl $\quad 0.00009800 \quad 1.70302600 \quad-0.15463100$

$\mathrm{Cl} \quad 1.47469800 \quad-0.85141300-0.15357900$

Radical: $6 b$

Number of imaginary frequencies: 0

Electronic energy: see table 8

Electric field direction: $F / / \mu^{0}$

Electric field strength $F: 0$ a.u.

$\begin{array}{lrrr}\mathrm{C} & 0.00002500 & -0.00001900 & 0.18464700 \\ \mathrm{Cl} & -1.47462300 & -0.85147200 & -0.15523400 \\ \mathrm{Cl} & 0.00008800 & 1.70279800 & -0.15523500 \\ \mathrm{Cl} & 1.47451100 & -0.85130500 & -0.15419600\end{array}$

Radical: $6 \mathrm{~b}$

Number of imaginary frequencies: 0

Electronic energy: see table 8

Electric field direction: $F / / \mu^{0}$

Electric field strength $F$ : 0.0050 a.u.

$\begin{array}{lrrr}\mathrm{C} & 0.00003000 & -0.00002200 & 0.18681600 \\ \mathrm{Cl} & -1.47444900 & -0.85136000 & -0.15595100 \\ \mathrm{Cl} & 0.00007800 & 1.70259100 & -0.15595100 \\ \mathrm{Cl} & 1.47434100 & -0.85120800 & -0.15493200\end{array}$

Radical: $6 \mathrm{~b}$

Number of imaginary frequencies: 0

Electronic energy: see table 8

Electric field direction: $F / / \mu^{0}$

Electric field strength $F$ : 0.01 a.u.

\begin{tabular}{|c|c|c|c|}
\hline C & 0.00003500 & -0.00002500 & 0.18935200 \\
\hline $\mathrm{Cl}$ & -1.47429500 & -0.85126100 & -0.15678800 \\
\hline $\mathrm{Cl}$ & 0.00006900 & 1.70240800 & -0.15678900 \\
\hline
\end{tabular}

$\mathrm{Cl} \quad \begin{array}{llll}1.47419200 & -0.85112200 & -0.15579500\end{array}$

Radical: $6 \mathrm{c}$

Number of imaginary frequencies: 0
Radical: $6 \mathrm{~b}$

Number of imaginary frequencies: 0

Electronic energy: see table 8

Electric field direction: $F / / \mu^{0}$

Electric field strength $F$ : -0.0075 a.u

$\begin{array}{llll}\text { C } & 0.00001700 & -0.00001600 & 0.18202900\end{array}$

Cl $\quad-1.47491700 \quad-0.85165900-0.15436800$

Cl $\quad 0.00010300 \quad 1.70314600 \quad-0.15436900$

Cl $\quad 1.47479600 \quad-0.85147000-0.15331100$

Radical: $6 \mathrm{~b}$

Number of imaginary frequencies: 0

Electronic energy: see table 8

Electric field direction: $F / / \mu^{0}$

Electric field strength $F$ : -0.0025 a.u

$\begin{array}{llll}\text { C } & 0.00002200 & -0.00001800 & 0.18369200\end{array}$

$\mathrm{Cl} \quad-1.47471700-0.85153200 \quad-0.15491900$

Cl $\quad 0.00009300 \quad 1.70290900-0.15491900$

Cl $\quad \begin{array}{llll}\text { Cl.47460200 } & -0.85135800 & -0.15387300\end{array}$

Radical: $6 b$

Number of imaginary frequencies: 0

Electronic energy: see table 8

Electric field direction: $F / / \mu^{0}$

Electric field strength $F$ : 0.0025 a.u.

$\begin{array}{llll}\text { C } & 0.00002700 & -0.00002100 & 0.18568700\end{array}$

Cl $\quad-1.47453400-0.85141500-0.15557800$

Cl $\quad 0.00008300 \quad 1.70269100 \quad-0.15557900$

Cl $\quad \begin{array}{llll}1.47442300 & -0.85125500 & -0.15454900\end{array}$

Radical: $6 b$

Number of imaginary frequencies: 0

Electronic energy: see table 8

Electric field direction: $F / / \mu^{0}$

Electric field strength $F$ : 0.0075 a.u.

$\begin{array}{lrrr}\mathrm{C} & 0.00003200 & -0.00002300 & 0.18803600 \\ \mathrm{Cl} & -1.47437000 & -0.85130900 & -0.15635400 \\ \mathrm{Cl} & 0.00007300 & 1.70249600 & -0.15635400 \\ \mathrm{Cl} & 1.47426400 & -0.85116300 & -0.15534700\end{array}$

Radical: 6c

Number of imaginary frequencies: 0 
Electronic energy: see table 8

Electric field direction: $F / / \mu^{0}$

Electric field strength F: -0.01 a.u.

$\begin{array}{lrrr}\mathrm{C} & -0.00010300 & 0.00004100 & 0.14504500 \\ \mathrm{Br} & 0.00015000 & 1.86617800 & -0.18760200 \\ \mathrm{Br} & -1.61606000 & -0.93320900 & -0.18760200 \\ \mathrm{Br} & 1.61601300 & -0.93300800 & -0.18607500\end{array}$

Radical: 6c

Number of imaginary frequencies: 0

Electronic energy: see table 8

Electric field direction: $F / / \mu^{0}$

Electric field strength $F$ : -0.005 a.u.

$\begin{array}{llll}\mathrm{C} & -0.00006200 & 0.00002000 & 0.15174100 \\ \mathrm{Br} & 0.00009400 & 1.86529000 & -0.18980400 \\ \mathrm{Br} & -1.61531500 & -0.93271800 & -0.18980400 \\ \mathrm{Br} & 1.61528400 & -0.93259100 & -0.18836700\end{array}$

Radical: $6 c$

Number of imaginary frequencies: 0

Electronic energy: see table 8

Electric field direction: $F / / \mu^{0}$

Electric field strength $F$ : 0 a.u.

$\begin{array}{llll}C & -0.00002700 & 0.00000200 & 0.15855800\end{array}$

$\begin{array}{lllll}\mathrm{Br} & 0.00004700 & 1.86445500 & -0.19204600\end{array}$

$\mathrm{Br} \quad-1.61461200-0.93226100 \quad-0.19204600$

$\begin{array}{llll}\mathrm{Br} & 1.61459200 & -0.93219400 & -0.19070000\end{array}$

Radical: 6c

Number of imaginary frequencies: 0

Electronic energy: see table 8

Electric field direction: $F / / \mu^{0}$

Electric field strength F: 0.0050 a.u.

$\begin{array}{lrrr}\mathrm{C} & 0.00000400 & -0.00001300 & 0.16552100 \\ \mathrm{Br} & 0.00001000 & 1.86368500 & -0.19433500 \\ \mathrm{Br} & -1.61396200 & -0.93184600 & -0.19433600 \\ \mathrm{Br} & 1.61394800 & -0.93182600 & -0.19308500\end{array}$

Radical: 6c

Number of imaginary frequencies: 0

Electronic energy: see table 8

Electric field direction: $F / / \mu^{0}$

Electric field strength $F$ : 0.01 a.u.

$\begin{array}{lrrr}\mathrm{C} & 0.00003000 & -0.00002400 & 0.17266200 \\ \mathrm{Br} & -0.00001800 & 1.86298800 & -0.19668200 \\ \mathrm{Br} & -1.61337200 & -0.93147500 & -0.19668400 \\ \mathrm{Br} & 1.61336000 & -0.93148800 & -0.19553000\end{array}$

Radical: 6d

Number of imaginary frequencies: 0

Electronic energy: see table 8

Electric field direction: $F / / \mu^{0}$

Electric field strength $F$ : -0.01 a.u.

$\begin{array}{llll}\text { C } & -0.00054200 & 0.00030700 & 0.07023800\end{array}$

I $\quad 0.000518002 .09469400 \quad-0.22054500$

I $\quad-1.81378500-1.04779200 \quad-0.22055100$

l $\quad 1.81380900-1.04720700 \quad-0.21791600$

Radical: 6d

Number of imaginary frequencies: 0

Electronic energy: see table 8

Electric field direction: $F / / \mu^{0}$

Electric field strength F: -0.005 a.u.

C $\quad-\quad \begin{array}{llll}0.00032100 & 0.00017400 & 0.09005200\end{array}$
Electronic energy: see table 8

Electric field direction: $F / / \mu^{0}$

Electric field strength $F$ : -0.0075 a.u.

$\begin{array}{llll}\mathrm{C} & -0.00008200 & 0.00003000 & 0.14837900 \\ \mathrm{Br} & 0.00012100 & 1.86572800 & -0.18869900 \\ \mathrm{Br} & -1.61568300 & -0.93296000 & -0.18869900 \\ \mathrm{Br} & 1.61564400 & -0.93279700 & -0.18721600\end{array}$

Radical: $6 c$

Number of imaginary frequencies: 0

Electronic energy: see table 8

Electric field direction: $F / / \mu^{0}$

Electric field strength $F$ : -0.0025 a.u.

$\begin{array}{llll}\text { C } & -0.00004400 & 0.00001000 & 0.15513200\end{array}$

$\begin{array}{lllll}\mathrm{Br} & 0.00006900 & 1.86486500 & -0.19091900\end{array}$

$\mathrm{Br} \quad-1.61495800 \quad-0.93248400 \quad-0.19092000$

$\mathrm{Br} \quad 1.61493200 \quad-0.93238900-0.18952800$

Radical: 6c

Number of imaginary frequencies: 0

Electronic energy: see table 8

Electric field direction: $F / / \mu^{0}$

Electric field strength $F$ : 0.0025 a.u.

$\begin{array}{llll}\text { C } & -0.00001100 & -0.00000600 & 0.16201900\end{array}$

$\begin{array}{lllll}\mathrm{Br} & 0.00002700 & 1.86406100 & -0.19318400\end{array}$

$\mathrm{Br} \quad-1.61428000 \quad-0.93204800 \quad-0.19318500$

$\begin{array}{lllll}\mathrm{Br} & 1.61426400 & -0.93200600 & -0.19188500\end{array}$

Radical: $6 c$

Number of imaginary frequencies: 0

Electronic energy: see table 8

Electric field direction: $F / / \mu^{0}$

Electric field strength F: 0.0075 a.u.

$\begin{array}{lrrr}\mathrm{C} & 0.00001800 & -0.00001900 & 0.16906700 \\ \mathrm{Br} & -0.00000500 & 1.86332700 & -0.19550100 \\ \mathrm{Br} & -1.61365900 & -0.93165400 & -0.19550200 \\ \mathrm{Br} & 1.61364700 & -0.93165300 & -0.19429900\end{array}$

Radical: $6 \mathrm{~d}$

Number of imaginary frequencies: 0

Electronic energy: see table 8

Electric field direction: $F / / \mu^{0}$

Electric field strength $F$ : -0.0075 a.u

$\begin{array}{llll}\text { C } & -0.00040900 & 0.00022800 & 0.08033300\end{array}$

l $\quad \begin{array}{llll}0.00033500 & 2.09379400 & -0.22388500\end{array}$

I $\quad-1.81308900-1.04718300-0.22389100$

I $\quad \begin{array}{llll}1.81316300 & -1.04683800 & -0.22133100\end{array}$

Radical: 6d

Number of imaginary frequencies: 0

Electronic energy: see table 8

Electric field direction: $F / / \mu^{0}$

Electric field strength $F$ : -0.0025 a.u. 
$\begin{array}{lrrr}\text { I } & 0.00023400 & 2.09287300 & -0.22709700 \\ \text { I } & -1.81233500 & -1.04663400 & -0.22710200\end{array}$

I $1.81242300-1.04641300-0.22462700$

Radical: 6d

Number of imaginary frequencies: 0

Electronic energy: see table 8

Electric field direction: $F / / \mu^{0}$

Electric field strength $F: 0$ a.u.

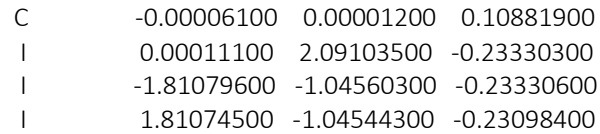

Radical: 6d

Number of imaginary frequencies: 0

Electronic energy: see table 8

Electric field direction: $F / / \mu^{0}$

Electric field strength F: 0.0050 a.u.

$\begin{array}{lrrr}\text { C } & 0.00006300 & -0.00006500 & 0.12515600 \\ \text { I } & -0.00004600 & 2.08952500 & -0.23867500 \\ \text { I } & -1.80956000 & -1.04470900 & -0.23867600 \\ \text { I } & 1.80954300 & -1.04475100 & -0.23658000\end{array}$

Radical: 6d

Number of imaginary frequencies: 0

Electronic energy: see table 8

Electric field direction: $F / / \mu^{0}$

Electric field strength F: 0.01 a.u.

$\begin{array}{llll}\text { C } & 0.00013700 & -0.00011100 & 0.14079700\end{array}$

$\begin{array}{lllll}\text { I } & -0.00013000 & 2.08816800 & -0.24381300\end{array}$

| $\quad-1.80842500-1.04395500-0.24381300$

$\begin{array}{lllll}\text { l } & 1.80841900 & -1.04410100 & -0.24194600\end{array}$

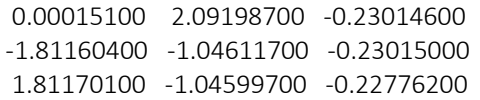

Radical: $6 \mathrm{~d}$

Number of imaginary frequencies: 0

Electronic energy: see table 8

Electric field direction: $F / / \mu^{0}$

Electric field strength $F$ : 0.0025 a.u.

C $\quad 0.00000900 \quad-0.00003100 \quad 0.11708200$

$\begin{array}{llll}0.00002100 & 2.09026400 & -0.23602200\end{array}$

$-1.81016900-1.04513800-0.23602400$

$\begin{array}{llll}1.81013900 & -1.04509400 & -0.23381100\end{array}$

Radical: 6d

Number of imaginary frequencies: 0

Electronic energy: see table 8

Electric field direction: $F / / \mu^{0}$

Electric field strength $F$ : 0.0075 a.u.

$\begin{array}{lrrr}\text { C } & 0.00010500 & -0.00009100 & 0.13305400 \\ \text { I } & -0.00009600 & 2.08882400 & -0.24126900 \\ \text { I } & -1.80897700 & -1.04431400 & -0.24127000 \\ \text { I } & 1.80896800 & -1.04441800 & -0.23928900\end{array}$

Below, the coordinates of the transition states are provided for the $\mathrm{NH}_{3}$ addition to 8 in the presence of an electric field oriented in the $\mathrm{F} / / \mathrm{b} 3$ direction with different field strengths.

Transition state: ortho-1

Number of imaginary frequencies: $1\left(-196.45 \mathrm{~cm}^{-1}\right)$

Gibbs free energy: $-402.977712 \mathrm{Ha}$

Electric field strength $F$ : -0.005 a.u.

\footnotetext{
C $\quad 2.43999802 .20609400 .2467140$

1.62624601 .10187000 .0752570

$3.6540610-0.3353760-0.1807190$

$4.43208100 .7793080-0.0050290$

$2.1962320-0.2549780-0.0447320$

$1.6200870-0.9048800-0.7124130$

$1.7688770-1.04788701 .4530790$

$0.7634490-0.95570501 .6162480$

$2.0223470-2.03803901 .4182280$

$2.2830590-0.60607502 .2187610$

3.84065702 .05059500 .2327320

4.47724802 .92263900 .3739870

$5.51594100 .7012510-0.0842950$

$4.0993160-1.2999520-0.4246940$

2.01541703 .19976100 .3700480

0.27033001 .08903000 .0488810

$-0.42492902 .34933300 .0606280$

$-1.48468302 .0993590-0.0372760$

$-0.25003802 .88197001 .0052310$

$-0.10515902 .9677660-0.7884340$

Transition state: ortho-1

Number of imaginary frequencies: $1\left(-253.55 \mathrm{~cm}^{-1}\right)$
}

Transition state: ortho-1

Number of imaginary frequencies: $1\left(-236.80 \mathrm{~cm}^{-1}\right)$

Gibbs free energy: -402.967584 $\mathrm{Ha}$

Electric field strength $F$ : -0.0025 a.u.

$\begin{array}{ll}\text { C } & 2.44638302 .21049100 .2359150 \\ \text { C } & 1.63272901 .10304600 .0612730 \\ \text { C } & 3.6609740-0.3323070-0.1826470 \\ \text { C } & 4.43788500 .7836010-0.0056330 \\ \text { C } & 2.2062020-0.2498190-0.0603310 \\ \text { H } & 1.6296380-0.9087810-0.7171130 \\ \text { N } & 1.7522480-1.05126401 .4626980 \\ \text { H } & 0.7449930-0.95260901 .6090500 \\ \text { H } & 1.9991690-2.04259001 .4314580 \\ \text { H } & 2.2570710-0.60940402 .2336360 \\ \mathrm{C} & 3.84427902 .05513400 .2251420 \\ \text { H } & 4.47994502 .92825700 .3646310 \\ \text { H } & 5.52208900 .7066200-0.0804720 \\ \text { H } & 4.1083260-1.2967840-0.4226500 \\ \text { H } & 2.01912403 .20288200 .3588000 \\ \text { O } & 0.28307401 .08854000 .0352020 \\ \text { C } & -0.42379102 .34544400 .0695680 \\ \text { H } & -1.48153202 .0862270-0.0186310 \\ \text { H } & -0.24044602 .86558801 .0191040 \\ \text { H } & -0.11782202 .9738120-0.7767990 \\ \text { Transition state: ortho-1 } \\ \text { Number of imaginary frequencies: } 1\left(-261.56 \mathrm{~cm}^{-1} \text {. }\right.\end{array}$


Gibbs free energy: $-402.958244 \mathrm{Ha}$ Electric field strength $F$ : 0 a.u.

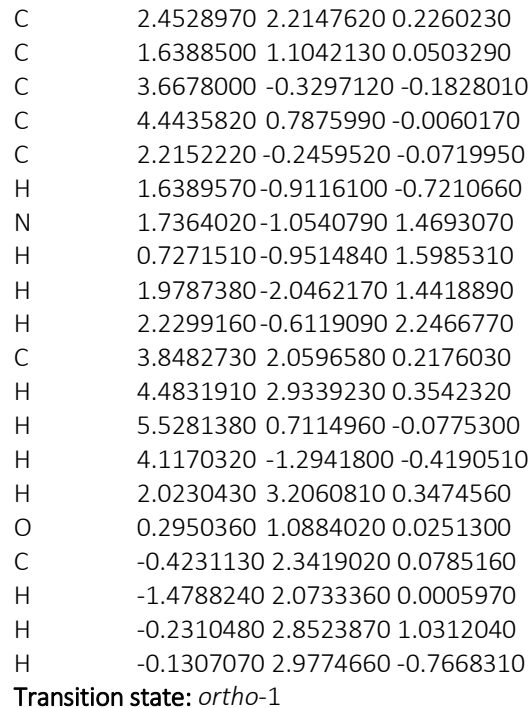

Transition state: ortho-

Number of imaginary frequencies: $1\left(-264.83 \mathrm{~cm}^{-1}\right)$ Gibbs free energy: $-402.942089 \mathrm{Ha}$ Electric field strength F: 0.0050 a.u.

$\begin{array}{ll}\text { C } & 2.46721102 .22350300 .2081430 \\ \text { C } & 1.65107501 .10697100 .0332690 \\ \text { C } & 3.6814240-0.3248070-0.1816170 \\ \text { C } & 4.45559400 .7952830-0.0074710 \\ \text { C } & 2.2323890-0.2393250-0.0900670 \\ \text { H } & 1.6568680-0.9154060-0.7270880 \\ \text { N } & 1.7055620-1.05942301 .4795200 \\ \text { H } & 0.6926910-0.95141201 .5744510 \\ \text { H } & 1.9400570-2.05298801 .4593010 \\ \text { H } & 2.1742120-0.61750102 .2712730 \\ \text { C } & 3.85787602 .06877800 .2024810 \\ \text { H } & 4.49185902 .94521400 .3320220 \\ \text { H } & 5.54098300 .7203450-0.0744160 \\ \text { H } & 4.1338140-1.2895070-0.4108700 \\ \text { H } & 2.03261803 .21302800 .3260600 \\ \text { O } & 0.31819501 .08943500 .0104570 \\ \text { C } & -0.42370102 .33526900 .0959170 \\ \text { H } & -1.47465402 .04635300 .0372120 \\ \text { H } & -0.21601002 .83062401 .0527130 \\ \text { H } & -0.15752702 .9816480-0.7490850\end{array}$

Transition state: ortho-1

Number of imaginary frequencies: $1\left(-263.67 \mathrm{~cm}^{-1}\right)$ Gibbs free energy: $-402.929419 \mathrm{Ha}$

Electric field strength $F$ : 0.01 a.u

C $\quad 2.48273302 .23214000 .1934000$ C $\quad 1.66303401 .11011700 .0207990$

C $\quad 3.6946850-0.3199130-0.1809860$ C $\quad 4.46834100 .8025970-0.0100650$

C $\quad 2.2485680-0.2336300-0.1036540$ $\mathrm{H} \quad 1.6732680-0.9181560-0.7303510$

N $\quad 1.6759110-1.06527301 .4881320$

H $\quad 0.6595140-0.95841301 .5470770$

H $\quad 1.9079330-2.05914901 .4765100$

H $\quad 2.1138960-0.62152002 .2956170$

C $\quad 3.86928802 .07757500 .1886690$

H $\quad 4.50297602 .95590500 .3108190$

H $\quad 5.55480300 .7281960-0.0750840$

H $\quad 4.1494860-1.2847730-0.4056160$

H $\quad 2.04389303 .22022700 .3076350$

O $\quad 0.34029101 .09235700 .0006490$

C $\quad-0.42641502 .33015000 .1118750$

H $\quad-1.47190302 .01931700 .0732110$

H $\quad-0.20309102 .81607501 .0695650$
Gibbs free energy: -402.949740 Ha Electric field strength F: 0.0025 a.u.

\begin{tabular}{ll} 
C & 2.45998202 .21917200 .2166290 \\
C & 1.64507601 .10557700 .0411220 \\
C & $3.6747140-0.3272350-0.1821730$ \\
C & $4.44958000 .7915010-0.0066290$ \\
C & $2.2240250-0.2424420-0.0817100$ \\
H & $1.6481860-0.9136170-0.7244620$ \\
N & $1.7207180-1.05668601 .4747030$ \\
H & $0.7096720-0.95033501 .5868840$ \\
H & $1.9582480-2.04972401 .4507160$ \\
H & $2.2025440-0.61500902 .2590950$ \\
C & 3.85292402 .06427300 .2098170 \\
H & 4.48729602 .93966000 .3429310 \\
H & $5.53452500 .7160480-0.0755070$ \\
H & $4.1256210-1.2918410-0.4145780$ \\
H & 2.02771403 .20955100 .3363650 \\
O & 0.30685101 .08867800 .0170800 \\
C & -0.42320002 .33832800 .0874620 \\
H & -1.47657802 .05966500 .0190400 \\
H & -0.22336902 .84045601 .0426730 \\
H & $-0.14399302 .9800620-0.7572560$ \\
\hline
\end{tabular}

Transition state: ortho-1

Number of imaginary frequencies: $1\left(-265.22 \mathrm{~cm}^{-1}\right)$

Gibbs free energy: $-402.935310 \mathrm{Ha}$

Electric field strength $F$ : 0.0075 a.u.

$\begin{array}{ll}\text { C } & 2.47477302 .22778400 .2005280 \\ \text { C } & 1.65700901 .10846400 .0265830 \\ \text { C } & 3.6879970-0.3223840-0.1812950 \\ \text { C } & 4.46177600 .7989420-0.0086590 \\ \text { C } & 2.2404820-0.2364460-0.0972410 \\ \text { H } & 1.6651200-0.9169200-0.7289500 \\ \text { N } & 1.6907480-1.06226801 .4839820 \\ \text { H } & 0.6760110-0.95460301 .5609550 \\ \text { H } & 1.9239240-2.05599601 .4680630 \\ \text { H } & 2.1443680-0.61933602 .2835280 \\ \text { C } & 3.86329102 .07316400 .1955260 \\ \text { H } & 4.49706202 .95056300 .3214440 \\ \text { H } & 5.54766100 .7243530-0.0744220 \\ \text { H } & 4.1416650-1.2871470-0.4080770 \\ \text { H } & 2.03799803 .21654800 .3166320 \\ \text { O } & 0.32932101 .09070200 .0050220 \\ \text { C } & -0.42473102 .33262100 .1039730 \\ \text { H } & -1.47307402 .03302900 .0551630 \\ \text { H } & -0.20922202 .82263101 .0615620 \\ H & -0.17164302 .9823820-0.7421120\end{array}$


Transition state: ortho-2

Number of imaginary frequencies: $1\left(-119.16 \mathrm{~cm}^{-1}\right)$ Gibbs free energy: $-402.947782 \mathrm{Ha}$

Electric field strength $F: 0$ a.u.

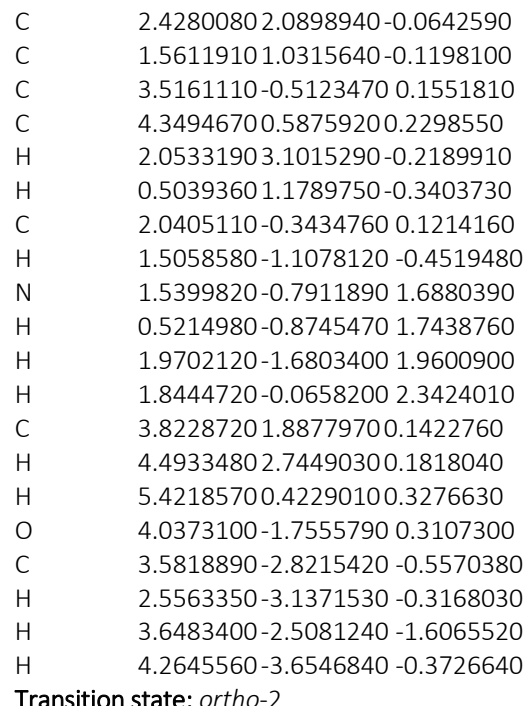

Transition state: ortho- 2

Number of imaginary frequencies: $1\left(-235.30 \mathrm{~cm}^{-1}\right)$ Gibbs free energy: $-402.914389 \mathrm{Ha}$

Electric field strength F: 0.0050 a.u.

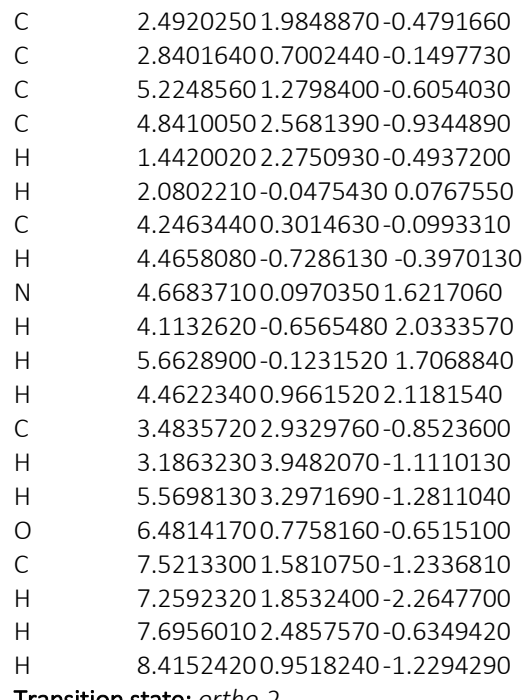

Transition state: ortho-2

Number of imaginary frequencies: $1\left(-196.95 \mathrm{~cm}^{-1}\right)$ Gibbs free energy: $-402.873989 \mathrm{Ha}$

Electric field strength F: 0.01 a.u.

$2.49936401 .9583960-0.4948940$ $2.85996800 .6791360-0.1597060$ $5.24631101 .2898570-0.5730250$ $4.85120202 .5683210-0.9113800$ $1.44533302 .2335470-0.5261290$ $2.1067160-0.07915900 .0556500$ $4.27460400 .2988860-0.0737960$ $4.5099650-0.7270430-0.3767930$ 4.63212900 .10843101 .6330000 $4.0606280-0.64367402 .0273770$ $5.6222030-0.10708801 .7663240$ 4.39827500 .97886202 .1162360 $3.48487202 .9195380-0.8489710$ $3.17934303 .9313830-1.1111340$
Transition state: ortho-2

Number of imaginary frequencies: $1\left(-203.57 \mathrm{~cm}^{-1}\right)$

Gibbs free energy: $-402.926802 \mathrm{Ha}$

Electric field strength $F: 0.0025$ a.u.

$\begin{array}{ll}\text { C } & 2.47966901 .9939790-0.5243920 \\ \text { C } & 3.06291900 .7545550-0.5050910 \\ \text { C } & 5.30297701 .8656970-0.4010780 \\ \text { C } & 4.67434903 .0951800-0.4000950 \\ \text { H } & 1.39979802 .0812470-0.6413790 \\ \text { H } & 2.4678330-0.1506010-0.6256850 \\ \text { C } & 4.51383800 .6170690-0.3076280 \\ \text { H } & 4.9586110-0.2535360-0.7987080 \\ \text { N } & 4.75553900 .10725601 .3439640 \\ \text { H } & 4.4029600-0.84100001 .4949480 \\ \text { H } & 5.75039300 .14765901 .5810460 \\ \text { H } & 4.24191700 .74892901 .9526150 \\ \text { C } & 3.27022503 .1754050-0.4413420 \\ \text { H } & 2.78612304 .1508050-0.4584450 \\ \text { H } & 5.28601503 .9966040-0.3956780 \\ \text { O } & 6.65880901 .8031060-0.2898720 \\ \text { C } & 7.38347300 .9394490-1.1960930 \\ \text { H } & 7.2246560-0.1239820-0.9667750 \\ \text { H } & 7.09287301 .1511050-2.2330110 \\ \text { H } & 8.43873401 .1841340-1.0481500 \\ \text { Transition } & \text { state: } 0 r t h 0-2\end{array}$

Number of imaginary frequencies: $1\left(-219.94 \mathrm{~cm}^{-1}\right)$

Gibbs free energy: $-402.893736 \mathrm{Ha}$

Electric field strength $F$ : 0.0075 a.u.

$\begin{array}{ll}\text { C } & 2.49370601 .9653240-0.4866800 \\ \text { C } & 2.85146900 .6845410-0.1534690 \\ \text { C } & 5.23520401 .2850790-0.5903400 \\ \text { C } & 4.84247802 .5672130-0.9248710 \\ \text { H } & 1.44097502 .2454520-0.5090890 \\ \text { H } & 2.0968710-0.07013700 .0687170 \\ \text { C } & 4.26284100 .2986080-0.0863420 \\ \text { H } & 4.4926560-0.7292760-0.3852560 \\ \text { N } & 4.65477100 .10417601 .6287080 \\ \text { H } & 4.0941540-0.65003302 .0329730 \\ \text { H } & 5.6481410-0.11030001 .7371780 \\ \text { H } & 4.43224200 .97386602 .1177220 \\ \text { C } & 3.47969702 .9219550-0.8520250 \\ \text { H } & 3.17563203 .9344730-1.1133040 \\ \text { H } & 5.56597003 .3020140-1.2711000 \\ \text { O } & 6.50158700 .7904700-0.6345680 \\ \text { C } & 7.52105001 .5942720-1.2460180 \\ \text { H } & 7.23861801 .8527120-2.2757410 \\ \text { H } & 7.70235002 .5097740-0.6649850 \\ \text { H } & 8.42130100 .9728780-1.2523570\end{array}$




$\begin{array}{ll}\text { H } & 5.57345103 .3058770-1.2551540 \\ \text { O } & 6.52032900 .7986850-0.6157200 \\ \text { C } & 7.52314201 .5942560-1.2574100 \\ \text { H } & 7.22050701 .8407840-2.2847890 \\ \text { H } & 7.71773002 .5191970-0.6946440 \\ \text { H } & 8.42564100 .9748710-1.2758920\end{array}$

Transition state: meta-1

Number of imaginary frequencies: $1\left(-182.90 \mathrm{~cm}^{-1}\right)$ Gibbs free energy: $-402.958190 \mathrm{Ha}$ Electric field strength $F:-0.005$ a.u.

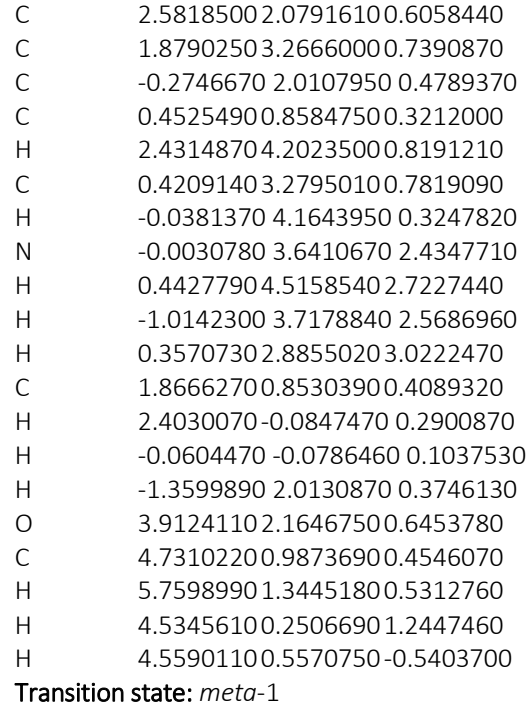

Transition state: meta-1

Number of imaginary frequencies: $1\left(-256.80 \mathrm{~cm}^{-1}\right)$ Gibbs free energy: $-402.949204 \mathrm{Ha}$

Electric field strength $F: 0$ a.u.

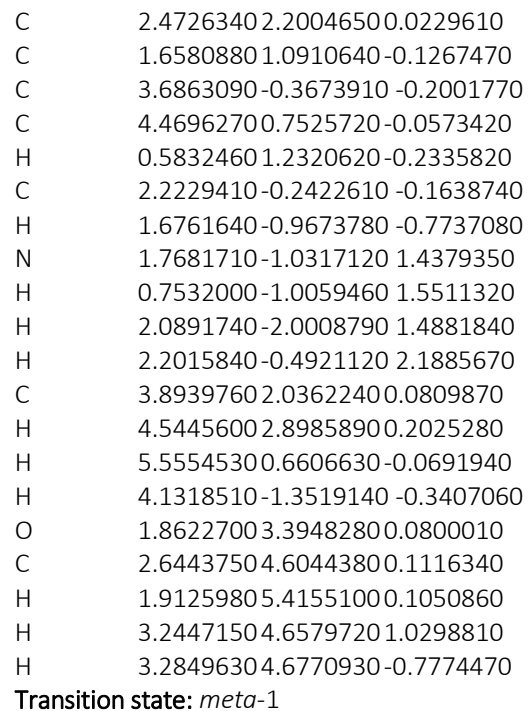

Transition state: meta-1

Number of imaginary frequencies: $1\left(-241.38 \mathrm{~cm}^{-1}\right)$

Gibbs free energy: $-402.943274 \mathrm{Ha}$

Electric field strength $F: 0.0050$ a.u.

$\begin{array}{ll}\text { C } & 2.60853502 .06789200 .6360770 \\ \text { C } & 1.91753803 .26112600 .7455560 \\ \text { C } & -0.22487102 .02165600 .4387950 \\ \text { C } & 0.48787300 .84684100 .3450020 \\ \text { H } & 2.47408704 .19427600 .8219200 \\ \text { C } & 0.47591503 .27510700 .7112370 \\ \text { H } & 0.01183104 .18174700 .3169290 \\ \text { N } & -0.10846103 .67526702 .5030620 \\ \text { H } & 0.31649804 .55322302 .8032220\end{array}$

Transition state: meta-1

Number of imaginary frequencies: $1\left(-243.98 \mathrm{~cm}^{-1}\right)$ Gibbs free energy: $-402.953350 \mathrm{Ha}$ Electric field strength F: -0.0025 a.u.

$\begin{array}{ll}\text { C } & 2.58805302 .07760100 .6130170 \\ \text { C } & 1.88790703 .26647600 .7372870 \\ \text { C } & -0.26144002 .01457600 .4636730 \\ \text { C } & 0.46133000 .85551600 .3260220 \\ \text { H } & 2.44119004 .20175900 .8144910 \\ \text { C } & 0.43540003 .27864000 .7584660 \\ \text { H } & -0.02631104 .17083100 .3225280 \\ \text { N } & -0.02884403 .64823702 .4559160 \\ \text { H } & 0.41145804 .52369102 .7470660 \\ \text { H } & -1.04192403 .72568102 .5696890 \\ \text { H } & 0.32029902 .89177303 .0472600 \\ \text { C } & 1.87319900 .85065700 .4228360 \\ \text { H } & 2.4091100-0.08923700 .3186470 \\ \text { H } & -0.0533630-0.08260400 .1184850 \\ \text { H } & -1.34591502 .01943800 .3544640 \\ \text { O } & 3.92301102 .15922800 .6538000 \\ \text { C } & 4.73227400 .98315600 .4392790 \\ \text { H } & 5.76414801 .33574200 .4983300 \\ H & 4.55074900 .23890701 .2261300 \\ H & 4.54133400 .5585570-0.5550270\end{array}$

Transition state: meta-1

Number of imaginary frequencies: $1\left(-253.09 \mathrm{~cm}^{-1}\right)$ Gibbs free energy: $-402.945850 \mathrm{Ha}$

Electric field strength $F$ : 0.0025 a.u.

$\begin{array}{ll}\text { C } & 2.60123802 .07171500 .6285720 \\ \text { C } & 1.90705903 .26330700 .7427230 \\ \text { C } & -0.23707102 .01944100 .4454150 \\ \text { C } & 0.47883400 .84975500 .3378950 \\ \text { H } & 2.46240204 .19721300 .8191650 \\ \text { C } & 0.46206703 .27638000 .7258650 \\ \text { H } & -0.00120404 .17844800 .3180720 \\ \text { N } & -0.08071603 .66576702 .4877560 \\ \text { H } & 0.34823704 .54351002 .7845200 \\ \text { H } & -1.09739603 .74680102 .5556690 \\ \text { H } & 0.24078202 .91044603 .0940150 \\ \text { C } & 1.88663300 .84521900 .4468820 \\ \text { H } & 2.4207290-0.09803700 .3636380 \\ \text { H } & -0.0399290-0.08916000 .1466010 \\ \text { H } & -1.32026002 .02839800 .3275170 \\ \text { O } & 3.94565402 .14644500 .6714090 \\ \text { C } & 4.73679900 .97511200 .4069230 \\ \text { H } & 5.77366201 .31944900 .4355510 \\ \text { H } & 4.58250400 .21176201 .1818520 \\ \text { H } & 4.51164000 .5666530-0.5876760 \\ \text { Transition state: } \text { meta-1 }\end{array}$

Number of imaginary frequencies: $1\left(-224.26 \mathrm{~cm}^{-1}\right)$ Gibbs free energy: $-402.941499 \mathrm{Ha}$

Electric field strength $F: 0.0075$ a.u.

$\begin{array}{ll}\text { C } & 2.61657502 .06340400 .6438740 \\ \text { C } & 1.92897603 .25854500 .7484770 \\ \text { C } & -0.21225402 .02389300 .4335700 \\ \text { C } & 0.49734100 .84385300 .3533210 \\ \text { H } & 2.48693004 .19087000 .8246350 \\ \text { C } & 0.49062403 .27376900 .6972280 \\ \text { H } & 0.02566104 .18494500 .3165810 \\ \text { N } & -0.13853303 .68537002 .5182960 \\ \text { H } & 0.28442704 .56229502 .8227790\end{array}$




$\begin{array}{ll}\mathrm{H} & -1.12627603 .76076002 .5446980 \\ \mathrm{H} & 0.19504202 .92006603 .1179450 \\ \mathrm{C} & 1.89360800 .84212600 .4585050 \\ \mathrm{H} & 2.4264710-0.10277400 .3844540 \\ \mathrm{H} & -0.0334070-0.09218100 .1618650 \\ \mathrm{H} & -1.30757002 .03255900 .3168190 \\ \mathrm{O} & 3.95794802 .13901700 .6802050 \\ \mathrm{C} & 4.74014800 .97103800 .3898440 \\ \mathrm{H} & 5.77916001 .31175700 .4044090 \\ \mathrm{H} & 4.59884900 .19696201 .1570020 \\ \mathrm{H} & 4.49874600 .5721590-0.6051860\end{array}$

Transition state: meta-1

Number of imaginary frequencies: $1\left(-204.66 \mathrm{~cm}^{-1}\right)$

Gibbs free energy: $-402.940538 \mathrm{Ha}$

Electric field strength $F$ : 0.01 a.u.

$\begin{array}{ll}\text { C } & 2.62565202 .05815800 .6520790 \\ \text { C } & 1.94169703 .25543900 .7520330 \\ \text { C } & -0.19894402 .02611300 .4306530 \\ \text { C } & 0.50748200 .84078700 .3633830 \\ \text { H } & 2.50135304 .18682600 .8276580 \\ \text { C } & 0.50642603 .27235500 .6849480 \\ \text { H } & 0.04084404 .18787800 .3173320 \\ \text { N } & -0.17188203 .69618902 .5328920 \\ \text { H } & 0.25202704 .57008902 .8434420 \\ \text { H } & -1.18907203 .80049802 .5113430 \\ \text { H } & 0.08156602 .93793903 .1654020 \\ \text { C } & 1.90907400 .83464900 .4834310 \\ \text { H } & 2.4387410-0.11370100 .4264270 \\ \text { H } & -0.0200910-0.09779800 .1972900 \\ \text { H } & -1.28091502 .04094600 .3006120 \\ \text { O } & 3.98572002 .12109500 .6991540 \\ \text { C } & 4.74960300 .96266800 .3517270 \\ \text { H } & 5.79235901 .29735800 .3380890 \\ \text { H } & 4.63521300 .16395001 .0989270 \\ \text { H } & 4.47481000 .5871880-0.6444610\end{array}$

Transition state: meta-2

Number of imaginary frequencies: $1\left(-253.79 \mathrm{~cm}^{-1}\right)$

Gibbs free energy: $-402.951459 \mathrm{Ha}$

Electric field strength $F: 0$ a.u.

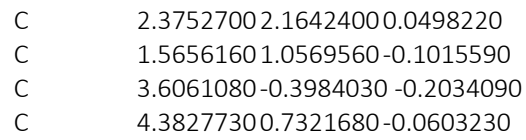

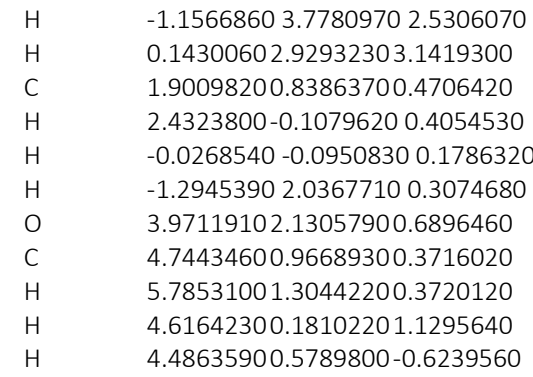

Transition state: meta- 2

Number of imaginary frequencies: $1\left(-216.81 \mathrm{~cm}^{-1}\right)$

Gibbs free energy: $-402.963804 \mathrm{Ha}$

Electric field strength $F$ : -0.0025 a.u

$\begin{array}{ll}\text { C } & 2.36912002 .16459300 .0515620 \\ \text { C } & 1.55599101 .0595140-0.0853030 \\ \text { C } & 3.5986570-0.3990370-0.2030310 \\ \text { C } & 4.37744800 .7306260-0.0652310 \\ \text { H } & 1.92928103 .16052500 .1024500 \\ \text { H } & 0.47360401 .1647660-0.1635170 \\ \text { H } & 4.0378720-1.3740730-0.3979810 \\ \text { C } & 2.1440630-0.2939390-0.1213870 \\ \text { H } & 1.5991710-1.0025570-0.7548670 \\ \text { N } & 1.6780200-1.00895701 .4254630 \\ \text { H } & 0.6645270-1.00786201 .5641730 \\ \text { H } & 2.0225810-1.97010901 .4815870 \\ \text { H } & 2.1175180-0.46114302 .1682300 \\ \text { C } & 3.76635202 .02713900 .0965020 \\ \text { H } & 4.42057702 .89055000 .2076980 \\ \text { O } & 5.71141000 .7716460-0.1012350 \\ \text { C } & 6.4476810-0.4529710-0.2803470 \\ \text { H } & 7.5005910-0.1651540-0.2560750 \\ \text { H } & 6.2296030-1.15193200 .5392640 \\ \text { H } & 6.2033490-0.9055330-1.2510520\end{array}$

Transition state: meta- 2

Number of imaginary frequencies: $1\left(-259.05 \mathrm{~cm}^{-1}\right)$

Gibbs free energy: $-402.939816 \mathrm{Ha}$

Electric field strength $F: 0.0025$ a.u.

$\begin{array}{ll}\text { C } & 2.38159802 .16368600 .0485180 \\ \text { C } & 1.57468501 .0543120-0.1141340 \\ \text { C } & 3.6138480-0.3980150-0.2015430 \\ \text { C } & 4.38835300 .7336370-0.0555220\end{array}$




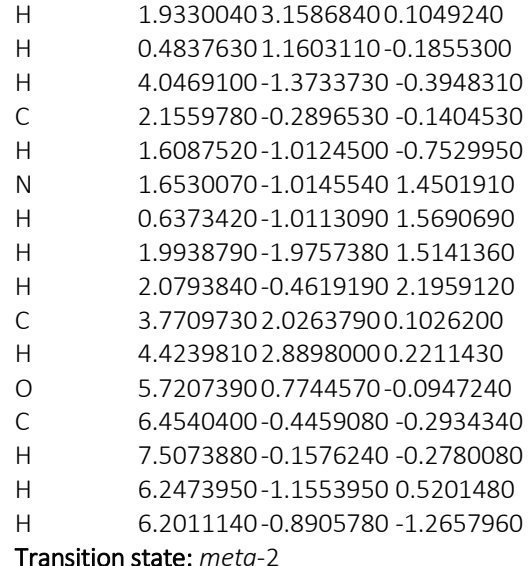

Transition state: meta-2

Number of imaginary frequencies: $1\left(-251.58 \mathrm{~cm}^{-1}\right)$

Gibbs free energy: $-402.928930 \mathrm{Ha}$

Electric field strength F: 0.0050 a.u.

$\begin{array}{ll}\text { C } & 2.38846202 .16292100 .0476470 \\ \text { C } & 1.58387901 .0513890-0.1246670 \\ \text { C } & 3.6221540-0.3977420-0.1988860 \\ \text { C } & 4.39451900 .7350930-0.0508520 \\ \text { H } & 1.94143903 .15461400 .1093600 \\ \text { H } & 0.50269001 .1518810-0.2175340 \\ \text { H } & 4.0655660-1.3733970-0.3809150 \\ \text { C } & 2.1782030-0.2836550-0.1690230 \\ \text { H } & 1.6279260-1.0292200-0.7468650 \\ \text { N } & 1.6010030-1.02466801 .4930910 \\ \text { H } & 0.5809360-1.02191901 .5643480 \\ \text { H } & 1.9377590-1.98491301 .5740420 \\ \text { H } & 1.9924360-0.46273002 .2494660 \\ \text { C } & 3.78127802 .02496600 .1106980 \\ \text { H } & 4.43169002 .88934400 .2377490 \\ \text { O } & 5.74141200 .7796300-0.0828690 \\ \text { C } & 6.4687570-0.4313460-0.3202900 \\ \text { H } & 7.5229240-0.1413080-0.3243480 \\ \text { H } & 6.2866140-1.16115300 .4814980 \\ \text { H } & 6.1977710-0.8616960-1.2947470\end{array}$

Transition state: meta-2

Number of imaginary frequencies: $1\left(-219.49 \mathrm{~cm}^{-1}\right)$ Gibbs free energy: $-402.909532 \mathrm{Ha}$

Electric field strength F: 0.01 a.u.

$\begin{array}{ll}\text { C } & 2.40432402 .15995200 .0473860 \\ \text { C } & 1.60349801 .0436860-0.1409470 \\ \text { C } & 3.6410890-0.3983400-0.1909740 \\ \text { C } & 4.40921300 .7372850-0.0409000 \\ \text { H } & 1.95214203 .14885600 .1148580 \\ \text { H } & 0.52253201 .1419130-0.2412080 \\ \text { H } & 4.0870520-1.3750490-0.3622350 \\ \text { C } & 2.2020360-0.2804040-0.1917170 \\ \text { H } & 1.6487850-1.0467570-0.7359360 \\ \text { N } & 1.5390750-1.03288901 .5355460 \\ \text { H } & 0.5160910-1.03988901 .5436480 \\ \text { H } & 1.8794840-1.98876501 .6400780 \\ \text { H } & 1.8791900-0.45615602 .3045930 \\ \text { C } & 3.79431202 .02283700 .1166770 \\ \text { H } & 4.44185602 .88904000 .2482630 \\ \text { O } & 5.76616000 .7838320-0.0696420 \\ \text { C } & 6.4878430-0.4150880-0.3513400 \\ \text { H } & 7.5425070-0.1215040-0.3767590 \\ \text { H } & 6.3333400-1.16798700 .4355150 \\ \text { H } & 6.1968860-0.8284800-1.3280030\end{array}$

Transition state: ipso

Number of imaginary frequencies: $1\left(-238.81 \mathrm{~cm}^{-1}\right)$

Gibbs free energy: $-402.947971 \mathrm{Ha}$

Electric field strength $F$ : 0 a.u.
$\begin{array}{ll}\mathrm{H} & 1.93698003 .15674700 .1070470 \\ \mathrm{H} & 0.49322601 .1561410-0.2028600 \\ \mathrm{H} & 4.0559960-1.3732590-0.3884590 \\ \mathrm{C} & 2.1670350-0.2863750-0.1556330 \\ \mathrm{H} & 1.6182360-1.0209980-0.7504170 \\ \mathrm{~N} & 1.6277710-1.01974701 .4719320 \\ \mathrm{H} & 0.6098840-1.01530801 .5688800 \\ \mathrm{H} & 1.9653660-1.98093501 .5436450 \\ \mathrm{H} & 2.0388800-0.46309202 .2223980 \\ \mathrm{C} & 3.77585202 .02567400 .1070760 \\ \mathrm{H} & 4.42758902 .88946100 .2304670 \\ \mathrm{O} & 5.73064100 .7771130-0.0887620 \\ \mathrm{C} & 6.4610240-0.4387230-0.3065070 \\ \mathrm{H} & 7.5147800-0.1496380-0.3006840 \\ \mathrm{H} & 6.2664610-1.15822100 .5014080 \\ \mathrm{H} & 6.1992100-0.8763710-1.2799470\end{array}$

Transition state: meta-2

Number of imaginary frequencies: $1\left(-237.28 \mathrm{~cm}^{-1}\right)$

Gibbs free energy: $-402.918827 \mathrm{Ha}$

Electric field strength $F: 0.0075$ a.u.

$\begin{array}{ll}\text { C } & 2.39593702 .16166200 .0471850 \\ \text { C } & 1.59338401 .0478670-0.1338680 \\ \text { C } & 3.6311720-0.3978610-0.1956330 \\ \text { C } & 4.40139100 .7362810-0.0460330 \\ \text { H } & 1.94641203 .15197500 .1119180 \\ \text { H } & 0.51237101 .1471670-0.2307010 \\ \text { H } & 4.0758470-1.3739930-0.3725400 \\ \text { C } & 2.1897780-0.2816720-0.1812680 \\ \text { H } & 1.6379720-1.0378730-0.7421280 \\ \text { N } & 1.5717550-1.02891301 .5143270 \\ \text { H } & 0.5498850-1.02942901 .5565300 \\ \text { H } & 1.9089850-1.98760401 .6059700 \\ \text { H } & 1.9402200-0.46058002 .2769270 \\ \mathrm{C} & 3.78731502 .02396500 .1139630 \\ \text { H } & 4.43631902 .88912900 .2439160 \\ \text { O } & 5.75316300 .7818500-0.0764430 \\ \text { C } & 6.4776310-0.4235400-0.3350310 \\ \text { H } & 7.5321220-0.1320580-0.3492970 \\ \text { H } & 6.3086420-1.16447300 .4597350 \\ \text { H } & 6.1971140-0.8458090-1.3106260\end{array}$

Transition state: ipso

Number of imaginary frequencies: $1\left(-242.50 \mathrm{~cm}^{-1}\right)$ Gibbs free energy: $-402.948148 \mathrm{Ha}$

Electric field strength $F$ : 0.0025 a.u. 


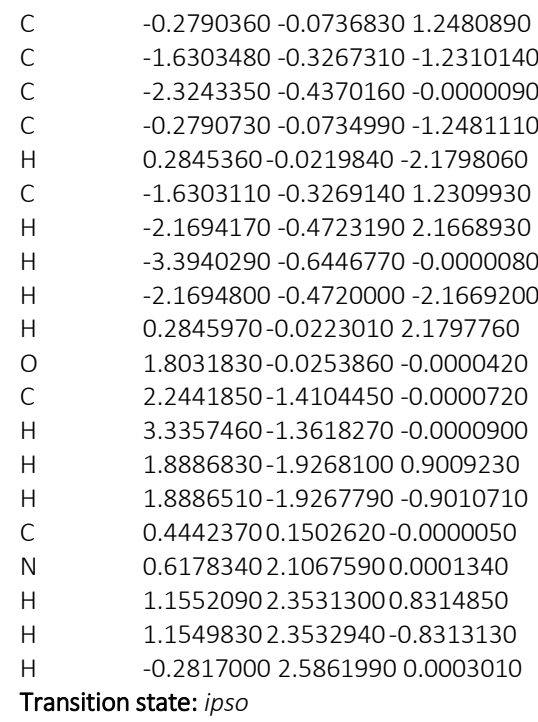

Transition state: ipso

Number of imaginary frequencies: $1\left(-246.41 \mathrm{~cm}^{-1}\right)$ Gibbs free energy: $-402.949356 \mathrm{Ha}$

Electric field strength F: 0.0050 a.u.
C $\quad 0.2765400-0.0714340-1.2481090$

C $\quad 1.6269590-0.32646901 .2314330$

C $\quad 2.3224320-0.43542100 .0000080$

C $\quad 0.2765510-0.07129501 .2481030$

H $\quad-0.2870370-0.01868502 .1798720$

C $\quad 1.6269490-0.3266070-1.2314230$

H $\quad 2.1663480-0.4728190-2.1670110$

H $\quad 3.3927010-0.63993000 .0000150$

H $\quad 2.1663670-0.47257502 .1670330$

H $\quad-0.2870580-0.0189310-2.1798790$

$-1.8087980-0.02402600 .0000000$

$-2.2318060-1.41165300 .0001300$

$-3.3243810-1.37821100 .0001290$

$-1.8707690-1.9262640-0.8998800$

$-1.8707660-1.92609900 .9002330$

$-0.44493200 .1605080-0.0000130$

$-0.61733502 .0962250-0.0001230$

$-1.14945602 .3513940-0.8320930$

$-1.14942302 .35149400 .8318380$

$0.28905002 .5634780-0.0001690$

Transition state: ipso

Number of imaginary frequencies: $1\left(-250.03 \mathrm{~cm}^{-1}\right)$

Gibbs free energy: $-402.951394 \mathrm{Ha}$

Electric field strength $F$ : 0.0075 a.u

C $\quad 0.2723290-0.0670260-1.2483030$

C $\quad 1.6211190-0.32626001 .2322350$

$2.3201860-0.43199900 .0000030$

$0.2723490-0.06687801 .2482990$

$-0.2910090-0.01150102 .1804030$

$1.6210980-0.3264070-1.2322300$

$2.1609940-0.4747880-2.1673060$

$3.3920220-0.62935000 .0000060$

$2.1610300-0.47452902 .1673200$

$-0.2910460-0.0117610-2.1804030$

$-1.8201870-0.02009000 .0000120$

$-2.2112690-1.41166900 .0001250$

$-3.3055690-1.40521100 .0001320$

$-1.8405150-1.9230350-0.8981690$

$-1.8405030-1.92289300 .8984940$

$-0.44576500 .1828430-0.0000110$

$-0.61572002 .0709420-0.0001230$

$-1.13807302 .3418740-0.8333280$

$-1.13812302 .34196200 .8330240$

$0.30205602 .5177360-0.0001200$

Transition state: ipso

Number of imaginary frequencies: $1\left(-252.04 \mathrm{~cm}^{-1}\right)$

Gibbs free energy: $-402.954222 \mathrm{Ha}$

Electric field strength $F$ : 0.01 a.u.

C $\quad 0.2723290-0.0670260-1.2483030$

C $\quad 1.6211190-0.32626001 .2322350$

C $\quad 2.3201860-0.43199900 .0000030$

C $\quad 0.2723490-0.06687801 .2482990$

H $\quad-0.2910090-0.01150102 .1804030$

C $\quad 1.6210980-0.3264070-1.2322300$

H $\quad 2.1609940-0.4747880-2.1673060$

H $\quad 3.3920220-0.62935000 .0000060$

H $\quad 2.1610300-0.47452902 .1673200$

H $\quad-0.2910460-0.0117610-2.1804030$

O $\quad-1.8201870-0.02009000 .0000120$

C $\quad-2.2112690-1.41166900 .0001250$

$\mathrm{H} \quad-3.3055690-1.40521100 .0001320$

H $\quad-1.8405150-1.9230350-0.8981690$

H $\quad-1.8405030-1.92289300 .8984940$

C $\quad-0.44576500 .1828430-0.0000110$

$\mathrm{N} \quad-0.61572002 .0709420-0.0001230$

H $\quad-1.13807302 .3418740-0.8333280$

H $\quad-1.13812302 .34196200 .8330240$

H $\quad 0.30205602 .5177360-0.0001200$ 
Transition state: para

Number of imaginary frequencies: $1\left(-252.56 \mathrm{~cm}^{-1}\right)$ Gibbs free energy: $-402.956435 \mathrm{Ha}$

Electric field strength F: 0.0050 a.u.
Transition state: para

Number of imaginary frequencies: $1\left(-89.44 \mathrm{~cm}^{-1}\right)$ Gibbs free energy: $-402.955858 \mathrm{Ha}$

Electric field strength $\mathrm{F}: 0.0025$ a.u.

$\begin{array}{ll}\text { C } & 0.90123301 .8545220-0.0056850 \\ \text { C } & 0.86822000 .4989640-0.1561770 \\ \text { C } & 3.34718000 .44760900 .1120870 \\ \text { C } & 3.34887401 .81436900 .2610030 \\ \text { C } & 2.13083802 .54368300 .2297770 \\ \text { H } & -0.00607202 .4495670-0.1073550 \\ \text { H } & -0.0678080-0.0029630-0.4026180 \\ \text { H } & 4.2920070-0.09446400 .0673420 \\ \text { H } & 4.30074302 .33198200 .3580390 \\ \text { O } & 2.02647903 .87418600 .3541290 \\ \text { C } & 3.21115404 .67261800 .5227780 \\ \text { H } & 3.87307604 .5677240-0.3472760 \\ \text { H } & 2.85459205 .70288500 .5953300 \\ \text { H } & 3.73828804 .39419001 .4451340 \\ \text { C } & 2.0910690-0.3162460-0.0067780 \\ \text { H } & 2.1499580-1.1683290-0.6943290 \\ \text { H } & 1.0652280-1.78923801 .4147240 \\ \text { H } & 2.7166840-1.81662101 .6076590 \\ \text { H } & 1.8267650-0.55713802 .2307100 \\ \text { N } & 1.9085200-1.20816301 .4460270\end{array}$

Transition state: para

Number of imaginary frequencies: $1\left(-243.53 \mathrm{~cm}^{-1}\right)$ Gibbs free energy: $-402.957413 \mathrm{Ha}$

Electric field strength $F$ : 0.0075 a.u.

$\begin{array}{ll}\text { C } & 0.90151101 .8690660-0.007214 \\ \text { C } & 0.87541700 .5129330-0.174119 \\ \text { C } & 3.34424600 .46196700 .0960420 \\ \text { C } & 3.34885301 .82840000 .2620050 \\ \text { C } & 2.13060102 .55503000 .2272380 \\ \text { H } & -0.00816902 .4623420-0.095864 \\ \text { H } & -0.06086600 .0096800-0.415692 \\ \text { H } & 4.2884660-0.08147400 .0606710 \\ \text { H } & 4.29995702 .34386100 .3754950 \\ \text { O } & 2.02778303 .88788800 .3542910 \\ \text { C } & 3.21381804 .68296600 .5121990 \\ \text { H } & 3.87478404 .5690630-0.357699 \\ \text { H } & 2.86047205 .71552700 .5756270 \\ \text { H } & 3.74423704 .41376501 .4354970 \\ \text { C } & 2.0966330-0.2869960-0.050394 \\ \text { H } & 2.1520640-1.1659800-0.698597 \\ \text { H } & 1.0625670-1.84041001 .4311550 \\ \text { H } & 2.7113280-1.86323801 .6317400 \\ \text { H } & 1.8123570-0.61913602 .2777090 \\ \text { N } & 1.9009700-1.25611801 .4844330\end{array}$

Transition state: para

Number of imaginary frequencies: $1\left(-207.30 \mathrm{~cm}^{-1}\right)$

Gibbs free energy: $-402.959156 \mathrm{Ha}$

Electric field strength $F: 0.01$ a.u.

$\begin{array}{ll}\text { C } & 0.90225301 .89969800 .0005600 \\ \text { C } & 0.88308500 .5411610-0.1819070 \\ \text { C } & 3.33969400 .48947100 .0984360 \\ \text { C } & 3.34702301 .85751200 .2794340 \\ \text { C } & 2.13048402 .58046400 .2286450 \\ \text { H } & -0.01071702 .4900740-0.0712100 \\ \text { H } & -0.05373500 .0356130-0.4155050 \\ \text { H } & 4.2824460-0.05716700 .0828610 \\ \text { H } & 4.29662102 .36890400 .4207230 \\ \text { O } & 2.03129303 .92251300 .3474380 \\ \text { C } & 3.22071204 .70893300 .4759690 \\ \text { H } & 3.88033904 .5677670-0.3917520 \\ \text { H } & 2.87674805 .74770700 .5108250 \\ \text { H } & 3.75822904 .46695201 .4032690 \\ \text { C } & 2.1037120-0.2390610-0.0989660 \\ \text { H } & 2.1565960-1.1463040-0.7022450 \\ \text { H } & 1.0617740-1.95083301 .4161200\end{array}$

$0.90151101 .8690660-0.007214$ $0.87541700 .5129330-0.174119$ 3.34885301 .82840000 .2620050 (1) $4.2884660-0.08147400 .0606710$ 3.88788800 .3542910 $3.87478404 .5690630-0.357699$ 41376501.4354970 $2.1520640-1.1659800-0.698597$ $1.0625670-1.84041001 .4311550$ $2.7113280-1.86323801 .6317400$ $1.8123570-0.61913602 .2777090$ $1.9009700-1.25611801 .4844330$ $1.0617740-1.95083301 .4161200$ 


\section{References}

1. Parr, R. G.; Szentpály, L. v.; Liu, S., Electrophilicity Index. J. Am. Chem. Soc. 1999, 121 (9), 1922-1924.

2. De Vleeschouwer, F.; Van Speybroeck, V.; Waroquier, M.; Geerlings, P.; De Proft, F., Electrophilicity and Nucleophilicity Index for Radicals. Org. Lett. 2007, 9 (14), 2721-2724.

3. Geerlings, P.; De Proft, F.; Langenaeker, W., Conceptual Density Functional Theory. Chem. Rev. 2003, 103 (5), 1793-1874.

4. Parr, R. G.; Pearson, R. G., Absolute hardness: companion parameter to absolute electronegativity. J. Am. Chem. Soc. 1983, 105 (26), 7512-7516.

5. Parr, R. G.; Donnelly, R. A.; Levy, M.; Palke, W. E., Electronegativity: The density functional viewpoint. J. Chem. Phys. 1978, 68 (8), 3801-3807.

6. Mulliken, R. S., A New Electroaffinity Scale; Together with Data on Valence States and on Valence Ionization Potentials and Electron Affinities. J. Chem. Phys. 1934, 2 (11), 782-793.

7. Becke, A. D., Density-functional thermochemistry. III. The role of exact exchange. J. Chem. Phys. 1993, 98 (7), 5648-5652.

8. Dunning, T. H., Gaussian basis sets for use in correlated molecular calculations. I. The atoms boron through neon and hydrogen. J. Chem. Phys. 1989, 90 (2), 1007-1023.

9. Domingo, L. R.; Pérez, P., Global and local reactivity indices for electrophilic/nucleophilic free radicals. Org. Biomol. Chem. 2013, 11 (26), 4350-4358.

10. De Vleeschouwer, F.; Chankisjijev, A.; Geerlings, P.; De Proft, F., Designing Stable Radicals with Highly Electrophilic or Nucleophilic Character: Thiadiazinyl as a Case Study. Eur. J. Org. Chem. 2015, 2015 (3), 506-513.

11. Pritchard, B. P.; Altarawy, D.; Didier, B.; Gibson, T. D.; Windus, T. L., New Basis Set Exchange: An Open, Up-to-Date Resource for the Molecular Sciences Community. J. Chem. Inf. Model. 2019, 59 (11), 4814-4820.

12. Peterson, K. A.; Shepler, B. C.; Figgen, D.; Stoll, H., On the Spectroscopic and Thermochemical Properties of ClO, BrO, IO, and Their Anions. J. Phys. Chem. A 2006, 110 (51), 1387713883

13. Peterson, K. A.; Figgen, D.; Goll, E.; Stoll, H.; Dolg, M., Systematically convergent basis sets with relativistic pseudopotentials. II. Small-core pseudopotentials and correlation consistent basis sets for the post-d group 16-18 elements. J. Chem. Phys. 2003, 119 (21), 11113-11123.

14. Gaussian 16, Revision A.03, Frisch, M. J.; Trucks, G. W.; Schlegel, H. B.; Scuseria, G. E.; Robb, M. A.; Cheeseman, J. R.; Scalmani, G.; Barone, V.; Petersson, G. A.; Nakatsuji, H.; Li, X.; Caricato, M.; Marenich, A. V.; Bloino, J.; Janesko, B. G.; Gomperts, R.; Mennucci, B.; Hratchian, H. P.; Ortiz, J. V.; Izmaylov, A. F.; Sonnenberg, J. L.; Williams; Ding, F.; Lipparini, F.; Egidi, F.; Goings, J.; Peng, B.; Petrone, A.; Henderson, T.; Ranasinghe, D.; Zakrzewski, V. G.; Gao, J.; Rega, N.; Zheng, G.; Liang, W.; Hada, M.; Ehara, M.; Toyota, K.; Fukuda, R.; Hasegawa, J.; Ishida, M.; Nakajima, T.; Honda, Y.; Kitao, O.; Nakai, H.; Vreven, T.; Throssell, K.; Montgomery Jr., J. A.; Peralta, J. E.; Ogliaro, F.; Bearpark, M. J.; Heyd, J. J.; Brothers, E. N.; Kudin, K. N.; Staroverov, V. N.; Keith, T. A.; Kobayashi, R.; Normand, J.; Raghavachari, K.; Rendell, A. P.; Burant, J. C.; Iyengar, S. S.; Tomasi, J.; Cossi, M.; Millam, J. M.; Klene, M.; Adamo, C.; Cammi, R.; Ochterski, J. W.; Martin, R. L.; Morokuma, K.; Farkas, O.; Foresman, J. B.; Fox, D. J., Gaussian, Inc., Wallingford, CT, 2016. 15. Applegate, B. E.; Miller, T. A., Calculation of the Jahn-Teller effect in benzene cation: Application to spectral analysis. J. Chem. Phys. 2002, 117 (23), 10654-10674.

16. Błoch-Mechkour, A.; Bally, T., Electromers of the benzene dimer radical cation. Phys. Chem. Chem. Phys. 2015, 17 (16), 10624-10629. 
17. Foroutan-Nejad, C.; Marek, R., Potential energy surface and binding energy in the presence of an external electric field: modulation of anion $-\pi$ interactions for graphene-based receptors. Phys. Chem. Chem. Phys. 2014, 16 (6), 2508-2514. 